\title{
Liposomal bupivacaine infiltration at the surgical site for the management of postoperative pain (Review)
}

Hamilton TW, Athanassoglou V, Mellon S, Strickland LHH, Trivella M, Murray D, Pandit HG

Hamilton TW, Athanassoglou V, Mellon S, Strickland LHH, Trivella M, Murray D, Pandit HG.

Liposomal bupivacaine infiltration at the surgical site for the management of postoperative pain.

Cochrane Database of Systematic Reviews 2017, Issue 2. Art. No.: CD011419.

DOI: 10.1002/14651858.CD011419.pub2.

www.cochranelibrary.com 
TABLE OF CONTENTS

HEADER 1

ABSTRACT

PLAIN LANGUAGE SUMMARY

SUMMARY OF FINDINGS

BACKGROUND

OBJECTIVES

METHODS

RESULTS

Figure 1.

Figure 2.

Figure 3.

Figure 4.

Figure 5.

Figure 6.

Figure 7.

Figure 8.

DISCUSSION

AUTHORS' CONCLUSIONS

ACKNOWLEDGEMENTS

REFERENCES

CHARACTERISTICS OF STUDIES

DATA AND ANALYSES

Analysis 1.1. Comparison 1 Liposomal bupivacaine vs control, Outcome 1 Cumulative pain score 0 to 72 hours.

Analysis 1.2. Comparison 1 Liposomal bupivacaine vs control, Outcome 2 Participants not requiring postoperative opioids. ... APPENDICES

WHAT'S NEW

CONTRIBUTIONS OF AUTHORS

DECLARATIONS OF INTEREST

SOURCES OF SUPPORT

DIFFERENCES BETWEEN PROTOCOL AND REVIEW

NOTES

INDEX TERMS 
[Intervention Review]

\section{Liposomal bupivacaine infiltration at the surgical site for the management of postoperative pain}

Thomas W Hamilton ${ }^{1}$, Vassilis Athanassoglou 2 , Stephen Mellon ${ }^{1}$, Louise H H Strickland ${ }^{1}$, Marialena Trivella ${ }^{3}$, David Murray ${ }^{1}$, Hemant G Pandit ${ }^{1}$

1Nuffield Department of Orthopaedics, Rheumatology and Musculoskeletal Sciences (NDORMS), University of Oxford, Oxford, UK. ${ }^{2}$ Nuffield Department of Anaesthetics, Oxford University Hospitals NHS Foundation Trust, Oxford, UK. ${ }^{3}$ Centre for Statistics in Medicine, University of Oxford, Oxford, UK

Contact address: Thomas W Hamilton, Nuffield Department of Orthopaedics, Rheumatology and Musculoskeletal Sciences (NDORMS), University of Oxford, Oxford, UK. thomas.hamilton@ndorms.ox.ac.uk, thomas.hamilton@sbs.ox.ac.uk.

Editorial group: Cochrane Pain, Palliative and Supportive Care Group.

Publication status and date: Stable (no update expected for reasons given in 'What's new'), published in Issue 2, 2020.

Citation: Hamilton TW, Athanassoglou V, Mellon S, Strickland LHH, Trivella M, Murray D, Pandit HG. Liposomal bupivacaine infiltration at the surgical site for the management of postoperative pain. Cochrane Database of Systematic Reviews 2017, Issue 2. Art. No.: CD011419. DOI: 10.1002/14651858.CD011419.pub2.

Copyright ( 2020 The Cochrane Collaboration. Published by John Wiley \& Sons, Ltd.

\section{A B S T R A C T}

\section{Background}

Despite multi-modal analgesic techniques, acute postoperative pain remains an unmet health need, with up to three quarters of people undergoing surgery reporting significant pain. Liposomal bupivacaine is an analgesic consisting of bupivacaine hydrochloride encapsulated within multiple, non-concentric lipid bi-layers offering a novel method of sustained-release analgesia.

\section{Objectives}

To assess the analgesic efficacy and adverse effects of liposomal bupivacaine infiltration at the surgical site for the management of postoperative pain.

\section{Search methods}

On 13 January 2016 we searched CENTRAL, MEDLINE, MEDLINE In-Process, Embase, ISI Web of Science and reference lists of retrieved articles. We obtained clinical trial reports and synopses of published and unpublished studies from Internet sources, and searched clinical trials databases for ongoing trials.

\section{Selection criteria}

Randomised, double-blind, placebo- or active-controlled clinical trials in people aged 18 years or over undergoing elective surgery, at any surgical site, were included if they compared liposomal bupivacaine infiltration at the surgical site with placebo or other type of analgesia.

\section{Data collection and analysis}

Two review authors independently considered trials for inclusion, assessed risk of bias, and extracted data. We performed data analysis using standard statistical techniques as described in the Cochrane Handbook for Systematic Reviews of Interventions, using Review Manager 5.3. We planned to perform a meta-analysis and produce a 'Summary of findings' table for each comparison however there were insufficient data to ensure a clinically meaningful answer. As such we have produced two 'Summary of findings' tables in a narrative format. Where possible we assessed the quality of evidence using GRADE. 


\section{Main results}

We identified nine studies (10 reports, 1377 participants) that met inclusion criteria. Four Phase II dose-escalating/de-escalating trials, designed to evaluate and demonstrate efficacy and safety, presented pooled data that we could not use. Of the remaining five parallelarm studies (965 participants), two were placebo controlled and three used bupivacaine hydrochloride local anaesthetic infiltration as a control. Using the Cochrane tool, we judged most studies to be at unclear risk of bias overall; however, two studies were at high risk of selective reporting bias and four studies were at high risk of bias due to size (fewer than 50 participants per treatment arm).

Three studies (551 participants) reported the primary outcome cumulative pain intensity over 72 hours following surgery. Compared to placebo, liposomal bupivacaine was associated with a lower cumulative pain score between the end of the operation ( 0 hours) and 72 hours (one study, very low quality). Compared to bupivacaine hydrochloride, two studies showed no difference for this outcome (very low quality evidence), however due to differences in the surgical population and surgical procedure (breast augmentation versus knee arthroplasty) we did not perform a meta-analysis.

No serious adverse events were reported to be associated with the use of liposomal bupivacaine and none of the five studies reported withdrawals due to drug-related adverse events (moderate quality evidence).

One study reported a lower mean pain score at 12 hours associated with liposomal bupivacaine compared to bupivacaine hydrochloride, but not at 24,48 or 72 hours postoperatively (very low quality evidence).

Two studies (382 participants) reported a longer time to first postoperative opioid dose compared to placebo (low quality evidence).

Two studies (325 participants) reported the total postoperative opioid consumption over the first 72 hours: one study reported a lower cumulative opioid consumption for liposomal bupivacaine compared to placebo (very low quality evidence); one study reported no difference compared to bupivacaine hydrochloride (very low quality evidence).

Three studies (492 participants) reported the percentage of participants not requiring postoperative opioids over initial 72 hours following surgery. One of the two studies comparing liposomal bupivacaine to placebo demonstrated a higher number of participants receiving liposomal bupivacaine did not require postoperative opioids (very low quality evidence). The other two studies, one versus placebo and one versus bupivacaine hydrochloride, found no difference in opioid requirement (very low quality evidence). Due to significant heterogeneity between the studies $\left(1^{2}=92 \%\right)$ we did not pool the results.

All the included studies reported adverse events within 30 days of surgery, with nausea, constipation and vomiting being the most common. Of the five parallel-arm studies, none performed or reported health economic assessments or patient-reported outcomes other than pain.

Using GRADE, the quality of evidence ranged from moderate to very low. The major limitation was the sparseness of data for outcomes of interest. In addition, a number of studies had a high risk of bias resulting in further downgrading.

\section{Authors' conclusions}

Liposomal bupivacaine at the surgical site does appear to reduce postoperative pain compared to placebo, however, at present the limited evidence does not demonstrate superiority to bupivacaine hydrochloride. There were no reported drug-related serious adverse events and no study withdrawals due to drug-related adverse events. Overall due to the low quality and volume of evidence our confidence in the effect estimate is limited and the true effect may be substantially different from our estimate.

\section{PLAIN LANGUAGE SUMMARY}

\section{Liposomal bupivacaine at the site of surgery to treat pain}

\section{Bottom Line}

Liposomal bupivacaine administered at the site of surgery appears to reduce postoperative pain when compared to placebo (salt water). At present there is limited evidence as to how effective it is compared to other painkillers, such as bupivacaine hydrochloride. Further large studies are required to see if there is a role for liposomal bupivacaine in this area.

\section{Background}

Despite painkillers, three in four people report pain following surgery. One method to treat pain is for the surgeon to inject a painkiller at the site of surgery to block the nerves that send pain signals to the brain. A new drug called liposomal bupivacaine has been developed which has been designed to release the painkiller over a much longer time and provide prolonged pain relief. This review has been designed to look at how good liposomal bupivacaine injected at the site of surgery is at treating pain and also to look at whether there are any risks associated with its use.

\section{Study characteristics and key results}


In January 2016, we found nine studies (10 reports) involving 1377 people that assessed liposomal bupivacaine following five different types of operation: total knee replacement; haemorrhoidectomy; inguinal hernia repair; bunionectomy and breast augmentation. The results suggested that compared to placebo (salt water) liposomal bupivacaine was better at reducing pain when injected at the site of surgery and also reduced both the overall requirement for, and duration before needing, additional, opiate-based (strong), painkillers. However, the limited evidence did not suggest that liposomal bupivacaine was better than the currently used painkiller bupivacaine hydrochloride. Overall across all the included studies no-one dropped out due to drug-related side effects.

\section{Quality of the evidence}

Due to the small number of studies and some limitations in the quality of these trials, we ranked the quality of evidence as moderate to very low. Further research is required to evaluate the role of liposomal bupivacaine infiltration at the surgical site to treat pain after surgery. 


\section{S U M MARY OF FINDINGS}

\section{Summary of findings for the main comparison. Summary of findings: liposomal bupivacaine vs placebo}

\section{Liposomal bupivacaine infiltration at the surgical site compared with placebo for the management of postoperative pain}

Patient or population: aged 18 years and older undergoing elective surgery at any surgical site

Settings: inpatient

Intervention: surgical site infiltration of liposomal bupivacaine

Comparison: surgical site infiltration of placebo

\begin{tabular}{|c|c|c|c|}
\hline Outcomes & Impact & $\begin{array}{l}\text { Number of partici- } \\
\text { pants } \\
\text { (number of stud- } \\
\text { ies) }\end{array}$ & $\begin{array}{l}\text { Quality of the evi- } \\
\text { dence } \\
\text { (GRADE) }\end{array}$ \\
\hline $\begin{array}{l}\text { Cumulative pain } \\
\text { score from the end } \\
\text { of operation ( } 0 \\
\text { hours) to } 72 \text { hours } \\
\text { (NRS } 0 \text { to 10) }\end{array}$ & $\begin{array}{l}\text { A reduction in cumulative pain score associated with the use of } \\
\text { liposomal bupivacaine was reported in one study. } \\
\text { The mean cumulative pain score from the end of operation to } \\
72 \text { hours (NRS } 0 \text { to } 10 \text { ) in the placebo control group was } 202.5 \\
\text { points with the mean cumulative pain score from the end of op- } \\
\text { eration to } 72 \text { hours in the liposomal bupivacaine intervention } \\
\text { group being } 60.7 \text { points lower ( } 90.4 \text { lower to } 31.1 \text { lower). }\end{array}$ & $\begin{array}{l}189 \text { participants } \\
\text { (1 study) }\end{array}$ & $\begin{array}{l}\oplus \odot \odot \ominus \\
\text { very low } a\end{array}$ \\
\hline $\begin{array}{l}\text { Serious adverse } \\
\text { events }\end{array}$ & $\begin{array}{l}\text { No reported drug-related serious adverse events, no study } \\
\text { withdrawals due to drug-related adverse events }\end{array}$ & $\begin{array}{l}382 \text { participants } \\
\text { (2 studies) }\end{array}$ & $\begin{array}{l}\oplus \oplus \ominus \ominus \\
\text { lowb }\end{array}$ \\
\hline $\begin{array}{l}\text { Mean pain score at } \\
12,24,48,72 \text { and } \\
96 \text { hours following } \\
\text { surgery (NRS } 0 \text { to } \\
\text { 10) }\end{array}$ & No data reported & No studies & \\
\hline $\begin{array}{l}\text { Time to first post- } \\
\text { operative opioid } \\
\text { dose over initial } 72 \\
\text { hours }\end{array}$ & $\begin{array}{l}\text { A longer time to first postoperative opioid dose associated with } \\
\text { the use of liposomal bupivacaine was reported in two studies. } \\
\text { In the placebo control group the time to first postoperative opi- } \\
\text { oid was } 4.3 \text { and } 1.2 \text { hours compared to } 7.2 \text { and } 14.3 \text { hours in the } \\
\text { liposomal bupivacaine groups respectively. The distribution of } \\
\text { data was not reported. }\end{array}$ & $\begin{array}{l}382 \text { participants } \\
\text { (2 studies) }\end{array}$ & $\begin{array}{l}\oplus \oplus \ominus \ominus \\
\text { lowc }\end{array}$ \\
\hline $\begin{array}{l}\text { Total postoper- } \\
\text { ative opioid con- } \\
\text { sumption over } \\
\text { first } 72 \text { hours }\end{array}$ & $\begin{array}{l}\text { A reduction in total postoperative opioid consumption over } \\
\text { first } 72 \text { hours associated with the use of liposomal bupivacaine } \\
\text { was reported in one study. In the placebo control group the } \\
\text { mean cumulative parenteral morphine equivalent dose over } \\
\text { the first } 72 \text { hours was } 29.1 \mathrm{mg} \text { and was } 6.8 \mathrm{mg} \text { lower ( } 12.8 \mathrm{mg} \\
\text { lower to } 0.9 \mathrm{mg} \text { lower) in the liposomal bupivacaine interven- } \\
\text { tion group. }\end{array}$ & $\begin{array}{l}189 \text { participants } \\
\text { (1 study) }\end{array}$ & $\begin{array}{l}\oplus \odot \odot \ominus \\
\text { very lowd }\end{array}$ \\
\hline $\begin{array}{l}\text { Percentage of par- } \\
\text { ticipants not re- } \\
\text { quiring postoper- } \\
\text { ative opioids over } \\
\text { initial } 72 \text { hours }\end{array}$ & $\begin{array}{l}\text { One study reported a higher proportion of participants not re- } \\
\text { quiring postoperative opioids over initial } 72 \text { hours associated } \\
\text { with the use of liposomal bupivacaine (RR } 0.82 ; 95 \% \mathrm{Cl} 0.72 \text { to } \\
0.94 \text { ), and one study found no difference (RR } 0.99 ; 95 \% \mathrm{Cl} 0.95 \\
\text { to } 1.03 \text { ). }\end{array}$ & $\begin{array}{l}382 \text { participants } \\
\text { (2 studies) }\end{array}$ & $\begin{array}{l}\oplus \odot \odot \ominus \\
\text { very lowe }\end{array}$ \\
\hline
\end{tabular}




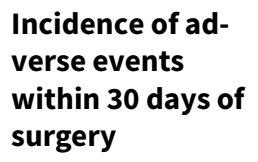

The incidence of cardiac events and wound complications with- 382 participants in 30 days of surgery were not reported in any study

Adverse events within 30 days of surgery were reported in all studies with nausea, constipation and vomiting being the most common.

\section{(2 studies)}

$\oplus \oplus \ominus \ominus$

low $f$

$\mathrm{Cl}$ : confidence interval; NRS: numeric rating scale; $\mathrm{RR}$ : risk ratio

GRADE Working Group grades of evidence

High quality: We are very confident that the true effect lies close to that of the estimate of the effect.

Moderate quality: We are moderately confident in the effect estimate; the true effect is likely to be close the estimate of effect, but there is a possibility that it is substantially different.

Low quality: Our confidence in the effect estimate is limited; the true effect may be substantially different from the estimate of the effect.

Very low quality: We have very little confidence in the effect estimate; the true effect is likely to be substantially different from the estimate of effect.

a We downgraded the quality of this evidence due to the sparseness of data (-1), indirectness $(-1)$ and risk of bias $(-1)$ due to the unclear risk of bias due to the sample size (50-199).

bWe downgraded the quality of this evidence one level due to the sparseness of data and a further level due the high risk of bias due to Golf 2011 being subject to a risk of performance bias as well as the unclear risk of bias due to the sample size (50-199) of the two studies. cWe downgraded the quality of this evidence one level due to the sparseness of data and a further level due to Golf 2011 being subject to a high risk of performance bias (as well as the unclear risk of bias due to the sample size (50-199) of the two studies). No meta-analysis was carried out because time to first postoperative opioid dose follows a skewed distribution and hence meta-analysis isn't recommended. Additionally there was expected heterogeneity due population characteristics (bunionectomy vs haemorrhoidectomy).

dWe downgraded the quality of this evidence due to the sparseness of data (-1), indirectness (-1) and risk of bias (-1) due to the unclear risk of bias due to the sample size (50-199).

eWe downgraded the quality of this evidence one level due to the to the sparseness of data, one level due to inconsistency, and a further level due to Golf 2011 being subject to a high risk of performance bias as well as the unclear risk of bias due to the sample size (50-199) of the two studies.

fWe downgraded the quality of this evidence one level due to the sparseness of data and a further level due the high risk of bias due to Golf 2011 being subject to a risk of performance bias as well as the unclear risk of bias due to the sample size (50-199) of the two studies.

\section{Summary of findings 2. Summary of findings: liposomal bupivacaine vs bupivacaine hydrochloride}

Liposomal bupivacaine infiltration at the surgical site compared with bupivacaine hydrochloride for the management of postoperative pain

Patient or population: aged 18 years and older undergoing elective surgery at any surgical site

Settings: inpatient

Intervention: surgical site infiltration of liposomal bupivacaine

Comparison: surgical site infiltration of bupivacaine hydrochloride

\begin{tabular}{llll}
\hline Outcomes & Impact & $\begin{array}{l}\text { Number of partici- } \\
\text { pants } \\
\text { (number of stud- } \\
\text { ies) }\end{array}$ & $\begin{array}{l}\text { Quality of the evi- } \\
\text { dence } \\
\text { (GRADE) }\end{array}$ \\
\hline $\begin{array}{l}\text { Cumulative pain } \\
\text { score from the end } \\
\text { of operation (0 } \\
\text { hours) to 72 hours } \\
\text { (NRS 0 to 10) }\end{array}$ & $\begin{array}{l}\text { No difference in cumulative pain score was reported in two } \\
\text { studies. }\end{array}$ & $\begin{array}{l}\text { In one study the mean cumulative pain score from the end of } \\
\text { operation to 72 hours (NRS 0 to 10) in the active control group } \\
\text { was 335.0 points and 24.0 points higher (5.7 lower to 53.7 high- } \\
\text { er) in the liposomal bupivacaine intervention group. In the oth- }\end{array}$ & (2 studies) \\
\hline
\end{tabular}

Liposomal bupivacaine infiltration at the surgical site for the management of postoperative pain (Review) 
er study the mean cumulative pain score from the end of operation to 72 hours (NRS 0 to 10) in the active control group was 468.2 points and 26.7 points lower ( 91.3 lower to 37.9 higher) in the liposomal bupivacaine intervention group. Data were not pooled as differences in outcomes were expected due to differences in surgical interventions between studies.

\begin{tabular}{l}
\hline $\begin{array}{l}\text { Serious adverse } \\
\text { events }\end{array}$ \\
\hline Mean pain score at \\
$12,24,48,72$ and \\
96 hours following \\
surgery (NRS 0 to \\
$10)$
\end{tabular}

No reported drug-related serious adverse events, no study withdrawals due to drug-related adverse events

\section{3 participants}

(3 studies) $\oplus \oplus \oplus \odot$

moderateb
A reduction in mean pain score at 12 hours, but not 24,48 or 72 hours, associated with the use of liposomal bupivacaine was reported in one study. Mean pain score at these time points were

\section{4 participants}

(1 study) not reported in other studies.

In the study that reported mean pain score (NRS 0 to 10) at 12 hours in the active control group it was 6.9 points and 1.3 points lower (2.4 lower to 0.2 lower) in the liposomal bupivacaine intervention group at this time point. $\oplus \odot \odot \odot$ very lowc

\section{Time to first post- operative opioid dose over initial 72 hours}

No data reported

No studies

\begin{tabular}{|c|c|c|c|}
\hline $\begin{array}{l}\text { Total postoper- } \\
\text { ative opioid con- } \\
\text { sumption over } \\
\text { first } 72 \text { hours }\end{array}$ & $\begin{array}{l}\text { No difference in cumulative parenteral morphine equivalent } \\
\text { dose over first } 72 \text { hours was reported in one study though no } \\
\text { estimate of variance was provided and as such estimates of ef- } \\
\text { fect could not be calculated. }\end{array}$ & $\begin{array}{l}134 \text { participants } \\
\text { (1 study) }\end{array}$ & $\begin{array}{l}\oplus \ominus \ominus \ominus \\
\text { very lowd }\end{array}$ \\
\hline $\begin{array}{l}\text { Percentage of par- } \\
\text { ticipants not re- } \\
\text { quiring postoper- } \\
\text { ative opioids over } \\
\text { initial } 72 \text { hours }\end{array}$ & $\begin{array}{l}\text { No difference in the percentage of participants not requiring } \\
\text { postoperative opioids over initial } 72 \text { hours was reported in one } \\
\text { study (RR } 0.95 ; 95 \% \mathrm{Cl} 0.86 \text { to } 1.05 \text { ). }\end{array}$ & $\begin{array}{l}134 \text { participants } \\
\text { (1 study) }\end{array}$ & $\begin{array}{l}\oplus \ominus \ominus \ominus \\
\text { very lowe }\end{array}$ \\
\hline $\begin{array}{l}\text { Incidence of ad- } \\
\text { verse events } \\
\text { within } 30 \text { days of } \\
\text { surgery }\end{array}$ & $\begin{array}{l}\text { The incidence of cardiac events and wound complications with- } \\
\text { in } 30 \text { days of surgery were not reported in any study } \\
\text { Adverse events within } 30 \text { days of surgery were reported in all } \\
\text { studies with nausea, constipation and vomiting being the most } \\
\text { common. }\end{array}$ & $\begin{array}{l}583 \text { participants } \\
\text { (3 studies) }\end{array}$ & $\begin{array}{l}\oplus \oplus \oplus \ominus \\
\text { moderatef }\end{array}$ \\
\hline
\end{tabular}

$\mathrm{Cl}$ : confidence interval; NRS: numeric rating scale; RR: risk ratio

GRADE Working Group grades of evidence

High quality: We are very confident that the true effect lies close to that of the estimate of the effect.

Moderate quality: We are moderately confident in the effect estimate; the true effect is likely to be close the estimate of effect, but there is a possibility that it is substantially different.

Low quality: Our confidence in the effect estimate is limited; the true effect may be substantially different from the estimate of the effect.

Very low quality: We have very little confidence in the effect estimate; the true effect is likely to be substantially different from the estimate of effect.

${ }^{a}$ We downgraded the quality of this evidence one level due to the sparseness of data, a further level because Smoot 2012 was subject to a high risk of bias due to the risk of performance bias and attrition bias due to early termination of the study (as well as the unclear risk of bias due to the sample size (50-199)), and a further level due to inconsistency. We did not pool of results as we predicted that participant characteristics, as well as nature of postoperative pain, would be different following breast augmentation and knee replacement. As such we expected there to be heterogeneity of the results due to population characteristics, not due to intervention characteristics. 
bWe downgraded the quality of this evidence one level due the high risk of bias due to Smoot 2012 being subject to a risk of performance and attrition bias due to early termination of the study (as well as the unclear risk of bias due to the sample size (50-199)).

cWe downgraded the quality of this evidence one level due to the sparseness of data, and a further level because Smoot 2012 was subject to a high risk of bias due to the risk of performance bias and attrition bias due to early termination of the study (as well as the unclear risk of bias due to the sample size (50-199)), and by a further level due to indirectness due to the limitations in interpreting data from a single study. dWe downgraded the quality of this evidence one level due to the sparseness of data, a further level because Smoot 2012 was subject to a high risk of bias due to the risk of performance bias and attrition bias due to early termination of the study (as well as the unclear risk of bias due to the sample size (50-199)) and by a further level due to indirectness due to the limitations in interpreting data from a single study. eWe downgraded the quality of this evidence one level due to the sparseness of data, and a further level because Smoot 2012 was subject to a high risk of bias due to the risk of performance bias and attrition bias due to early termination of the study (as well as the unclear risk of bias due to the sample size (50-199)), and by a further level due to indirectness due to the limitations in interpreting data from a single study. fWe downgraded the quality of this evidence one level due the high risk of bias due to Smoot 2012 being subject to a risk of performance and attrition bias due to early termination of the study (as well as the unclear risk of bias due to the sample size (50-199)). 


\section{B A C K G R O U N D}

\section{Description of the condition}

The treatment of acute postoperative pain remains an unmet health need. Despite the development of guidelines to assist clinicians and allied health professionals to recognise and treat the so-called 'fifth vital sign', it has been reported that up to three quarters of surgical patients receive inadequate pain relief (Apfelbaum 2003; Gan 2014; Lorentzen 2012; Nimmaanrat 2007). Optimising postoperative pain management, and reducing the requirement for systemic analgesia, in particular opiates, through the use of multi-modal analgesia has many benefits. These include patient benefits, such as reduced morbidity and mortality, as well as benefits to the healthcare system through enhanced patient satisfaction and reduced healthcare-associated costs including a reduced postoperative length of stay. Furthermore, there is increasing evidence that optimising perioperative and postoperative analgesia reduces the incidence of chronic postsurgical pain as well as enhancing long-term patient-reported functional outcomes (Kehlet 2006).

\section{Description of the intervention}

The concept of multi-modal analgesia was introduced over 20 years ago and its use has expanded to many surgical specialties (Kehlet 1993). Multi-modal analgesia employs a range of techniques all aiming to inhibit the multiple pathways of nociceptive stimuli along their path, from the site of surgical injury, passing through the peripheral nervous system to the central nervous system. Using paracetamol, non-steroidal antiinflammatory drugs (NSAIDs), gabapentinoids, as well as local and regional anaesthetic techniques, the need for oral or parenteral opioids in the postoperative period, and as a consequence their side effects, is reduced. Local anaesthetic incisional infiltration, where local anaesthetic is infiltrated at the site of the surgical incision at the time of surgery, and local anaesthetic peripheral nerve blocks are commonly used as part of a multi-modal regime with the view that modification of pain stimuli at their origin will reduce the transmission of nociceptive stimuli, thereby reducing downstream organ dysfunction and pain and stress responses, including centrally mediated changes in the spinal cord or cerebral cortex (Kehlet 2006). The use of liposomal bupivacaine for peripheral nerve blockade will be the subject of a separate review (Hamilton 2016).

Local anaesthetic incisional infiltration is used in a wide range of operations. The local anaesthetic can be administered prior to wound incision as pre-emptive analgesia, during surgery, or immediately following wound closure. Bupivacaine hydrochloride is the most commonly used local anaesthetic for local infiltration, however its duration of action is a major limiting factor. Despite the addition of drugs such as epinephrine and clonidine to enhance the duration of action many people report significant rebound pain when the effect of the local anaesthetic wears off (Apfelbaum 2003). As such, there has been a great deal of interest in sustainedrelease local anaesthetics such as liposomal bupivacaine, which are administered in the same manner but have been reported to have an effect that lasts significantly longer than currently used drugs (Grant 2004).

The adverse effects of bupivacaine and liposomal bupivacaine administered at the surgical site are typical of those associated with other amide-type local anaesthetics. A major cause of adverse reactions to these drugs is high plasma levels, which may be due to overdosage, rapid absorption from the injection site, diminished tolerance, accidental intravascular injection or slow metabolic degradation. Side effects that require immediate treatment are related to neurological and cardiovascular toxicity, which can cause fits and cardiac arrest resistant to standard treatment. These reactions are generally dose-related and due to excessively high plasma levels. Other side effects include gastrointestinal symptoms (nausea, vomiting, constipation), nervous system side effects (perioral tingling, dizziness, headache, syncope, somnolence), skin side effects (pruritus), fungal infections and pyrexia. In addition, for liposomal bupivacaine the potential exists for local adverse effects due to the liposomal component, which is known to undergo slow lipid degradation and clearance at the injection site.

\section{How the intervention might work}

Liposomal bupivacaine consists of bupivacaine hydrochloride encapsulated within multiple, non-concentric lipid bi-layers. This encapsulation technique produces vesicles of a diameter of 10 to 20 micrometres that contain the active drug, which offers a novel method of sustained release (Spector 1996). Release of the active drug from these multi-vesicular liposomes is via three mechanisms, membrane breakdown, membrane reorganisation and diffusion (Mantripragada 2002). The relative importance of each mechanism is not known.

Following its release from the liposome vesicles, the active component bupivacaine hydrochloride, an amide local anaesthetic, binds to the intracellular portion of voltage-gated sodium channels thereby preventing depolarisation of the nerve cell and thus conduction of nociceptive stimuli. Bupivacaine hydrochloride is subsequently metabolised, primarily in the liver via a microsomal cytochrome P450 3A4 mediated pathway to pipecoloxylidide, with 5\% undergoing renal excretion and around $15 \%$ being excreted unchanged (Gantenbein 2000). The multivesicular liposome component of liposome bupivacaine undergoes a slow process of lipid degradation and clearance; studies have demonstrated that a significant proportion of the liposome component is detectable at the injection site at periods exceeding 21 days following administration (Mantripragada 2002).

\section{Why it is important to do this review}

Regional anaesthetic techniques using local anaesthetics have an established role as part of a multi-modal technique across a wide range of surgical specialties. Currently their duration of action is a major limiting factor with patients reporting rebound pain. Liposomal bupivacaine is a new therapy utilising a novel mechanism to provide sustained release of local anaesthetic at the origin of pain, which has the potential to address this limitation. At present there are a limited number of trials evaluating liposomal bupivacaine for the management of postoperative pain. This independent review has been designed to critically appraise the current literature on liposomal bupivacaine administered at the surgical site in people aged 18 years and over undergoing elective surgery to evaluate its clinical and cost effectiveness in managing postoperative pain. 


\section{O B JECTIVES}

To assess the analgesic efficacy and adverse effects of liposomal bupivacaine infiltration at the surgical site for the management of postoperative pain.

\section{METHODS}

\section{Criteria for considering studies for this review}

\section{Types of studies}

We included prospective randomised and quasi-randomised controlled trials (including cluster-randomised trials) that compared liposomal bupivacaine infiltration against placebo or other types of analgesia. We included data from clinical trials registries and clinical trial records in the review. We included studies irrespective of publication status or language.

\section{Types of participants}

We included all trials with participants aged 18 years and older undergoing elective surgery at any surgical site, without restriction on any co-morbidities.

\section{Types of interventions}

We included all double-blind randomised controlled trials (RCTs) that compared the effects of a single dose of liposomal bupivacaine infiltrated at the surgical site against placebo or other types of analgesia delivered systemically, via local infiltration, perineural injection, or epidural or subarachnoid (spinal) routes. We considered studies reporting on pre-emptive, intraoperative and postoperative wound infiltration eligible for inclusion provided the drug was administered not earlier than 30 minutes prior to the procedure or later than 30 minutes after wound closure.

\section{Types of outcome measures}

We included patient-reported outcome measures of pain, use of supplementary opiate analgesia (incidence of supplementary analgesia, time to supplementary analgesia, mean and total opiate consumption, opiate or other analgesia-related adverse events) and measures of cost effectiveness. We included withdrawals from the trials and adverse events.

\section{Primary outcomes}

- Cumulative pain intensity assessed on a $100 \mathrm{~mm}$ visual analogue scale (VAS) over the initial 72 hours following surgery, at rest or with activity. However, we considered all types of pain scales with standardisation of pain intensity data described by other means than a $100 \mathrm{~mm}$ VAS, where possible.

- Serious adverse events, specifically incidence of cardiac events and incidence of wound complications within 30 days of surgery.

\section{Secondary outcomes}

- Mean pain score, at rest or with activity, assessed on a 100 mm VAS at 12, 24, 48, 72 and 96 hours following surgery. We considered all types of pain scales with standardisation of pain intensity data described by other means than a $100 \mathrm{~mm}$ VAS, where possible.

- Time to first postoperative opioid dose over initial 72 hours.

- Total postoperative opioid consumption over first 72 hours.
- Percentage of participants not requiring postoperative opioids over initial 72 hours.

- Health economics assessed using a recognised health economic technique.

- Incidence of adverse events within 30 days of surgery.

- Patient-reported outcomes, using validated outcome scores, at any time point following surgery.

\section{Search methods for identification of studies}

\section{Electronic searches}

We searched the following electronic databases:

- CENTRAL (in the Cochrane Library) Issue 1, 2016;

- MEDLINE (Ovid) 1946 to 13 January 2016;

- Embase (Ovid) 1974 to 13 January 2016;

- Web of Science (ISI Web of Knowledge) 1945 to 13 January 2016;

We used MeSH or equivalent and text word terms with no language restrictions. We tailored searches to individual databases. The search strategies used are shown in Appendix 1.

\section{Searching other resources}

We searched the metaRegister of controlled trials (mRCT) (www.isrctn.com/page/mrct) (4 January 2016), clinicaltrials.gov (www.clinicaltrials.gov) (4 January 2016) and the World Health Organization (WHO) International Clinical Trials Registry Platform (ICTRP) (http://apps.who.int/trialsearch/) (4 January 2016) for ongoing trials. In addition, we searched reference lists of reviews and retrieved articles for additional studies and citation searches performed on key articles. We contacted study authors where necessary for additional information.

\section{Data collection and analysis}

\section{Selection of studies}

We assessed studies independently and in duplicate for eligibility (TWH, VA). In the first instance, we selected studies from the title and abstract. For those deemed relevant, we obtained the full text. Different pairs of authors (TWH, VA, LHS) assessed the full text according to the eligibility criteria. We resolved disagreement by consensus with input from the senior author (HP). We have presented a summary of the search strategy yield and study selection as a PRISMA flowchart (Liberati 2009). We retrieved the full texts of eligible studies and collated data where there were multiple publications of individual studies.

\section{Data extraction and management}

Two authors (TWH, VA) extracted data independently and in duplicate and recorded them onto a pre-tested, standardised, electronic data collection form. We resolved inconsistency in data collection by discussion with input of a third author (LHS). Where additional information was required we contacted the study authors and study sponsors.

\section{Assessment of risk of bias in included studies}

We used the Oxford Quality Score (Jadad 1996) as the basis for inclusion, limiting inclusion to studies that were randomised and double blind as a minimum. 
Two authors (TWH, VA) also independently assessed risk of bias for each study, using the criteria outlined in the Cochrane Handbook for Systematic Reviews of Interventions (Higgins 2011a) and adapted from those used by Cochrane Pregnancy and Childbirth, with any disagreements resolved by discussion. We assessed the following for each study.

- Random sequence generation (checking for possible selection bias). We assessed the method used to generate the allocation sequence as: low risk of bias (any truly random process, e.g. random number table; computer random number generator); unclear risk of bias (method used to generate sequence not clearly stated). We excluded studies using a non-random process (e.g. odd or even date of birth; hospital or clinic record number).

- Allocation concealment (checking for possible selection bias). The method used to conceal allocation to interventions prior to assignment determines whether intervention allocation could have been foreseen in advance of or during recruitment, or changed after assignment. We assessed the methods as: low risk of bias (e.g. telephone or central randomisation; consecutively numbered sealed opaque envelopes); unclear risk of bias (method not clearly stated). We excluded studies that did not conceal allocation (e.g. open list).

- Blinding of participants and personnel (checking for possible performance bias). We assessed the methods used to blind study participants and personnel from knowledge of which intervention a participant received. We assessed methods as: low risk of bias (study states that it was blinded and describes the method used to achieve blinding, such as identical tablets matched in appearance or smell, or a double-dummy technique); unclear risk of bias (study states that it was blinded but does not provide an adequate description of how it was achieved). We excluded studies that were not double blind.

- Blinding of outcome assessment (checking for possible detection bias). We assessed the methods used to blind study participants and outcome assessors from knowledge of which intervention a participant received. We assessed the methods as: low risk of bias (study has a clear statement that outcome assessors were unaware of treatment allocation, and ideally describes how this was achieved); unclear risk of bias (study states that outcome assessors were blind to treatment allocation but lacks a clear statement on how it was achieved). Studies where outcome assessment was not blinded were excluded.

- Incomplete outcome data (checking for possible attrition bias due to the amount, nature and handling of incomplete outcome data). We assessed the methods used to deal with incomplete data as: low risk (less than $10 \%$ of participants did not complete the study or used 'baseline observation carried forward' analysis, or both); unclear risk of bias (used 'last observation carried forward' analysis); high risk of bias (used 'completer' analysis).

- Selective outcome reporting. We compared outcomes of interest published in the protocol, clinical trials registry entry and methods section against those published in the study report. Where all outcomes of interest were reported then we considered these studies as at low risk of bias. Where there was incomplete outcome data reporting we considered these studies as at high risk of bias.

- Size of study (checking for possible biases confounded by small size). We assessed studies as being at: low risk of bias (200 participants or more per treatment arm); unclear risk of bias (50 to 199 participants per treatment arm); high risk of bias (fewer than 50 participants per treatment arm).

\section{Measures of treatment effect}

A lack of data prevented a quantitative assessment of the efficacy of liposomal bupivacaine infiltration at the surgical site for the management of postoperative pain. For dichotomous data we planned to calculate the risk ratio (RR) and for continuous data the standardised mean difference (SMD), along with 95\% confidence intervals $(95 \% \mathrm{Cl})$ (RevMan 2014). We planned, where possible, for efficacy outcomes, to calculate the numbers needed to treat for a beneficial outcome (NNTB) and harmful outcome (NNTH) for adverse events.

\section{Unit of analysis issues}

We assessed outcomes at the patient level and proposed to analyse studies involving multiple treatment arms by dividing the sample size of the control group into the appropriate number of groups depending on the number of arms of the trial.

\section{Dealing with missing data}

We contacted study authors and sponsors to request further information in the event of missing data. We did not attempt data imputation because of the controversies associated with imputing data from multiple scoring schemes, especially due to possible small sample sizes per scoring scale (Sterne 2009).

\section{Assessment of heterogeneity}

We examined the heterogeneity of included studies, where possible, using the 12 statistic (Higgins 2003) as described in the Cochrane Handbook for Systematic Reviews of Interventions (Deeks 2011). Where there was substantial heterogeneity (that is I2 greater than $85 \%$ ) we did not attempt pooled analysis. Had it been possible to perform meta-analysis, as we expected a degree of variability among the eligible studies in terms of the measurement scale used and the subjectivity of the outcome, we planned to use a random-effects model.

\section{Assessment of reporting biases}

We assessed for publication bias, due to non-reporting of negative studies, by contacting the principal investigators of unpublished trials registered as completed on trial registries. As there were fewer than 10 studies included we did not explore publication bias by means of a funnel plot.

\section{Data synthesis}

A lack of data prevented a quantitative assessment of the efficacy of liposomal bupivacaine infiltration at the surgical site for the management of postoperative pain and as such we did not perform meta-analysis. In future updates of this review, where outcome data are found to be of sufficient quality, and participants, interventions, comparisons and outcomes judged to be sufficiently similar to ensure an answer that is clinically meaningful, then we will perform a meta-analysis.

\section{Quality of the Evidence}

We planned to assess the quality of the evidence for each of the primary and secondary outcomes independently in duplicate 
(TH, LS) using the GRADE system for all of the primary and secondary outcomes assessed. However, this was not possible for all outcomes due to the lack of data available.

The GRADE approach uses five considerations (study limitations, consistency of effect, imprecision, indirectness and publication bias) to assess the quality of the body of evidence for each outcome.

The GRADE system uses the following criteria for assigning grade of evidence.

- High: we are very confident that the true effect lies close to that of the estimate of the effect.

- Moderate: we are moderately confident in the effect estimate; the true effect is likely to be close to the estimate of effect, but there is a possibility that it is substantially different.

- Low: our confidence in the effect estimate is limited; the true effect may be substantially different from the estimate of the effect.

- Very low: we have very little confidence in the effect estimate; the true effect is likely to be substantially different from the estimate of effect.

The grade is decreased if:

- serious (-1) or very serious (-2) limitation to study quality;

- important inconsistency (-1);

- some (-1) or major (-2) uncertainty about directness;

- imprecise or sparse data (-1);

- high probability of reporting bias (-1).

Further information on the use of the GRADE System and GRADEprofiler Guideline Development Tool software can be found in Chapter 12.2 of the Cochrane Handbook for Systematic Reviews of Interventions (GRADEPro GDT 2015; Schünemann 2011).

\section{'Summary of findings' table}

Due to the lack of data we have produced two 'Summary of findings' tables as a narrative to present the main findings in a transparent and simple tabular format. In future updates, we will update these depending on data availability.

\section{Subgroup analysis and investigation of heterogeneity}

We did not perform subgroup analysis due to lack of sufficient data. In future updates of this review we will carry out subgroup analysis for different doses (based on the licensed recommendations for dosage) of liposomal bupivacaine administered and different surgical sites. The indications for these subgroup analyses are that in basic science studies it has been demonstrated that a dose response curve is seen and, as such, the dose of liposomal bupivacaine may have an effect on outcome. Furthermore, different surgeries will have different pain profiles and, in addition, the release pattern of bupivacaine hydrochloride from liposomal bupivacaine may be altered by the local environment and therefore different efficacies may be observed at different surgical sites.

\section{Sensitivity analysis}

We planned to perform sensitivity analysis based on the following domains from the Cochrane tool for assessing risk of bias: blinding of outcome assessment and incomplete outcome data. Due to lack of sufficient data, we did not perform sensitivity analysis.

\section{RE S U L T S}

\section{Description of studies}

\section{Results of the search}

Using electronic searches we identified 179 possible studies for inclusion. We identified an additional 43 possible studies, 40 by searches of clinical trials registers and three by searching reference lists of included studies. After removal of duplicates, we screened the titles of 127 records and excluded 59 studies as these were irrelevant. We explored the full text of 68 studies. We excluded 21 studies (see Excluded studies) and identified 37 ongoing studies, leaving nine studies (10 reports) for inclusion in the review (see Characteristics of included studies). For a flowchart of the study selection process, please see Figure 1. 
Figure 1. Study flow diagram

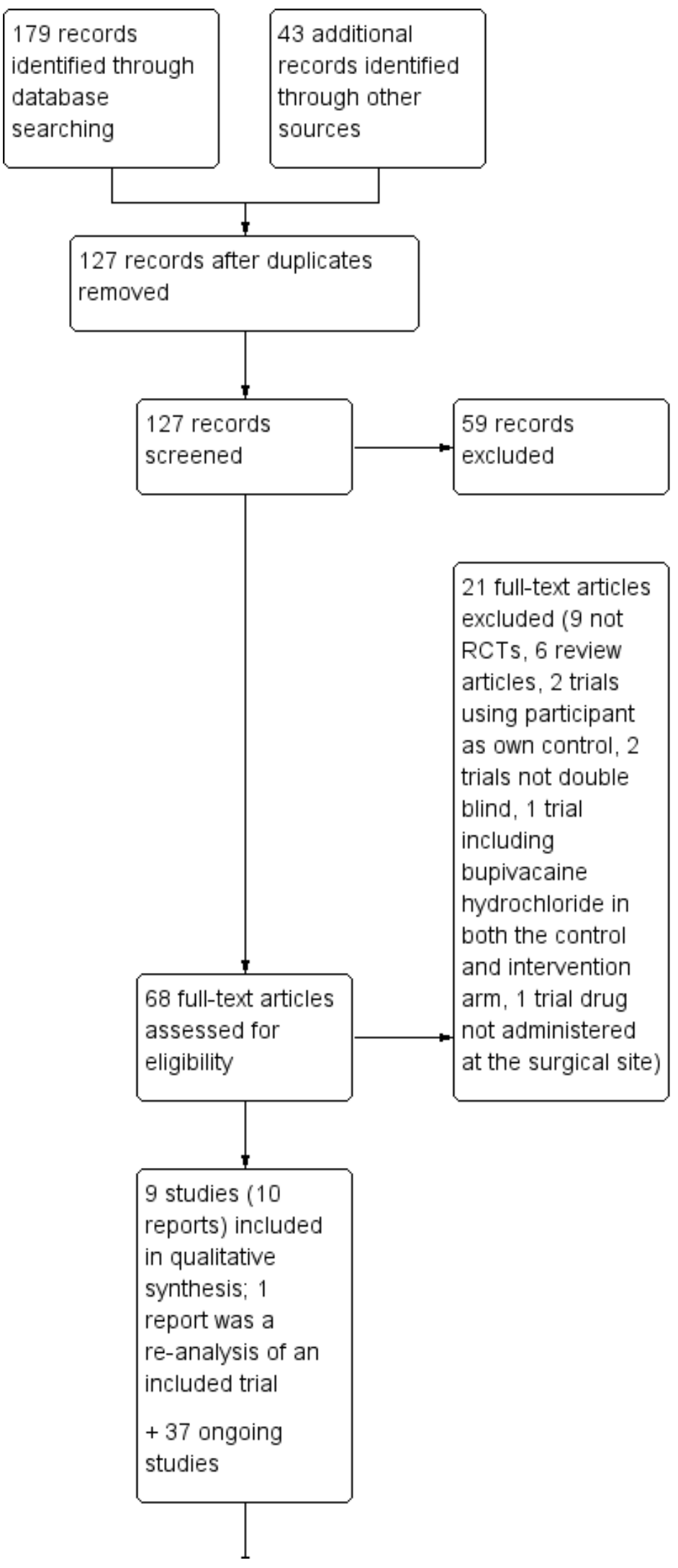


Figure 1. (Continued)

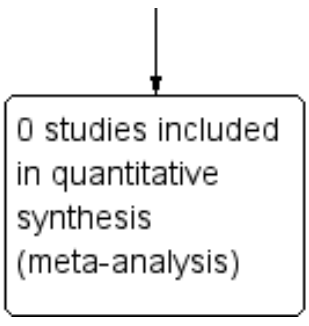

\section{Included studies}

We identified nine studies (10 reports) involving 1377 participants that met inclusion criteria, with 780 participants randomised to receive liposomal bupivacaine infiltration at the surgical site. All studies were conducted in the inpatient setting. In the control group, two studies used placebo ( $0.9 \%$ sodium chloride) at the surgical site (one haemorrhoidectomy Gorfine 2011 (results of this study also reported by Schmidt 2012 (secondary reference of Gorfine 2011)), one bunionectomy (Golf 2011)) and seven studies used bupivacaine hydrochloride at the surgical site (Bramlett 2012; Haas 2012; Langford 2008; NCT 00744848; NCT 00745290; Smoot 2012 (long-term follow-up of this study reported by Minkowitz 2012 (secondary reference of Smoot 2012); White 2009).

Studies were conducted across five surgical sites including:

- total knee replacement; two studies, 383 participants (Bramlett 2012; NCT 00745290);

- haemorrhoidectomy; three studies, 493 participants (Gorfine 2011; Haas 2012; NCT 00744848);

- inguinal hernia repair; two studies, 174 participants (Langford 2008; White 2009);

- bunionectomy; one study, 193 participants (Golf 2011);

- breast augmentation, one study, 134 participants (Smoot 2012).

The dose of liposomal bupivacaine in included studies ranged from $66 \mathrm{mg}$ to $532 \mathrm{mg}$. The timing of administration of liposomal bupivacaine or control varied between studies. In one study it was administered in a staged fashion, starting after dissection (Bramlett 2012), in three studies it was administered intra-operatively but the timing was not specified (Golf 2011; NCT 00745290; White 2009) and in five studies it was administered at the end of surgery (Gorfine 2011; Haas 2012; Langford 2008; NCT 00744848; Smoot 2012). We identified five simultaneous parallel-arm studies (Golf 2011; Gorfine 2011; NCT 00744848; NCT 00745290; Smoot 2012) and four Phase II adaptive trials, where the dose was escalating/deescalating (Bramlett 2012; Haas 2012; Langford 2008; White 2009). The adaptive trials randomised sequential cohorts of participants to control or intervention arms, with the dose of liposomal bupivacaine in the intervention arm increased or decreased conditional on the efficacy and safety of the previous cohort. We have discussed the results of the simultaneous parallel-arm and adaptive-design studies separately.

We have given details of randomisation schedule and interventions, together with details of all eligible studies, in the Characteristics of included studies tables. Outcomes of interest were not investigated in all studies or not reported (reporting bias), or reported in an idiosyncratic manner in adaptive trial designs. As such we were not able to include data from every study in all analyses.

\section{Excluded studies}

We excluded 21 studies as:

- nine were not RCTs;

- six were review papers;

- two trials, both assessing liposomal bupivacaine for bilateral breast augmentation, used the patient as own control preventing inclusion of these data;

- two trials were not appropriately blinded, with the outcome assessors or participants, or both, not blinded to treatment allocation;

- one trial did not assess liposomal bupivacaine at the surgical site;

- one included bupivacaine hydrochloride, at different doses, in both the control and intervention arm.

The study that included bupivacaine hydrochloride, at different doses in both the control and intervention arm, was an RCT evaluating the efficacy of liposomal bupivacaine at the surgical site for the management of pain following total knee replacement. This trial compared $266 \mathrm{mg}$ liposomal bupivacaine mixed with $75 \mathrm{mg}$ bupivacaine hydrochloride against an active control arm of $150 \mathrm{mg}$ bupivacaine hydrochloride. At the time of writing the trial protocol it was not advised to mix liposomal bupivacaine with other drugs, in particular bupivacaine, due the risk of premature de-encapsulation of liposomal bupivacaine. As such we excluded this study from the analysis. However, it must be noted that in December 2015, an amendment to the FDA-licensed indication was made which approved admixing liposomal bupivacaine with bupivacaine, including co-administration in the same syringe, as it has been proposed that admixing with bupivacaine hydrochloride enhances early postoperative analgesia. Whilst excluded from this analysis, in future updates of this review we will include studies evaluating liposomal bupivacaine admixed with bupivacaine hydrochloride. We have given details of excluded studies in the Characteristics of excluded studies tables.

We also identified 37 ongoing studies, details of which are given in the Characteristics of ongoing studies tables.

\section{Risk of bias in included studies}

A summary of the risk of bias assessment using the Cochrane tool can be seen in Figure 2 and Figure 3. 
Figure 2. Risk of bias summary: review authors' judgements about each risk of bias item for each included study

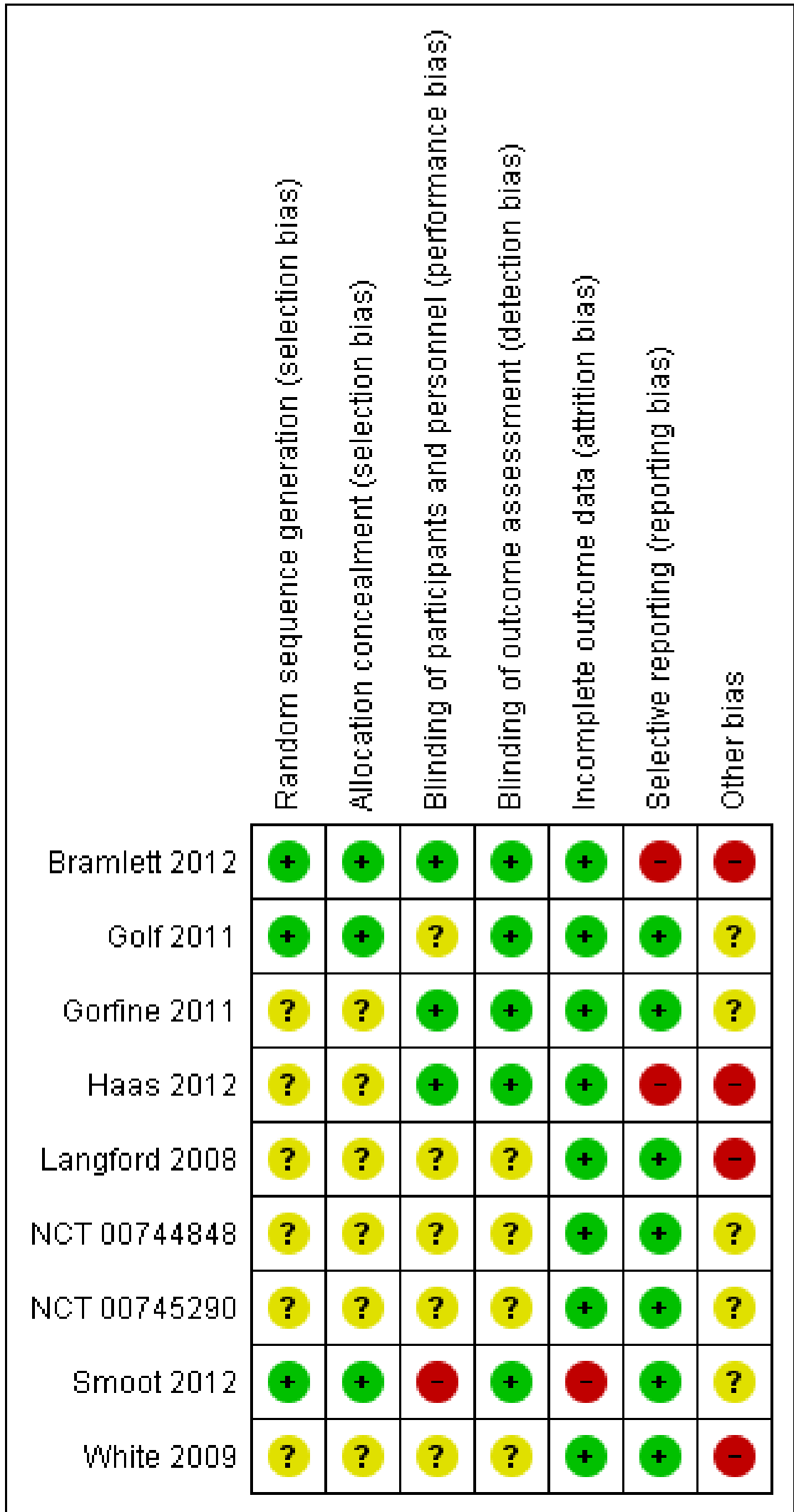


Figure 3. Risk of bias graph: review authors' judgements about each risk of bias item presented as percentages across all included studies

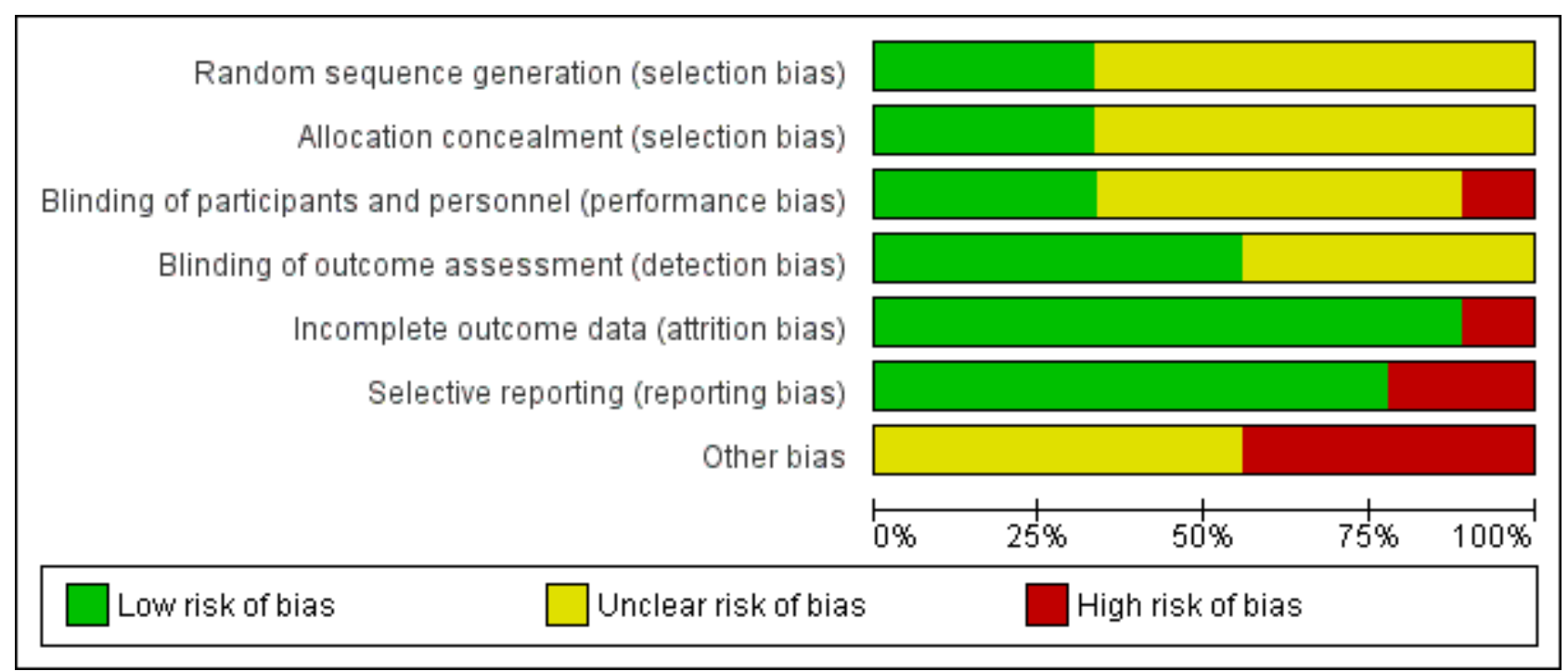

On the five-point Oxford Scale (Jadad 1996) addressing randomisation, blinding, and withdrawals, five studies scored three points (Langford 2008; NCT 00744848; NCT 00745290; Smoot 2012; White 2009), three studies scored four points (Golf 2011; Gorfine 2011; Haas 2012), and one study scored five points (Bramlett 2012), with studies scoring three or more points considered unlikely to be subject to major systematic bias (Khan 1996).

\section{Allocation}

Three studies clearly described the method of randomisation (computer-generated randomisation) and allocation concealment (central-allocation) and we assigned them a low risk of bias for selection bias (Bramlett 2012; Golf 2011; Smoot 2012).

Six studies (two conference abstracts (Langford 2008; White 2009), two clinical trials registry entries (NCT 007448848; NCT 00745290) and two complete manuscripts (Gorfine 2011; Haas 2012)), did not describe the method of random sequence generation or allocation concealment and as such presented an unclear risk of selection bias.

\section{Blinding}

\section{Blinding of participants and personnel (performance bias)}

Liposomal bupivacaine is cloudy and has a different visual appearance to both normal saline and bupivacaine hydrochloride. Furthermore liposomal bupivacaine is more viscous than both normal saline and bupivacaine hydrochloride. As such there is a risk of performance bias by the surgeon who administers drug at the time of surgery. To reduce the risk of performance bias the injection technique was standardised in three trials (Bramlett 2012; Gorfine 2011; Haas 2012) and we regarded these as presenting a low risk of performance bias.

Five studies (two conference abstracts (Langford 2008; White 2009), two clinical trials registry entries (NCT 00744848; NCT 00745290) and one manuscript (Golf 2011), did not state whether the injection technique was standardised, presenting an unclear risk of performance bias.
One study (Smoot 2012), left the injection technique at the discretion of the operating surgeon, presenting a high risk of performance bias. Both the participant and outcome assessor remained blinded and as such we considered this study doubleblind and included it in this review.

\section{Blinding of outcome assessment (detection bias)}

Five studies blinded participants and staff involved in assessment of outcome measures to the treatment allocation (Bramlett 2012; Golf 2011; Gorfine 2011; Haas 2012; Smoot 2012), presenting a low risk of detection bias.

Four studies (two conference abstracts (Langford 2008; White 2009) and two clinical trials registry entries (NCT 00744848; NCT 00745290), did not state whether the participants and staff were blinded, presenting an unclear risk of detection bias.

\section{Incomplete outcome data}

We assessed one study as having a high risk of attrition bias (Smoot 2012), as it was terminated early by the study sponsor for "administrative reasons". We assessed all other studies as having a low risk of attrition bias with greater than 95\% follow-up of randomised participants.

\section{Selective reporting}

We assessed seven of the nine studies as having a low risk of reporting bias. As each included study investigated a number of outcome measures, often at multiple time points, outcome measures were commonly reported as being non-significant without other measures of variance being reported. We assessed two studies as having a high risk of reporting bias (Bramlett 2012; Haas 2012), as cumulative pain scores other than that of the primary endpoint were not reported.

\section{Other potential sources of bias}

As the majority of trials were drug development trials, that is, Phase II and Phase III, the sample size of the treatment and control groups was small. We considered four of the included trials at 
high risk of bias due to having fewer than 50 participants per treatment arm (Bramlett 2012; Haas 2012; Langford 2008; White 2009), with the remainder considered at unclear risk of bias due to sample sizes of between 50 and 199 participants per treatment arm (Golf 2011; Gorfine 2011; NCT 00744848; NCT 00745290; Smoot 2012). All studies were commissioned, funded or published by Pacira Pharmaceuticals Incorporated, manufacturer of liposomal bupivacaine, presenting an unclear risk of bias.

\section{Effects of interventions}

See: Summary of findings for the main comparison Summary of findings: liposomal bupivacaine vs placebo; Summary of findings 2 Summary of findings: liposomal bupivacaine vs bupivacaine hydrochloride

\section{Results of simultaneous parallel-arm studies}

The five simultaneous parallel-arm studies reported the following outcomes (Golf 2011; Gorfine 2011; NCT 00744848; NCT 00745290; Smoot 2012).

\section{Cumulative pain intensity over 72 hours following surgery}

- Three studies with 551 participants assessed cumulative pain intensity over 72 hours following surgery (Gorfine 2011; NCT 00745290; Smoot 2012). One study assessing liposomal bupivacaine $266 \mathrm{mg}$ in participants undergoing excisional haemorrhoidectomy, was placebo controlled (Gorfine 2011), and two studies using liposomal bupivacaine $532 \mathrm{mg}$, in total knee replacement and breast augmentation respectively, used bupivacaine hydrochloride $200 \mathrm{mg}$ as a control (NCT 00745290; Smoot 2012). They recorded pain scores on an 11-point Numeric Rating Scale (NRS; 0 to 10) with cumulative pain intensity over 72 hours calculated using a windowed worst observation carried forward, plus last observation carried forward method in two studies (Gorfine 2011; Smoot 2012) (Appendix 2). One study did not specify the method of calculation (NCT 00745290).
- We have reported the results of these studies in Analysis 1.1 (Figure 4).

- One placebo-controlled study demonstrated a significant reduction in cumulative pain score over 72 hours associated with the use of liposomal bupivacaine (Gorfine 2011). Using GRADE, we downgraded the quality of this evidence one level due to the sparseness of data, a further level due to indirectness and concerns about the generalisability of limited data presented to the population undergoing elective surgery, and one level due to the unclear risk of bias presented by the sample size of the included study (Summary of findings for the main comparison). Overall we judged the evidence to be of very low quality, meaning that we have very little confidence in the effect estimate and that the true effect is likely to be substantially different from the estimate of effect.

- The two studies that used bupivacaine hydrochloride as a control did not demonstrate a difference in cumulative pain scores from 0 to 72 hours associated with the use of liposomal bupivacaine (NCT 00745290; Smoot 2012). Whilst both studies did not demonstrate a difference in cumulative pain score, we decided not to pool the data as we predicted that participant characteristics, as well as the nature of postoperative pain, would be different following breast augmentation and knee replacement, and as such a pooled analysis would not be appropriate. Using GRADE, we downgraded the quality of this evidence one level due to the sparseness of data, a further level due to Smoot 2012 being subject to a high risk of performance bias and attrition bias due to early termination of the study (as well as an unclear risk of bias due to the sample size), and by a further level due to indirectness and concerns about the generalisability of limited data presented to the population undergoing elective surgery (Summary of findings 2). Overall we judged the evidence to be of very low quality, meaning that we have very little confidence in the effect estimate and that the true effect is likely to be substantially different from the estimate of effect.

Figure 4. Forest plot of comparison: 1 Liposomal bupivacaine vs control, outcome: 1.1 Cumulative pain score 0 to 72 hours

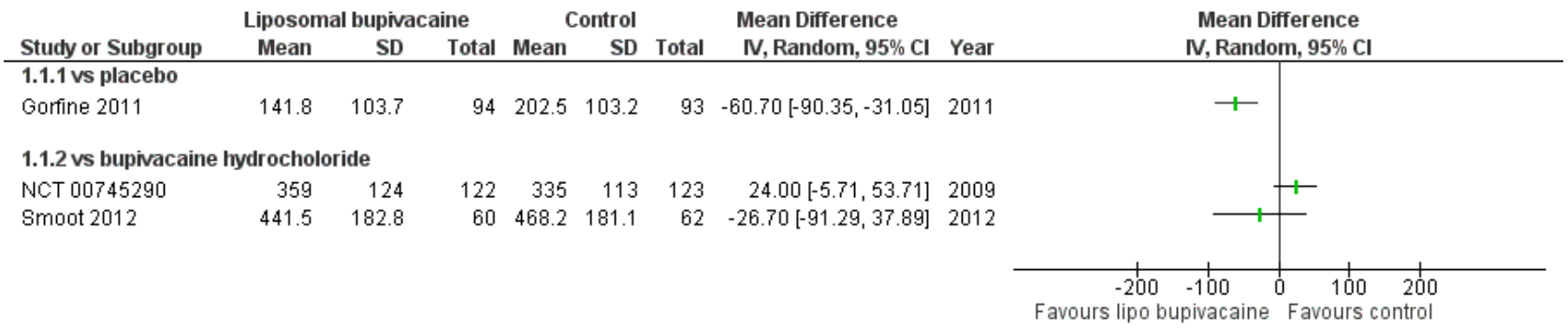

\section{Serious adverse events}

- There were no serious adverse events reported to be associated with the use of liposomal bupivacaine and none of the five studies (Golf 2011; Gorfine 2011; NCT 00744848; NCT 00745290; Smoot 2012), 964 participants, reported withdrawals due to drug-related adverse events.

- Compared to placebo, 2 studies, 382 participants, using GRADE, we downgraded the quality of this evidence one level due sparseness of the data and one level due to Golf 2011 being subject to a high risk of performance bias and both studies presenting an unclear risk of bias due to their sample size (50-199). Overall we judged the evidence to be of low quality, meaning our confidence in the effect estimate is limited and that the true effect may be substantially different from the estimate of the effect.

- Compared to bupivacaine hydrochloride, 3 studies, 583 participants, using GRADE, we downgraded the quality of this evidence one level due to Smoot 2012 being subject to a high risk of performance bias and attrition bias due to early termination of the study. Overall we judged the evidence to be of moderate quality, meaning we were moderately confident in the effect 
estimate and that the true effect is likely to be close to the estimate of effect, but there is a possibility that it is substantially different.

\section{Mean pain score at 12, 24, 48, 72 and 96 hours following surgery}

- The mean pain score using an 11-point NRS (0 to 10) at 12, 24, 48 and 72 hours following breast augmentation surgery was reported by Smoot 2012, 136 participants, who found a significantly lower pain score at 12 hours in those participants receiving liposomal bupivacaine $532 \mathrm{mg}$ compared to bupivacaine hydrochloride $200 \mathrm{mg}(P=0.014$; Figure 5) with no difference in mean pain score (mean NRS not reported) found at 24,48 or 72 hours.
- The other simultaneous parallel-arm studies did not report mean pain score at 12, 24, 48, 72 or 96 hours following surgery.

- Using GRADE, we downgraded the quality of this evidence one level due to the sparseness of data; a further level due to Smoot 2012 being subject to a high risk of performance bias and attrition bias due to early termination of the study; and by a further level due to indirectness and the limitations in interpreting data from a single study. Overall we judged the evidence to be of very low quality, meaning we had very little confidence in the effect estimate and that the true effect is likely to be substantially different from the estimate of effect.

Figure 5. Table of results for included simultaneous parallel-arm trials

\begin{tabular}{|c|c|c|c|c|c|c|c|c|c|c|c|c|}
\hline & & & & $\begin{array}{l}\text { Cumulafive } \\
\text { pain score } \\
0 \text { to } 72 \\
\text { hours }\end{array}$ & $\begin{array}{l}12 \\
\text { hours }\end{array}$ & $\begin{array}{l}24 \\
\text { hours }\end{array}$ & $\begin{array}{l}\text { Mean P: } \\
43 \\
\text { hours }\end{array}$ & $\begin{array}{l}\text { in Socore } \\
72 \\
\text { hours }\end{array}$ & $\begin{array}{l}96 \\
\text { hours }\end{array}$ & $\begin{array}{l}\text { Time to first } \\
\text { opiaid } \\
0 \text { to } 96 \\
\text { hours }\end{array}$ & $\begin{array}{l}\text { Oumulaive } \\
\text { opioid use } \\
0 \text { to } 72 \\
\text { hours }\end{array}$ & $\begin{array}{l}\text { Patients not } \\
\text { requiring } \\
\text { post. } \\
\text { cperative } \\
\text { opiaids } 0-72 \mathrm{~h}\end{array}$ \\
\hline Study & Arm & Intervertion & Paricipants & $\begin{array}{l}\text { Mean } \\
\text { (SD) }\end{array}$ & $\begin{array}{l}\text { Mean } \\
\text { (SD) }\end{array}$ & $\begin{array}{l}\text { Mean } \\
\text { (SD) }\end{array}$ & $\begin{array}{l}\text { Mesn } \\
\text { (SD) }\end{array}$ & $\begin{array}{l}\text { Mean } \\
\text { (SD) }\end{array}$ & $\begin{array}{l}\text { Mean } \\
\text { (SD) }\end{array}$ & $\begin{array}{l}\text { Median } \\
\text { (Range) } \\
\text { hours }\end{array}$ & $\begin{array}{l}\text { Mean } \\
\text { (SD) } \\
\text { mg }\end{array}$ & $n(\%)$ \\
\hline \multicolumn{13}{|c|}{ 5.1 Liposomal bupivacaine vs placebo } \\
\hline $\begin{array}{l}\text { Golf } \\
2011\end{array}$ & $T_{4}$ & LB $106 \mathrm{mg}$ & 97 & & & & & & & $\begin{array}{l}7.2 \\
(N R)\end{array}$ & & $\begin{array}{l}2 \\
(2 \%)\end{array}$ \\
\hline & $\mathrm{C}$ & $\mathrm{NaCl} 0.9 \%$ & 96 & & & & & & & $\begin{array}{l}4.3 \\
\text { (NR) }\end{array}$ & & $\begin{array}{l}1 \\
(1 \%)\end{array}$ \\
\hline $\begin{array}{l}\text { Gonfine } \\
2011\end{array}$ & h & LB 266mg & 95 & $\begin{array}{l}141.8 \\
(104.3)\end{array}$ & & & & & & 14.3 & $\begin{array}{l}22.3 \\
(21.0)\end{array}$ & $\begin{array}{l}24 \\
(26 \%)\end{array}$ \\
\hline & $\mathrm{C}$ & NaC1 $0.9 \%$ & 94 & $\begin{array}{l}202.5 \\
(103.7)\end{array}$ & & & & & & 12 & $\begin{array}{l}29.1 \\
(20.7)\end{array}$ & $\begin{array}{l}9 \\
(10 \%)\end{array}$ \\
\hline
\end{tabular}

\begin{tabular}{|c|c|c|c|c|c|c|c|}
\hline \multirow[t]{2}{*}{$\begin{array}{l}\text { NCT } \\
\text { Co744848 }\end{array}$} & $\bar{h}$ & LB 266mg & 101 & & & & \\
\hline & $\mathrm{C}$ & $\begin{array}{l}\mathrm{BHCl} \\
100 \mathrm{mg}\end{array}$ & 103 & & & & \\
\hline \multirow[t]{2}{*}{$\begin{array}{l}\text { NCT } \\
00745290\end{array}$} & $\mathrm{~h}$ & LB 532mg & 122 & $\begin{array}{l}359 \\
(124)\end{array}$ & & & \\
\hline & C & $\begin{array}{l}\text { BHCl } \\
200 \mathrm{mg}\end{array}$ & 123 & $\begin{array}{l}335 \\
(113)\end{array}$ & & & \\
\hline \multirow[t]{2}{*}{$\begin{array}{l}\text { Smoot } \\
2012\end{array}$} & $\bar{T}$ & LB 532mg & 66 & $\begin{array}{l}441.5 \\
(163)\end{array}$ & $\begin{array}{l}5.6 \\
(3.2)\end{array}$ & $\begin{array}{l}13.5 \\
\text { (NR) }\end{array}$ & $\begin{array}{l}6 \\
(10 \%)\end{array}$ \\
\hline & C & $\begin{array}{l}\text { BHCl } \\
200 \mathrm{mg}\end{array}$ & 70 & $\begin{array}{l}468.2 \\
\text { (181) }\end{array}$ & $\begin{array}{l}6.9 \\
\text { (3.1) }\end{array}$ & $\begin{array}{l}20.4 \\
\text { (NR) }\end{array}$ & $\begin{array}{l}3 \\
(5 \%)\end{array}$ \\
\hline
\end{tabular}

LB = Liposamal bupivacaine; $\mathrm{BHC}=\mathrm{Bupivacaine} \mathrm{hydrochloride;} \mathrm{FNB} \mathrm{=} \mathrm{Femaral} \mathrm{Nerve} \mathrm{Block;} \mathrm{RHCl}=\mathrm{Ropivacaine} \mathrm{hydrochloride;} \mathrm{NR}=\mathrm{Not}$ reported pain soore at rest reported by Gorphine 2011 and with activity NCT 00745290 and Smoot 2012 =not reported

\section{Time to first postoperative opioid dose over initial 72 hours}

- Two studies, 382 participants, reported the median time to first opioid dose following bunionectomy and haemorrhoidectomy respectively with both studies finding the time to first postoperative opioid dose to be significantly longer $(P<0.0001)$ in those participants receiving liposomal bupivacaine $(106 \mathrm{mg}$ and $266 \mathrm{mg}$ respectively) compared to placebo (Golf 2011; Gorfine 2011). We did not pool the data as they were not normally distributed and in addition participant characteristics, as well as the nature of postoperative pain, would be different 
following bunionectomy and haemorrhoidectomy; as such, a pooled analysis would not be appropriate.

- The other simultaneous parallel-arm studies did not report time to first postoperative opioid dose.

- Using GRADE, we downgraded the quality of this evidence one level due to the sparseness of data and a further level due to Golf 2011 being subject to a high risk of performance bias. Overall we judged the evidence to be of low quality, meaning that our confidence in the effect estimate was limited and the true effect may be substantially different from our estimate of effect.

\section{Total postoperative opioid consumption over first 72 hours}

- Two studies with 325 participants reported the total postoperative opioid consumption over the first 72 hours (Gorfine 2011; Smoot 2012).

- One study compared liposomal bupivacaine $266 \mathrm{mg}$ with placebo (Gorfine 2011) in participants undergoing haemorrhoidectomy and reported a reduction in cumulative parenteral morphine equivalent dose of $6.8 \mathrm{mg}(95 \% \mathrm{Cl}(-12.8$ $\mathrm{mg}$ to $-0.9 \mathrm{mg}$ ) for the liposomal bupivacaine arm. Using GRADE, we downgraded the quality of this evidence one level due to the sparseness of data, a further level due to indirectness due to the limitations in interpreting data from a single study, and a further level due to the unclear risk of bias due the sample size of the included study (50-199). Overall we judged the evidence to be of very low quality, meaning we had very little confidence in the effect estimate and that the true effect is likely to be substantially different from the estimate of effect.

- One trial compared liposomal bupivacaine $532 \mathrm{mg}$ with bupivacaine hydrochloride $200 \mathrm{mg}$ (Smoot 2012) in participants undergoing breast augmentation and found no difference in cumulative parenteral morphine equivalent dose (Figure 5). Using GRADE, we downgraded the quality of this evidence one level due to the sparseness of data, a further level due to indirectness due to the limitations in interpreting data from a single study and a further level due to Smoot 2012 being subject to a high risk of performance bias and attrition bias due to early termination of the study. Overall we judged the evidence to be of very low quality, meaning we had very little confidence in the effect estimate and that the true effect is likely to be substantially different from the estimate of effect.

\section{Percentage of participants not requiring postoperative opioids over initial 72 hours}

- Three studies with 492 participants reported the percentage of participants not requiring postoperative opioids over initial 72 hours following surgery (Golf 2011; Gorfine 2011; Smoot 2012). Two studies were placebo controlled (Gorfine 2011; Golf 2011), and one study used bupivacaine hydrochloride as a control (Smoot 2012). One of the two studies comparing liposomal bupivacaine with placebo demonstrated a higher number of participants receiving liposomal bupivacaine did not require postoperative opioids. The other two studies, one versus placebo, one versus bupivacaine hydrochloride, found no difference in opioid requirement. Due to significant heterogeneity between the studies $\left(I^{2}=92 \%\right)$ we have not shown the pooled result (Figure 6). Possible reasons for heterogeneity could be due to differences in pain response after different surgical procedures or differences in pain response between patient groups undergoing specific surgeries.

- Compared to placebo, 2 studies, 382 participants, using GRADE, we downgraded the quality of this evidence one level due to the sparseness of data, one level due to inconsistency of data, and a further level due to Golf 2011 being subject to a high risk of performance bias and unclear risk of bias due to the sample size (50-199). Overall we judged the evidence to be of very low quality, meaning we had very little confidence in the effect estimate and that the true effect is likely to be substantially different from the estimate of effect.

- Compared to bupivacaine hydrochloride, 1 study, 134 participants, using GRADE, we downgraded the quality of this evidence one level due to the sparseness of data, a further level due to Smoot 2012 being subject to a high risk of performance bias and attrition bias due to early termination of the study and by a further level due to indirectness and the limitations in interpreting data from a single study. Overall we judged the evidence to be of very low quality, meaning we had very little confidence in the effect estimate and that the true effect is likely to be substantially different from the estimate of effect.

Figure 6. Forest plot of comparison: 1 Liposomal bupivacaine vs control, outcome: 1.2 Participants not requiring postoperative opioids

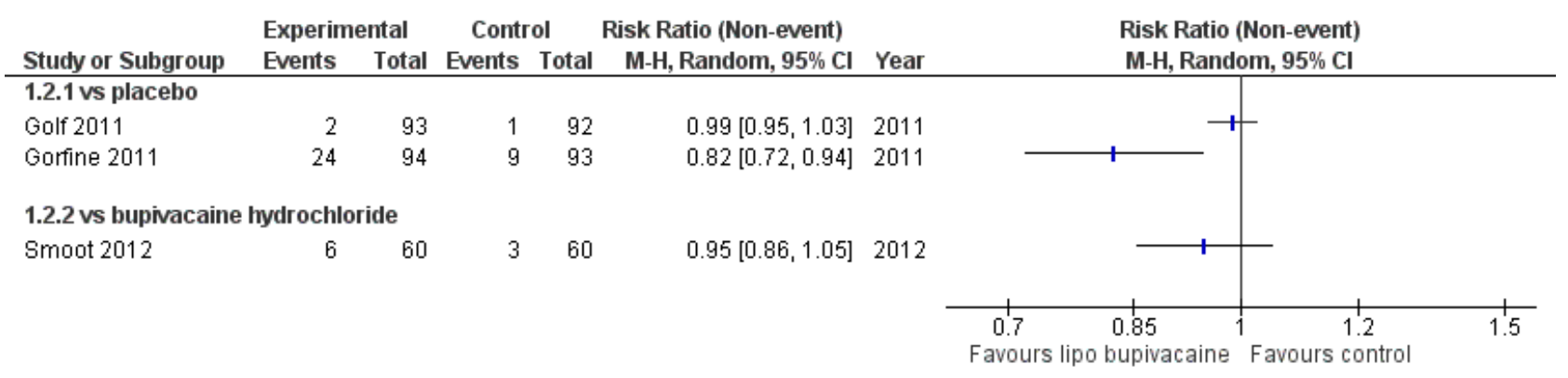

\section{Health economics assessment}

- None of the included studies presented a health economic assessment.

\section{Incidence of adverse events within 30 days of surgery}

- None of the included studies reported the incidence of cardiac events and wound complications within 30 days of surgery. 
- All the included studies reported adverse events within 30 days of surgery, with nausea, constipation and vomiting being the most common.

- Nausea was reported in $38 \%$ of participants receiving placebo (Golf 2011), 31\% to $58 \%$ of those receiving bupivacaine hydrochloride (NCT 00744848; NCT 00745290; Smoot 2012) and $44 \%$ to $62 \%$ of those participants receiving liposomal bupivacaine (Golf 2011; NCT 00744848; NCT 00745290; Smoot 2012).

- Constipation was reported in between $9 \%$ and $38 \%$ of participants receiving bupivacaine hydrochloride (NCT 00744848; NCT 00745290; Smoot 2012) and between 16\% and $46 \%$ of participants receiving liposomal bupivacaine (NCT 00744848; NCT 00745290; Smoot 2012).

- Vomiting was reported in $18 \%$ of participants receiving placebo (Golf 2011), $20 \%$ to $34 \%$ of those receiving bupivacaine hydrochloride (NCT 00745290; Smoot 2012) and 15\% to 31\% of participants receiving liposomal bupivacaine (Golf 2011; NCT 00745290; Smoot 2012).

- We decided not to pool the data as we predicted that participant characteristics, as well as the nature of adverse events, would be different following different surgical procedures and, as such, a pooled analysis would not be appropriate.

- Compared to placebo, 2 studies, 382 participants, using GRADE, we downgraded the quality of this evidence one level due sparseness of the data and one level due to Golf 2011 being subject to a high risk of performance bias and both studies presenting an unclear risk of bias due to their sample size (50-199). Overall we judged the evidence to be of low quality, meaning our confidence in the effect estimate is limited and that the true effect may be substantially different from the estimate of the effect.

- Compared to bupivacaine hydrochloride, 3 studies, 583 participants, using GRADE, we downgraded the quality of this evidence one level due to Smoot 2012 being subject to a high risk of performance bias and attrition bias due to early termination of the study. Overall we judged the evidence to be of moderate quality, meaning we were moderately confident in the effect estimate and that the true effect is likely to be close to the estimate of effect, but there is a possibility that it is substantially different.

\section{Patient-reported outcomes}

- None of the included studies reported patient-reported outcomes (outside of pain), using validated outcome scores, at any time point following surgery.

\section{Results of adaptive-design trials}

We identified four dose-escalating/de-escalating studies (Bramlett 2012; Haas 2012; Langford 2008; White 2009). Dose-escalating/deescalating studies are designed to evaluate efficacy and safety. An illustrative example of a typical adaptive-design trial is shown in Figure 7. In the four Phase II adaptive-design studies (Bramlett 2012; Haas 2012; Langford 2008; White 2009), the results from the control groups of all dose-escalating steps in the randomisation process were reported collectively as a single population. Data from adaptive-design trials cannot be included in meta-analysis for a number of reasons: a) the decision to escalate or de-escalate a dose is conditional on the failure of the previous dose on either the efficacy, or safety, or cost-effectiveness of the intervention, introducing bias in any pooled analysis, and b) the randomisation ratio is altered with each escalation/de-escalation while the control group population is typically reported cumulatively for all dose levels. We therefore have decided to report the information from these studies as a narrative and we have included it in Figure 8. In hindsight, due to the role of adaptive-design trials in identifying an efficient and safe dose for further exploration of the intervention in larger scale trials, and the limitations imposed in including such data in meta-analyses, we may consider excluding trials of this design from the definition in Types of studies in future updates of this review. 
Figure 7. Illustrative example of an adaptive-design trial. The decision to escalate, or de-escalate a dose is conditional on the failure of the previous dose on the efficacy, or safety, or cost-effectiveness of the intervention, introducing bias in any pooled analysis. The randomisation ratio is altered with each escalation/de-escalation while the control group population is typically reported cumulatively for all dose levels

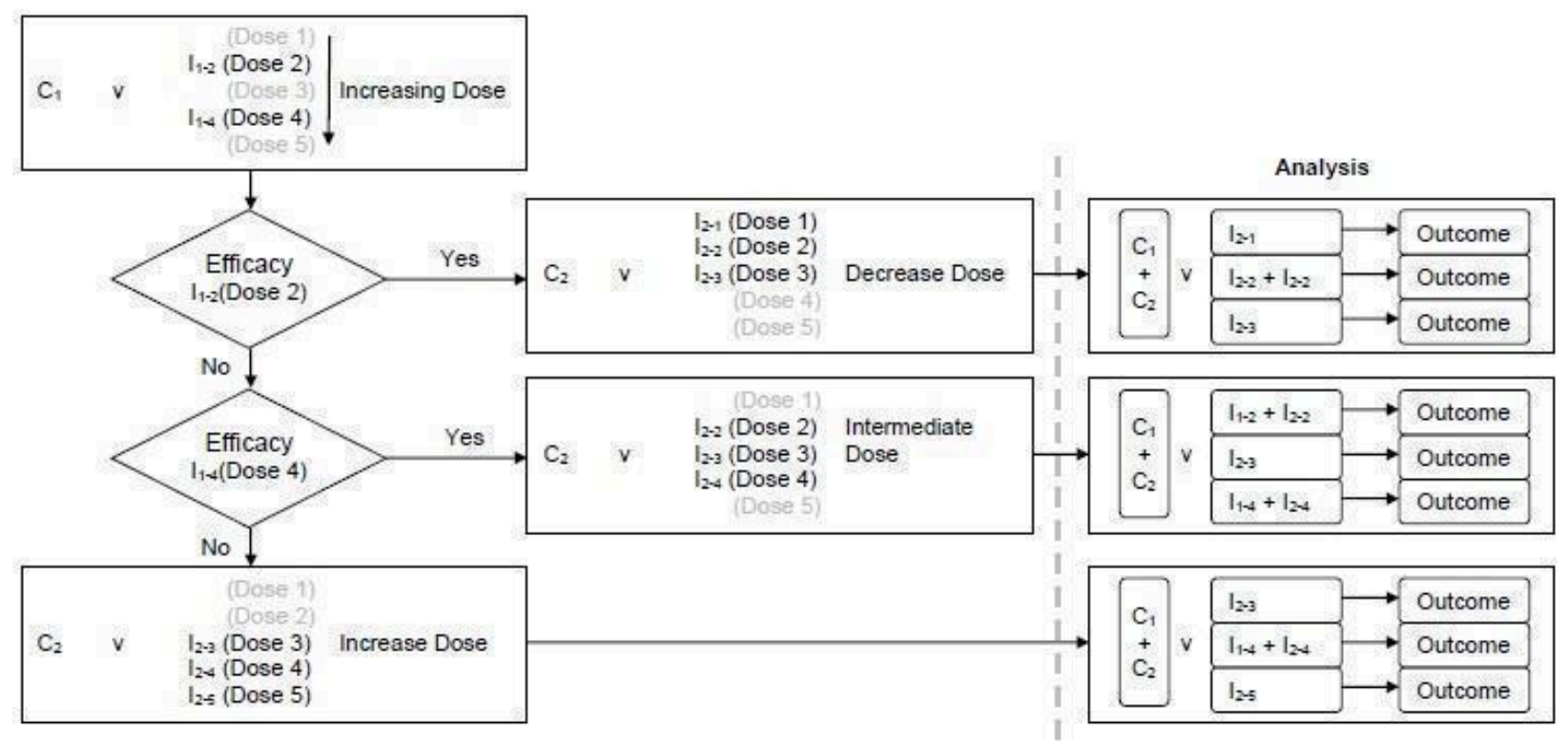


Figure 8. Table of results for adaptive-design trials

\begin{tabular}{|c|c|c|c|c|c|c|c|c|c|c|c|c|}
\hline & & & & $\begin{array}{l}\text { Curnulabve } \\
\text { pain score }\end{array}$ & & & Mean Ps & in Score & & $\begin{array}{l}\text { Time to first } \\
\text { opicid }\end{array}$ & $\begin{array}{l}\text { Oumulafive } \\
\text { opioid use }\end{array}$ & $\begin{array}{l}\text { Pafents not } \\
\text { requiring } \\
\text { post- }\end{array}$ \\
\hline & & & & $\begin{array}{l}0 \text { so } 72 \\
\text { hours }\end{array}$ & $\begin{array}{l}12 \\
\text { hours }\end{array}$ & $\begin{array}{l}24 \\
\text { hours }\end{array}$ & $\begin{array}{l}49 \\
\text { hours }\end{array}$ & $\begin{array}{l}72 \\
\text { hours }\end{array}$ & $\begin{array}{l}96 \\
\text { hours }\end{array}$ & $\begin{array}{l}0 \text { to } 96 \\
\text { hours }\end{array}$ & $\begin{array}{l}0 \text { to } 72 \\
\text { hours }\end{array}$ & $\begin{array}{l}\text { operative } \\
\text { opiaids }\end{array}$ \\
\hline & & & & $\begin{array}{l}\text { Mean } \\
\text { (SD) }\end{array}$ & $\begin{array}{l}\text { Mean } \\
\text { (SD) }\end{array}$ & $\begin{array}{l}\text { Mean } \\
\text { (SD) }\end{array}$ & $\begin{array}{l}\text { Mean } \\
\text { (SD) }\end{array}$ & $\begin{array}{l}\text { Mean } \\
\text { (SD) }\end{array}$ & $\begin{array}{l}\text { Mean } \\
\text { (SD) }\end{array}$ & $\begin{array}{l}\text { Median } \\
\text { (Range) }\end{array}$ & $\begin{array}{l}\text { Mean } \\
\text { (SD) }\end{array}$ & $n(\%)$ \\
\hline Study & Avm & Intervertion & Participants & & & & & & & hours & $\mathrm{mg}$ & \\
\hline \multirow[t]{5}{*}{$\begin{array}{l}\text { Bramleat } \\
2012\end{array}$} & h & LB 133mg & 27 & $\begin{array}{l}9.3 \\
\langle\mathrm{NR}\rangle\end{array}$ & & $\begin{array}{l}3.8 \\
\langle 2.2\rangle\end{array}$ & $\begin{array}{l}5.2 \\
\langle 2.1\rangle\end{array}$ & $\begin{array}{l}3.9 \\
(2.8)\end{array}$ & $\begin{array}{l}3.4 \\
(2.9)\end{array}$ & & & \\
\hline & $b_{2}$ & LB266mg & 25 & $\begin{array}{l}8.1 \\
\text { (NR) }\end{array}$ & & $\begin{array}{l}3.1 \\
(2.4)\end{array}$ & $\begin{array}{l}4.7 \\
(2.3)\end{array}$ & $\begin{array}{l}3.4 \\
(2.4)\end{array}$ & $\begin{array}{l}2.9 \\
(2.4)\end{array}$ & & & \\
\hline & b & LB 399mg & 26 & $\begin{array}{l}7.9 \\
\text { (NR) }\end{array}$ & & $\begin{array}{l}3.6 \\
(2.1)\end{array}$ & $\begin{array}{l}4.1 \\
\langle 2.2)\end{array}$ & $\begin{array}{l}3.4 \\
(2.1)\end{array}$ & $\begin{array}{l}3.0 \\
\langle 2.0\rangle\end{array}$ & & & \\
\hline & 4 & LB 532mg & 25 & $\begin{array}{l}6.5 \\
(\mathrm{NR})\end{array}$ & & $\begin{array}{l}2.4 \\
(2.4)\end{array}$ & $\begin{array}{l}4.2 \\
\langle 2.1\rangle\end{array}$ & $\begin{array}{l}2.9 \\
(2.3)\end{array}$ & $\begin{array}{l}1.9 \\
(2.3)\end{array}$ & & & \\
\hline & $\mathrm{C}$ & $\begin{array}{l}\mathrm{BHCl} \\
150 \mathrm{mg}\end{array}$ & 35 & $\begin{array}{l}9.2 \\
(\mathrm{NR})\end{array}$ & & $\begin{array}{l}4.3 \\
(3.3)\end{array}$ & $\begin{array}{l}4.8 \\
(2.4)\end{array}$ & $\begin{array}{l}3.8 \\
(2.3)\end{array}$ & $\begin{array}{l}3.0 \\
(2.7)\end{array}$ & & & \\
\hline \multirow[t]{4}{*}{$\begin{array}{l}\text { Hass } \\
2012\end{array}$} & $T_{4}$ & LB 66mg & 24 & $\begin{array}{l}224 \\
(162)\end{array}$ & & & & & & $\begin{array}{l}9 \\
\langle 0.1 \text { to } 96.0\rangle\end{array}$ & $\begin{array}{l}44 \\
\text { NR) }\end{array}$ & \\
\hline & $b_{2}$ & LB 199mg & 25 & $\begin{array}{l}171 \\
(175)\end{array}$ & & & & & & $\begin{array}{l}11 \\
(0.2 \text { bo } 96.0)\end{array}$ & $\begin{array}{l}21 \\
\text { NR) }\end{array}$ & \\
\hline & $\mathbf{b}$ & LB 399mg & 24 & $\begin{array}{l}176 \\
(175)\end{array}$ & & & & & & $\begin{array}{l}19 \\
\langle 0.1 \text { bo } 96.0)\end{array}$ & $\begin{array}{l}12 \\
\text { NR) }\end{array}$ & \\
\hline & $\mathrm{C}$ & BHCl $75 \mathrm{mg}$ & 26 & $\begin{array}{l}331 \\
(178)\end{array}$ & & & & & & $\begin{array}{l}8 \\
\langle 0.3 \text { to 96.0) }\end{array}$ & $\begin{array}{l}29 \\
\text { NR) }\end{array}$ & \\
\hline \multirow[t]{5}{*}{$\begin{array}{l}\text { Langford } \\
2009\end{array}$} & $I_{4}$ & LB $175 \mathrm{mg}$ & 12 & & $\begin{array}{l}26.4 \\
(21.2)\end{array}$ & $\begin{array}{l}27.2 \\
(23.5)\end{array}$ & $\begin{array}{l}33.4 \\
(30.2)\end{array}$ & $\begin{array}{l}23.8 \\
(20.2)\end{array}$ & $\begin{array}{l}15.5 \\
\langle 15.5\rangle\end{array}$ & & $\begin{array}{l}5.5 \\
\text { NR) }\end{array}$ & $\begin{array}{l}10 \\
(83.3)\end{array}$ \\
\hline & $b$ & LB 225mg & 12 & & $\begin{array}{l}21.4 \\
(19.2)\end{array}$ & $\begin{array}{l}29.8 \\
(18.6)\end{array}$ & $\begin{array}{l}31.6 \\
(27.5)\end{array}$ & $\begin{array}{l}24.1 \\
(23.6)\end{array}$ & $\begin{array}{l}14.4 \\
(16.3)\end{array}$ & & $\begin{array}{l}1.1 \\
\text { NR) }\end{array}$ & $\begin{array}{l}9 \\
\langle 75\rangle\end{array}$ \\
\hline & $\bar{b}$ & LB 300mg & 12 & & $\begin{array}{l}22.0 \\
(17.0)\end{array}$ & $\begin{array}{l}20.8 \\
(18.6)\end{array}$ & $\begin{array}{l}28.5 \\
(24.6)\end{array}$ & $\begin{array}{l}16.8 \\
(14.8)\end{array}$ & $\begin{array}{l}16.1 \\
\langle 18.5\rangle\end{array}$ & & $\begin{array}{l}13.4 \\
\text { (NR) }\end{array}$ & $\begin{array}{l}9 \\
\langle 75\rangle\end{array}$ \\
\hline & h & LB 350mg & 14 & & $\begin{array}{l}24.6 \\
(19.0)\end{array}$ & $\begin{array}{l}29.9 \\
(24.2)\end{array}$ & $\begin{array}{l}27.5 \\
(24.9)\end{array}$ & $\begin{array}{l}21.7 \\
(23.1)\end{array}$ & $\begin{array}{l}15.1 \\
\langle 20.0\rangle\end{array}$ & & $\begin{array}{l}11.1 \\
\text { NR) }\end{array}$ & $\begin{array}{l}10 \\
(71.4)\end{array}$ \\
\hline & C & $\begin{array}{l}\mathrm{BHCl} \\
100 \mathrm{mg}\end{array}$ & 26 & & $\begin{array}{l}49.0 \\
(18.0)\end{array}$ & $\begin{array}{l}48.7 \\
(20.1)\end{array}$ & $\begin{array}{l}39.4 \\
(20.8)\end{array}$ & $\begin{array}{l}35.7 \\
(22.5)\end{array}$ & $\begin{array}{l}24.0 \\
\langle 20.1\rangle\end{array}$ & & $\begin{array}{l}15.4 \\
\text { (NR) }\end{array}$ & $\begin{array}{l}13 \\
(50)\end{array}$ \\
\hline \multirow[t]{4}{*}{$\begin{array}{l}\text { Whise } \\
2009\end{array}$} & $\overline{T_{4}}$ & LB93mg & 25 & $\begin{array}{l}286.9 \\
\langle 146.4\rangle\end{array}$ & & & & & & & & \\
\hline & $\mathrm{b}$ & LB 160mg & 24 & $\begin{array}{l}274.6 \\
(115.4)\end{array}$ & & & & & & & & \\
\hline & $\mathrm{b}$ & LB306mg & 25 & $\begin{array}{l}274.4 \\
(253.4)\end{array}$ & & & & & & & & \\
\hline & C & $\begin{array}{l}\mathrm{BHCl} \\
105 \mathrm{mg}\end{array}$ & 24 & $\begin{array}{l}298.1 \\
(136.6)\end{array}$ & & & & & & & & \\
\hline
\end{tabular}

LB = Liposoma bupivacaine; BHC = Bupivacaine hydrochloride; NR = Not reported; pain socre at rest reported by Bramlent 2012 and Hass 2012 and with activity Lang ford 2008 and While 2009 ; $=$ not reported

\section{DISCUSSION}

\section{Summary of main results}

We identified nine studies that met inclusion criteria for this review. Four Phase II dose-escalating/de-escalating studies (Bramlett 2012; Haas 2012; Langford 2008; White 2009), designed to evaluate and demonstrate efficacy and safety, presented pooled data which could not be used in this analysis. Of the remaining five studies two were placebo controlled (Golf 2011; Gorfine 2011) and three used bupivacaine hydrochloride as a control (NCT 00744848; NCT 00745290; Smoot 2012).

Compared to placebo one study (Gorfine 2011) reported a lower cumulative pain score 0 to 72 hours after surgery, two studies reported a longer time to first postoperative opioid (Golf 2011; 
Gorfine 2011), and one study reported a lower cumulative opioid consumption 0 to 72 hours after surgery associated with the used of liposomal bupivacaine (Gorfine 2011). Compared to bupivacaine hydrochloride two studies found no difference in the cumulative pain score 0 to 72 hours after surgery associated with the use of liposomal bupivacaine (NCT 00745290; Smoot 2012), and one study reported a lower mean pain score at 12 hours, but not at 24, 48 or 72 hours postoperatively (Smoot 2012). Three studies reported the number of participants not requiring postoperative opioids (Golf 2011; Gorfine 2011; Smoot 2012), however significant heterogeneity $(12=92 \%)$ was observed, limiting further analysis. Data comparing liposomal bupivacaine with femoral nerve block were not available for inclusion in the analysis.

Of the five parallel-arm studies which did not have an adaptive design assessing liposomal bupivacaine against either placebo or bupivacaine hydrochloride, no studies reported health economic assessments or patient-reported outcomes other than pain (Golf 2011; Gorfine 2011; NCT 00744848; NCT 00745290; Smoot 2012). Nausea, constipation and vomiting were the most commonly reported adverse events. Data regarding cardiac events and wound complications were not reported. No withdrawals were reported to be due to drug-related adverse events.

Using GRADE we considered the quality of evidence to be very low to moderate with further research considered very likely to have an important impact on our confidence in the estimate of effect. This assessment of quality was predominantly due to sparseness of data as well as a high risk of bias in some of the included studies.

Liposomal bupivacaine does appear to have efficacy in reducing postoperative pain compared to placebo when infiltrated at the surgical site, but, at present the limited evidence does not demonstrate superiority to bupivacaine hydrochloride. Due to the low quality and volume of evidence our confidence in the effect estimate is limited and the true effect may be substantially different from our estimate.

\section{Overall completeness and applicability of evidence}

The main limitations of this review are the small number of studies, incomplete outcome data reporting and significant heterogeneity observed between studies. The use of adaptive-design doseescalating/de-escalating Phase II studies is necessary to evaluate and demonstrate efficacy and safety of a novel drug, however, when the decision to escalate/de-escalate is conducted in a conditional manner this can lead to the introduction of bias as well as leading to imbalance in the randomisation ratio (where the control group is reported cumulatively). This review found four of the nine included studies to be of an adaptive design, and we decided to exclude these from the analysis. Assessing the five remaining studies, these were conducted across four surgical sites (bunionectomy, haemorrhoidectomy, knee replacement and breast augmentation) with differences in pain profiles, as well as differences in the way that people report pain at these surgical sites being a possible explanation for the heterogeneity seen in this review.

\section{Quality of the evidence}

The quality of evidence ranged from moderate to very low across the different outcomes. The major limitation in quality was the sparseness of data for the outcomes of interest. In addition, we assessed a number of included studies as at high risk of bias resulting in further downgrading of the quality assessment. As such our confidence in the effect estimate was limited and the true effect may be substantially different from our estimates of effect.

\section{Potential biases in the review process}

Liposomal bupivacaine is a relatively new drug and has been recently licensed. As such many studies investigating its efficacy and safety are currently underway. Our review identified 37 ongoing studies (See Characteristics of ongoing studies) which will report over the next few years. Whilst every effort has been made to minimise bias in this review, new evidence will continue to emerge in this field that may impact on the conclusions drawn. Methods used to minimise the possibility of bias in this review included the use of a comprehensive broad search strategy based on previous Cochrane Reviews for RCTs in postoperative pain, such that we could identify all relevant studies. Additionally, we searched reference lists of potentially relevant studies and reviews, and searched trials registries.

\section{Agreements and disagreements with other studies or reviews}

The results of this meta-analysis disagree with previous metaanalyses performed by Bergese 2012a and Dasta 2012 which reported the use of liposomal bupivacaine to be associated with lower cumulative pain scores between 0 and 72 hours after the end of the operation, longer time to first opioid and lower cumulative postoperative opioid usage between 0 and 72 hours postoperatively compared to bupivacaine hydrochloride control. There are several reasons for the disagreement seen between ours and the previous meta-analyses. Firstly, previous metaanalyses included the results of adaptive-design studies, which, as discussed, we do not believe is valid. Secondly, previous meta-analyses pooled data from a range of different surgical procedures in which patient demographics and postoperative pain profiles would be expected to be different; and finally both previous meta-analyses were performed in collaboration with Pacira Pharmaceuticals Inc. who manufacture the drug and funded the drug development studies, and as such had privileged access to the complete set of data for each of the studies.

\section{AUTHORS'CONCLUSIONS}

\section{Implications for practice}

\section{General Implications}

Liposomal bupivacaine does appear to have efficacy in reducing postoperative pain compared to placebo when infiltrated at the surgical site, however, at present the limited evidence does not demonstrate superiority to bupivacaine hydrochloride. We assessed the quality of the evidence as moderate to very low and as such our confidence in the effect estimate is limited and the true effect may be substantially different from our estimates.

\section{For people with postoperative pain}

The current data do not support or refute the use of liposomal bupivacaine infiltration at the surgical site to reduce postoperative pain. 


\section{For clinicians}

Further evidence as the clinical and cost effectiveness of liposomal bupivacaine infiltration at the surgical site is required as, due to the quality of evidence, the current data do not support or refute the use of liposomal bupivacaine infiltration at the surgical site for the management of postoperative pain.

\section{For policymakers}

The current data do not permit firm estimates of effect size due to the low quantity and quality. As such the current data do not support or refute the use of liposomal bupivacaine infiltration at the surgical site to reduce postoperative pain. Further evidence of clinical, as well as cost-effectiveness, is required.

\section{For funders of the intervention}

Currently the limited evidence does not demonstrate superiority to bupivacaine hydrochloride, however due to the quality of the evidence our confidence in the effect estimate is limited and the true effect may be substantially different from our estimates. The current data do not support or refute the use of liposomal bupivacaine infiltration at the surgical site to reduce postoperative pain and further evidence of clinical, as well as cost-effectiveness, is required.

\section{Implications for research}

\section{General implications}

Good quality, large, active comparator randomised controlled studies are required to establish the clinical and cost effectiveness of liposomal bupivacaine infiltration at the surgical site for the management of postoperative pain. Studies should be conducted across a range of surgical sites with the results stratified and interpreted by site. Studies should be focused on surgeries that are known to be associated with significant postoperative pain, particularly surgeries where improved pain control may deliver significant clinical benefits through reduced morbidity, or costeffectiveness benefits through faster rehabilitation and discharge (i.e. total knee replacement).

\section{Design}

Future studies should be parallel-arm, active comparator randomised controlled trials with broad inclusion criteria, such that results are applicable to the general population. Studies should be well designed and adequately powered, involving more than 200 participants per arm, to reduce the risk of bias.

\section{Measurement (end points)}

This review focuses on the management of postoperative pain however it is important to note that recovery following surgery is multi-factorial, with patients highly valuing the absence of nausea and sedation as well the ability to mobilise and perform self-care, as well as other factors. A gold standard outcome measure for postoperative recovery following surgery has yet to be established however it is prudent that in addition to the clinical outcome measures of pain scores and opioid usage, future studies should also evaluate patient-reported functional outcome measures, which are likely to be surgery-specific, as these outcome measures will provide further information about the effectiveness of any intervention from the patient perspective.

\section{ACKNOWLEDGEMENTS}

The authors wish to thank Joanne Abbott, Information Specialist, for her assistance with developing the search strategy.

TWH Funding Acknowledgement: supported by the NIHR Biomedical Research Centre, based at Oxford University Hospitals Foundation Trust, Oxford. The views expressed are those of the authors and not necessarily those of the NHS, the NIHR or the Department of Health.

CRG Funding Acknowledgement: the National Institute for Health Research (NIHR) is the largest single funder of the Cochrane PaPaS Group. Disclaimer: the views and opinions expressed therein are those of the authors and do not necessarily reflect those of the NIHR, NHS or the Department of Health. 


\section{R E F E R E N C E S}

\section{References to studies included in this review}

Bramlett 2012 \{published data only\}

Bramlett K, Onel E, Viscusi ER, Jones K. A randomized, doubleblind, dose-ranging study comparing wound infiltration of DepoFoam bupivacaine, an extended-release liposomal bupivacaine, to bupivacaine $\mathrm{HCl}$ for postsurgical analgesia in total knee arthroplasty. Knee 2012;19(5):530-6.

\section{Golf 2011 \{published data only\}}

Golf M, Daniels SE, Onel E. A phase 3, randomized, placebocontrolled trial of DepoFoam $(\mathrm{R})$ bupivacaine (extended-release bupivacaine local analgesic) in bunionectomy. Advances in Therapy 2011;28(9):776-88.

\section{Gorfine 2011 \{published data only\}}

* Gorfine SR, Onel E, Patou G, Krivokapic ZV. Bupivacaine extended-release liposome injection for prolonged postsurgical analgesia in patients undergoing hemorrhoidectomy: a multicenter, randomized, double-blind, placebo-controlled trial. Diseases of the Colon \& Rectum 2011;54(12):1552-9.

Schmidt WK, Patou G, Joshi GP. Evaluating therapeutic benefit in postsurgical analgesia requires global assessment: an example from liposome bupivacaine in hemorrhoidectomy. Hospital Practice 2012;40(1):160-5.

\section{Haas 2012 \{published data only\}}

Haas E, Onel E, Miller H, Ragupathi M, White P F. A doubleblind, randomized, active-controlled study for posthemorrhoidectomy pain management with liposome bupivacaine, a novel local analgesic formulation. The American Journal of Surgery 2012;78(5):574-81.

\section{Langford 2008 \{published data only\}}

Langford RM, Chappell GM, Karrasch JA. Abstract P-9088 A single administration of DepoBupivacaine intraoperatively results in prolonged detectable plasma bupivacaine and analgesia in patients undergoing inguinal hernia repair. Presented at the Annual Postgraduate Assembly in Anesthesiology of the New York State Society of Anesthesiologists, December 12-16, 2008, New York, NY. 2008.

\section{NCT 00744848 \{unpublished data only\}}

No authors listed. NCT 00744848. clinicaltrials.gov/ct2/show/ study/NCT00744848 2009.

\section{NCT 00745290 \{unpublished data only\}}

NCT00745290. A phase 3 study to evaluate the safety and efficacy of SKY0402 in subjects undergoing total knee arthroplasty (TKA). clinicaltrials.gov/ct2/show/NCT00745290 2009.

\section{Smoot 2012 \{published data only\}}

Minkowitz HS, Onel E, Patronella CK, Smoot JD. A twoyear observational study assessing the safety of DepoFoam bupivacaine after augmentation mammaplasty. Aesthetic Surgery Journal 2012;32(2):186-93.
* Smoot JD, Bergese SD, Onel E, Williams HT, Hedden W. The efficacy and safety of DepoFoam bupivacaine in patients undergoing bilateral, cosmetic, submuscular augmentation mammaplasty: a randomized, double-blind, active-control study. Aesthetic Surgery Journal 2012;32(1):69-76.

White 2009 \{published data only\}

White PF, Schooley G, Ardeleanu M. Abstract S-242 Analgesia following a single administration of Depo bupivacaine intraoperatively in patients undergoing inguinal herniorrhaphy: preliminary dose ranging studies. Anaesthetics and Analgesia 2009;108(Supplement):S1-S332.

\section{References to studies excluded from this review}

\section{Bagsby 2014 \{published data only\}}

Bagsby DT, Ireland PH, Meneghini RM. Liposomal bupivacaine versus traditional periarticular injection for pain control after total knee arthroplasty. Journal of Arthroplasty 2014;29(8):1687-90.

\section{Barrington 2015 \{published data only\}}

Barrington JW, Olugbode O, Lovald S, Ong K, Watson H, Emerson RH. Liposomal bupivacaine a comparative study of more than 1000 total joint arthroplasty cases. Orthopedic Clinics of North America 2015;46(4):469-77.

Baxter 2013 \{published data only\}

Baxter R, Bramlett K, Onel E, Daniels S. Impact of local administration of liposome bupivacaine for postsurgical analgesia on wound healing: a review of data from ten prospective, controlled clinical studies. Clinical Therapeutics 2013;35(3):312-20.e5.

\section{Bergese 2012 \{published data only\}}

Bergese SD, Onel E, Morren M, Morganroth J. Bupivacaine extended-release liposome injection exhibits a favourable cardiac safety profile. Regional Anesthesia \& Pain Medicine 2012;37(2):145-51.

\section{Bergese 2012a \{published data only\}}

Bergese SD, Ramamoorthy S, Patou G, Bramlett K, Gorfine SR, Candiotti KA. Efficacy profile of liposome bupivacaine, a novel formulation of bupivacaine for postsurgical analgesia. Journal of Pain Research 2012;5:107-16.

Cohen 2012 \{published data only\}

Cohen SM. Extended pain relief trial utilizing infiltration of Exparel, a long-acting multivesicular liposome formulation of bupivacaine: a Phase IV health economic trial in adult patients undergoing open colectomy. Journal of Pain Research 2012;5:567-72.

\section{Cohen 2014 \{published data only\}}

Cohen SM, Vogel JD, Marcet JE, Candiotti KA. Liposome bupivacaine for improvement in economic outcomes and opioid burden in GI surgery: IMPROVE Study pooled analysis. Journal of Pain Research 2014;7:359-66. 
Collis 2015 \{published data only\}

Collis PN, Hunter AM, Vaughn MD, Carreon LY, Huang J, Malkani AL. Periarticular injection after total knee arthroplasty using liposomal bupivacaine vs a modified Ranawat suspension: a prospective, randomized study. The Journal of Arthroplasty 2015 [Epub ahead of print]. [DOI: 10.1016/ j.arth.2015.09.025]

\section{Dasta 2012 \{published data only\}}

Dasta J, Ramamoorthy S, Patou G, Sinatra R. Bupivacaine liposome injectable suspension compared with bupivacaine $\mathrm{HC}$ for the reduction of opioid burden in the postsurgical setting. Current Medical Research \& Opinion 2012;28(10):1609-15.

\section{Edwards 2015 \{published data only\}}

Edwards MC, Sorokin E, Brzezienski M, Nahai FR, Scranton R, Wall $\mathrm{H}$, et al. Impact of liposome bupivacaine on the adequacy of pain management and patient experiences following aesthetic surgery: results from an observational study. Plastic Surgery 2015;23(1):15-20.

Hu 2013 \{published data only\}

Hu D, Onel E, Singla N, Kramer WG, Hadzic A. Pharmacokinetic profile of liposome bupivacaine injection following a single administration at the surgical site. Clinical Drug Investigation 2013;33(2):109-15.

\section{Knight 2015 \{published data only\}}

Knight RB, Walker PW, Keegan KA, Overholser SM, Baumgartner TS, Ebertowski JS 2nd, et al. A randomized controlled trial for pain control in laparoscopic urologic surgery: $0.25 \%$ bupivacaine versus long-acting liposomal bupivacaine. Journal of Endourology 2015;29(9):1019-24.

\section{Marcet 2013 \{published data only\}}

Marcet JE, Nfonsam VN, Larach S. An extended paln relief trial utilizing the infiltration of a long-acting Multivesicular liPosome foRmulation Of bupiVacaine, EXPAREL (IMPROVE): a Phase IV health economic trial in adult patients undergoing ileostomy reversal. Journal of Pain Research 2013;6:549-55.

\section{McKeown 2014 \{published data only\}}

McKeown E, Bastawrous A, Chuang K. Experience with liposomal bupivacaine in minimally invasive colon surgery. Diseases of the Colon and Rectum. 2014; Vol. 57, issue 5:75-358.

\section{Nadeau 2015 \{published data only\}}

Nadeau MH, Saraswat A, Vasko A, Elliot JO, Vasko SD. Bupivacaine versus liposomal bupivacaine for postoperative pain control after augmentation mammaplasty: a prospective, randomized, double-blind trial. Aesthetic Surgery Journal 2015 [Epub ahead of print]. [DOI: 10.1093/asj/sjv149]

\section{NCT 01206608 \{unpublished data only\}}

NCT01206608. Evaluation of the safety and efficacy of a single dose of SKY0402 in subjects undergoing augmentation mammoplasty. clinicaltrials.gov/ct2/show/NCT01206608 2010.

Schroer 2015 \{published data only\}

Schroer WC, Diesfield PG, LeMarr AR, Morton DJ, Reedy ME. Does extended-release liposomal bupivacaine better control pain than bupivacaine after total knee arthroplasty (TKA)? A prospective, randomized clinical trial. Journal of Arthroplasty 2015;30(9 Supplement):64-7.

Surdam 2015 \{published data only\}

Surdam JW, Licini DJ, Baynes NT, Arce BR. The use of Exparel (liposomal bupivacaine) to manage postoperative pain in unilateral total knee arthroplasty patients. The Journal of Arthroplasty 2015;30(2):325-9.

\section{Viscusi 2014 \{published data only\}}

Viscusi ER, Sinatra R, Onel E, Ramamoorthy SL. The safety of liposome bupivacaine, a novel local analgesic formulation. Clinical Journal of Pain 2014;30(2):102-10.

\section{Vogel 2013 \{published data only\}}

Vogel JD. Liposome bupivacaine (EXPAREL (R)) for extended pain relief in patients undergoing ileostomy reversal at a single institution with a fast-track discharge protocol: an IMPROVE Phase IV health economics trial. Journal of Pain Research 2013;6:605-10.

\section{White 2015 \{published data only\}}

White S, Vaughan C, Raiff D, Eward W, Bolognesi M. Impact of liposomal bupivacaine administration on postoperative pain in patients undergoing total knee Replacement. Pharmacotherapy 2015;35(5):477-81.

\section{References to ongoing studies}

NCT01907191 \{unpublished data only\}

NCT01907191. Ultrasound guided local infiltration analgesia for hip arthroscopy. ClinicalTrials.gov/show/NCT019071912013.

NCT02011464 \{unpublished data only\} NCT02011464. Evaluation Exparel delivered in knee replacement. ClinicalTrials.gov/show/NCT02011464 2013.

NCT02044302 \{unpublished data only\}

NCT02044302. A prospective trial to reduce post-operative pain in implant based breast reconstruction. ClinicalTrials.gov/show/ NCT02044302 2014.

NCT02052180 \{unpublished data only\}

NCT02042180. Early post-operative pain control following wrist operations. ClinicalTrials.gov/show/NCT02052180 2014.

NCT02052557 \{unpublished data only\}

NCT02052557. The effect of Exparel on post operative pain and narcotic use after colon surgery. ClinicalTrials.gov/show/ NCT02052557 2013.

\section{NCT02060591 \{unpublished data only\}}

NCT02060591. Comparison of two periarticular injection medications for adjunctive pain management following total knee arthroplasty (TKA). ClinicalTrials.gov/show/NCT02060591 2014. 
NCT02104414 \{unpublished data only\}

NCT02104414. Efficacy of rectal infiltration of Exparel for analgesic benefit following hemorrhoidectomy. ClinicalTrials.gov/show/NCT02104414 2014.

\section{NCT02111746 \{unpublished data only\}}

NCT02111746. PAIN - Postoperative Analgesia INvestigation. ClinicalTrials.gov/show/NCT02111746 2014.

\section{NCT02128646 \{unpublished data only\}}

NCT02128646. Liposomal bupivacaine (Exparel) for postoperative pain control for open and laparoscopic abdominal hernia repair. ClinicalTrials.gov/show/NCT02128646 2015.

\section{NCT02189317 \{unpublished data only\}}

NCT02189317. Liposomal bupivacaine for pain control following anterior cruciate ligament reconstruction. clinicaltrials.gov/ct2/ show/NCT02189317 2014

\section{NCT02197273 \{unpublished data only\}}

NCT02197273. Liposomal bupivacaine versus standard analgesia in TJA. ClinicalTrials.gov/show/NCT02197273 2014.

\section{NCT02214810 \{unpublished data only\}}

NCT02214810. A study of postsurgical pain control for lower extremity fractures. ClinicalTrials.gov/show/NCT02214810 2014.

NCT02219087 \{unpublished data only\}

NCT02219087. Liposomal bupivacaine versus standard of care in total knee surgery. ClinicalTrials.gov/show/NCT02219087 2014.

\section{NCT02242201 \{unpublished data only\}}

NCT02242201. THA lumbar plexus versus periarticular. clinicaltrials.gov/ct2/show/NCT02242201 2014.

NCT02274870 \{unpublished data only\}

NCT02274870. Liposomal bupivacaine for post operative pain after knee replacement surgery. ClinicalTrials.gov/show/ NCT02274870 2014

\section{NCT02287246 \{unpublished data only\}}

NCT02287246. Efficacy of extended-release liposomal bupivacaine for post-operative urogynecologic surgery. ClinicalTrials.gov/show/NCT02287246 2014.

\section{NCT02296099 \{unpublished data only\}}

NCT02296099. Trial liposomal bupivacaine following retropubic suburethral sling for stress urinary incontinence. ClinicalTrials.gov/show/NCT02296099 2014.

\section{NCT02299349 \{unpublished data only\}}

NCT02299349. Bupivacaine liposome suspension versus a concentrated multi drug periarticular injection. ClinicalTrials.gov/show/NCT02299349 2013.

\section{NCT02352922 \{unpublished data only\}}

NCT02352922. Randomized trial of wound infiltration with extended-release bupivacaine before laparoscopic or robotic hysterectomy. ClinicalTrials.gov/show/NCT02352922 2015.
NCT02369523 \{unpublished data only\}

NCT02369523. Multimodal pain management following primary TKA. ClinicalTrials.gov/show/NCT02369523 2015.

NCT02381353 \{unpublished data only\}

NCT02381353. Exparel injection for postoperative orbital pain. ClinicalTrials.gov/show/NCT02381353 2015.

NCT02426164 \{unpublished data only\}

NCT02426164. Liposomal bupivacaine in total knee arthroplasty. ClinicalTrials.gov/show/NCT02426164 2015.

NCT02444533 \{unpublished data only\} NCT02444533. EXPAREL ${ }^{\circledR}$ for pain after tonsillectomy. ClinicalTrials.gov/show/NCT02444533 2015.

NCT02449915 \{unpublished data only\}

NCT02449915. Improvement of pain following robotic sacrocolpopexy and rectocele repair for pelvic organ prolapse. ClinicalTrials.gov/show/NCT02449915 2015.

NCT02472314 \{unpublished data only\} NCT02472314. Exparel for postoperative pain management in shoulder surgery. ClinicalTrials.gov/show/NCT02472314 2015.

NCT02473198 \{unpublished data only\}

NCT02473198. Femoral nerve block compared to Exparel in total knee replacement. ClinicalTrials.gov/show/NCT02473198 2015.

NCT02480621 \{unpublished data only\}

NCT02480621. Liposomal bupivacaine with bupivacaine in ankle fracture ORIF. ClinicalTrials.gov/show/NCT02480621 2015.

NCT02499575 \{unpublished data only\}

NCT02499575. Pericapsular Exparel for pain relief in bunionectomy and related procedures. ClinicalTrials.gov/show/ NCT02499575 2015.

\section{NCT02515851 \{unpublished data only\}}

NCT02515851. A randomized, double-blind controlled trial of bupivacaine extended-release liposome injection for postsurgical analgesia in patients undergoing open-reduction internal fixation of the distal radius. ClinicalTrials.gov/show/ NCT02515851 2015.

NCT02517905 \{unpublished data only\} NCT02517905. Evaluation of EXPAREL for prolonged postsurgical analgesia in subjects undergoing third molar extraction. ClinicalTrials.gov/show/NCT02517905 2015.

NCT02542956 \{unpublished data only\}

NCT02542956. Comparison of local anesthetic infusion pump versus DepoFoam bupivacaine for pain management. ClinicalTrials.gov/show/NCT02542956 2015.

NCT02543801 \{unpublished data only\}

NCT02543801. A clinical trial of two periarticular multimodal drug injections in total hip arthroplasty. ClinicalTrials.gov/show/ NCT025438012015. 
NCT02571283 \{unpublished data only\}

NCT02571283. Peri-articular injection utilizing a pain cocktail with and without Exparel. ClinicalTrials.gov/show/NCT02571283 2015.

\section{NCT02591888 \{unpublished data only\}}

NCT02591888. Impact of liposomal bupivacaine administered following placement of a transobturator suburethral sling. ClinicalTrials.gov/show/NCT02591888 2015.

NCT02606448 \{unpublished data only\}

NCT02606448. Exparel infiltration in anterior cruciate ligament reconstruction. ClinicalTrials.gov/show/NCT02606448 2015.

\section{NCT02616367 \{unpublished data only\}}

NCT2616367. Comparison of ropivacaine and liposomal bupivacaine for total knee arthroplasty. ClinicalTrials.gov/show/ NCT02616367 2015.

\section{NCT02659501 \{unpublished data only\}}

NCT02659501. Liposomal bupivacaine in implant based breast reconstruction. clinicaltrials.gov/ct2/show/NCT026595012015.

\section{Additional references}

\section{Apfelbaum 2003}

Apfelbaum JL, Chen C, Mehta SS, Gan TJ. Postoperative pain experience: results from a national survey suggest postoperative pain continues to be undermanaged. Anesthesia and Analgesia 2003;97(2):534-40.

\section{Deeks 2011}

Deeks JJ, Higgins JPT, Altman DG (editors). Chapter 9: Analysing data and undertaking meta-analyses. In: Higgins JPT, Green $S$ (editors). Cochrane Handbook for Systematic Reviews of Interventions Version 5.1.0 (updated March 2011). The Cochrane Collaboration, 2011. Available from handbook.cochrane.org.

\section{Gan 2014}

Gan TJ, Habib AS, Miller TE, White W, Apfelbaum JL. Incidence, patient satisfaction, and perceptions of post-surgical pain: results from a US national survey. Current Medical Research and Opinion 2014;30(1):149-60.

\section{Gantenbein 2000}

Gantenbein M, Attolini L, Bruguerolle B, Villard PH, Puyoou F, Durand $A$, et al. Oxidative metabolism of bupivacaine into pipecolylxylidine in humans is mainly catalyzed by CYP3A. Drug Metabolism and Disposition 2000;28(4):383-5.

\section{GRADEPro GDT 2015 [Computer program]}

McMaster University (developed by Evidence Prime, Inc.). GRADEpro Guideline Development Tool. McMaster University (developed by Evidence Prime, Inc.), 2015.

\section{Grant 2004}

Grant GJ, Barenholz Y, Bolotin EM, Bansinath M, Turndorf H, Piskoun B, et al. A novel liposomal bupivacaine formulation to produce ultralong-acting analgesia. Anesthesiology 2004;101(1):133-7.

\section{Hamilton 2016}

Hamilton TW, Athanassoglou V, Trivella M, Mellon S, Murray D, Pandit HG. Liposomal bupivacaine peripheral nerve block for the management of postoperative pain. Cochrane Database of Systematic Reviews 2016, Issue 8. [DOI: 10.1002/14651858.CD011476.pub2]

\section{Higgins 2003}

Higgins JPT, Thompson SG, Deeks JJ, Altman DG. Measuring inconsistency in meta-analyses. BMJ 2003;327:557-60.

\section{Higgins 2011a}

Higgins JPT, Altman DG, Sterne JAC (editors). Chapter 8: Assessing risk of bias in included studies. In: Higgins JPT, Green $\mathrm{S}$ (editors). Cochrane Handbook for Systematic Reviews of Interventions Version 5.1.0 (updated March 2011). The Cochrane Collaboration, 2011. Available from handbook.cochrane.org.

\section{Jadad 1996}

Jadad AR, Moore RA, Carroll D, Jenkinson C, Reynolds DJ, Gavaghan DJ, et al. Assessing the quality of reports of randomized clinical trials: is blinding necessary?. Controlled Clinical Trials 1996;17(1):1-12.

\section{Kehlet 1993}

Kehlet H, Dahl JB. The value of "multimodal" or "balanced analgesia" in postoperative pain treatment. Anesthesia and Analgesia 1993;77(5):1048-56.

\section{Kehlet 2006}

Kehlet $\mathrm{H}$, Jensen TS, Woolf CJ. Persistent postsurgical pain: risk factors and prevention. Lancet 2006;367(9522):1618-25.

\section{Khan 1996}

Khan KS, Daya S, Jadad A. The importance of quality of primary studies in producing unbiased systematic reviews. Archives of Internal Medicine 1996;156(6):661-6.

\section{Liberati 2009}

Liberati A, Altman DG, Tetzlaff J, Mulrow C, Gotzsche PC, loannidis JP, et al. The PRISMA statement for reporting systematic reviews and meta-analyses of studies that evaluate health care interventions: explanation and elaboration. Journal of Clinical Epidemiology 2009;62(10):e1-34.

\section{Lorentzen 2012}

Lorentzen V, Hermansen IL, Botti M. A prospective analysis of pain experience, beliefs and attitudes, and pain management of a cohort of Danish surgical patients. European Journal of Pain 2012;16(2):278-88

\section{Mantripragada 2002}

Mantripragada S. A lipid based depot (DepoFoam((R)) technology) for sustained release drug delivery. Progress in Lipid Research 2002;41(5):392-406.

\section{Nimmaanrat 2007}

Nimmaanrat S, Liabsuetrakul T, Uakritdathikarn T, Wasinwong W. Attitudes, beliefs, and expectations of gynecological patients toward postoperative pain and its 
management. Journal of the Medical Association of Thailand 2007;90(11):2344-51.

\section{RevMan 2014 [Computer program]}

The Nordic Cochrane Centre, The Cochrane Collaboration. Review Manager 5 (RevMan 5). Version 5.3. Copenhagen: The Nordic Cochrane Centre, The Cochrane Collaboration, 2014.

\section{Schünemann 2011}

Schünemann HJ, Oxman AD, Vist GE, Higgins JPT, Deeks JJ, Glasziou P, et al. Chapter 12: Interpreting results and drawing conclusions. In: Higgins JPT, Green S (editors), Cochrane Handbook for Systematic Reviews of Interventions Version 5.1.0 (updated March 2011). The Cochrane Collaboration, 2011. Available from handbook.cochrane.org.

\section{Spector 1996}

Spector MS, Zasadzinski JA, Sankaram MB. Topology of multivesicular liposomes, a model biliquid foam. Langmuir 1996;12(20):4704-8.

\section{CHARACTERISTICS OF STUDIES}

Characteristics of included studies [ordered by study ID]

\section{Sterne 2009}

Sterne JAC, White AR, Carlin JB, Spratt M, Royston P, Kenward MG, et al. Multiple imputation for missing data in epidemiological and clinical research: potential and pitfalls. BMJ 2009;338:b2393.

\section{References to other published versions of this review}

\section{Hamilton 2014}

Hamilton TW, Athanassoglou V, Mellon S, Trivella M, Murray D, Pandit HG. Liposomal bupivacaine infiltration at the surgical site for the management of postoperative pain. Cochrane Database of Systematic Reviews 2014, Issue 12. [DOI: 10.1002/14651858.CD011419]

* Indicates the major publication for the study

Bramlett 2012

Methods Phase II dose-ranging randomised controlled study, participant and assessor blinded. 5 parallel groups. Participants enrolled into 3 consecutive cohorts based on efficacy and safety results of previous cohort.

- Cohort 1: randomised 1:1:1 to control (Arm 1) or liposomal bupivacaine $133 \mathrm{mg}$ (Arm 2) or liposomal bupivacaine $266 \mathrm{mg}$ (Arm 3)

- Cohort 2: randomised 2:2:2:5 to control (Arm 1) or liposomal bupivacaine $133 \mathrm{mg}$ (Arm 2) or liposomal bupivacaine $266 \mathrm{mg}$ (Arm 3) or (Arm 4) liposomal bupivacaine $399 \mathrm{mg}$

- Cohort 3: randomised 2:5 to control (Arm 1) or liposomal bupivacaine $532 \mathrm{mg}$ (Arm 5)

Liposomal bupivacaine or control administered in a staged fashion starting after dissection but before prostheses insertion with the final injections administered before wound closure

\section{Participants}

People undergoing primary unilateral total knee replacement under general anaesthesia $(n=138)$

Age 18-75 years

\section{ASA 1-3}

Location: 10 centres (USA and Czech Republic)

Dates: October 2007-November 2008

Interventions

A single dose of the control or intervention drug was administered at the time of operation via wound infiltration using a standardised technique

Control:

- Arm 1: bupivacaine hydrochloride $150 \mathrm{mg}$ with epinephrine $1: 200,000(n=35)$

Intervention:

- Arm 2: liposomal bupivacaine $133 \mathrm{mg}(\mathrm{n}=27)$

- Arm 3: liposomal bupivacaine $266 \mathrm{mg}(\mathrm{n}=25)$

- Arm 4: liposomal bupivacaine $399 \mathrm{mg}(\mathrm{n}=26)$ 
Bramlett 2012 (Continued)

- Arm 5: liposomal bupivacaine $532 \mathrm{mg}(\mathrm{n}=25)$

Primary outcome
- Cumulative pain score (AUC) with activity (maximum active knee flexion) 0 -96 $\mathrm{h}$
Secondary outcomes
- Cumulative pain score (AUC) with rest and activity 0 to: $24,48,72,96$ and $120 \mathrm{~h}$
- Mean pain score (NRS 0 to 10$)$ at: $24,48,72,96$ and $120 \mathrm{~h}$
- Total rescue opioid consumption $(\mathrm{mg}) 24,48,72,96$ and $120 \mathrm{~h}$
- Cumulative opioid consumption $(\mathrm{mg}) 48,72,96$ and $120 \mathrm{~h}$
- Blinded care providers' satisfaction with postoperative analgesia (day 8 )
- Time to resumption of work or daily activities
- Adverse events (vital signs, wound healing, scarring, electrocardiogram results) day 0 to day 36
- Drug pharmacokinetics

\section{Risk of bias}

\begin{tabular}{|c|c|c|}
\hline Bias & Authors' judgement & Support for judgement \\
\hline $\begin{array}{l}\text { Random sequence genera- } \\
\text { tion (selection bias) }\end{array}$ & Low risk & Randomisation codes were generated via computer randomisation \\
\hline $\begin{array}{l}\text { Allocation concealment } \\
\text { (selection bias) }\end{array}$ & Low risk & Central randomisation separate to trial sites \\
\hline $\begin{array}{l}\text { Blinding of participants } \\
\text { and personnel (perfor- } \\
\text { mance bias) } \\
\text { All outcomes }\end{array}$ & Low risk & $\begin{array}{l}\text { Participants were blinded. Personnel preparing and administering the study } \\
\text { drug and control (who were not involved in post-operative assessments) were } \\
\text { not blinded but the injection technique was specified to decrease the risk of } \\
\text { performance bias. }\end{array}$ \\
\hline $\begin{array}{l}\text { Blinding of outcome as- } \\
\text { sessment (detection bias) } \\
\text { All outcomes }\end{array}$ & Low risk & Staff performing post operative assessment were blinded \\
\hline $\begin{array}{l}\text { Incomplete outcome data } \\
\text { (attrition bias) } \\
\text { All outcomes }\end{array}$ & Low risk & Low dropout rate, 6 of 138 participants did not complete the study \\
\hline $\begin{array}{l}\text { Selective reporting (re- } \\
\text { porting bias) }\end{array}$ & High risk & Incomplete reporting of outcomes of interest as stated in study methods \\
\hline Other bias & High risk & $\begin{array}{l}\text { High risk of bias - sample size }<50 \text { participants/arm } \\
\text { Unclear risk of bias - funding provided by Pacira Pharmaceuticals as well as } 2 \\
\text { authors were employees or consultants for Pacira }\end{array}$ \\
\hline
\end{tabular}

Golf 2011

Methods Phase III RCT, participant and assessor blinded. 2 parallel groups.

Liposomal bupivacaine or control administered intra-operatively (timing not specified) 
Golf 2011 (Continued)

Participants

People undergoing primary first metatarsal bunionectomy under midazolam and/or propofol sedation followed by a Mayo block $(n=193)$

Age 18 years and older

Location: 1 centre (USA)

Dates: April 2000-August 2009

Interventions

A single dose of the control or intervention drug was administered at the time of operation via wound infiltration. The infiltration technique was not specified

Control:

- Arm 1: sodium chloride $0.9 \%(n=96)$

Intervention:

- Arm 2: liposomal bupivacaine $106 \mathrm{mg}(\mathrm{n}=97)$

Primary outcome
- Cumulative pain score (AUC) at rest $0-24 \mathrm{~h}$
Secondary outcomes
- Cumulative pain score (AUC) at rest 0 to: $36,48,60$ and $72 \mathrm{~h}$
- Pain score (NRS 0 -10) at: $2,4,8,12,24,36,48,60$ and $72 \mathrm{~h}$
- Total rescue opioid consumption $(\mathrm{mg}) 0$ to $72 \mathrm{~h}$
- Cumulative opioid consumption (mg) 0 to: $24,36,48,60$ and $72 \mathrm{~h}$
- Time to first rescue opioid
- Proportion of participants pain free (NRS $\leq 1$ ) at: $2,4,8,12,24,36,48,60$ and $72 \mathrm{~h}$
- Patient satisfaction with postoperative analgesia 24 and $72 \mathrm{~h}+8$
- Adverse events (vital signs, wound healing) day 0 -day 30

Clinical Trials reference: NCT 00890682

\section{Risk of bias}

\begin{tabular}{lll}
\hline Bias & Authors' judgement & Support for judgement \\
\hline $\begin{array}{l}\text { Random sequence genera- } \\
\text { tion (selection bias) }\end{array}$ & Low risk & Randomisation codes were generated via computer randomisation \\
\hline $\begin{array}{l}\text { Allocation concealment } \\
\text { (selection bias) }\end{array}$ & Low risk & Central randomisation separate to trial sites \\
\hline $\begin{array}{l}\text { Blinding of participants } \\
\begin{array}{l}\text { and personnel (perfor- } \\
\text { mance bias) }\end{array}\end{array}$ & Unclear risk & $\begin{array}{l}\text { It was not stated whether the surgeon was blinded and no standard injection } \\
\text { technique was specified presenting a risk of performance bias. As such we con- } \\
\text { sidered this study to have an unclear risk of performance bias. }\end{array}$ \\
\hline
\end{tabular}

\begin{tabular}{|c|c|c|}
\hline $\begin{array}{l}\text { Blinding of outcome as- } \\
\text { sessment (detection bias) } \\
\text { All outcomes }\end{array}$ & Low risk & Staff performing post operative assessment were blinded \\
\hline
\end{tabular}

Incomplete outcome data Low risk Data exist for all randomised participants (attrition bias)

All outcomes 
Golf 2011 (Continued)

Selective reporting (re- Low risk $\quad$ All stated outcomes of interest reported
porting bias)

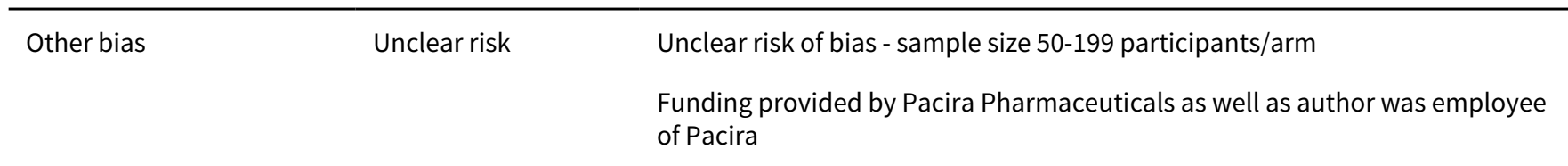

Gorfine 2011

Methods Phase III RCT, participant and assessor blinded. 2 parallel groups.

Liposomal bupivacaine or control administered at the end of surgery

Participants People undergoing excisional haemorrhoidectomy (Miller-Morgan technique) under general anaesthesia $(n=189)$

Age 18 years and older

\section{ASA 1-3}

Location: 13 centres (Republic of Georgia, Poland and Serbia)

Dates: May 2009-August 2009

Interventions

A single dose of the control or intervention drug was administered at the time of operation via wound infiltration using a standardised technique

Control:

- Arm 1: sodium chloride $0.9 \%(n=94)$

Intervention:

- Arm 2: liposomal bupivacaine $266 \mathrm{mg}(\mathrm{n}=95)$

Outcomes
Primary outcome
- Cumulative pain score (AUC) $0-72 \mathrm{~h}$
- Cumulative opioid consumption $(\mathrm{mg}) 12,24,36,48,60$ and $72 \mathrm{~h}$
- Time to first rescue opioid
- Proportion of participants not requiring rescue opioid 0 to: $12,24,36,48,60$ and $72 \mathrm{~h}$
- Brief Pain Inventory (BPI) Assessment 24 and $72 \mathrm{~h}$ and $30 \mathrm{~d}$
- Blinded care providers satisfaction with wound healing (day 30 )
- Patient satisfaction with postoperative analgesia 24 and $72 \mathrm{~h}+8$
- Adverse events (vital signs, clinical and laboratory assessments) day 0 -day 30

Notes Clinical Trials reference: NCT 00890721

Trial also reported by Schmidt 2012 (Secondary reference of Gorfine 2011)

\section{Risk of bias}

Bias Authors' judgement Support for judgement


Gorfine 2011 (Continued)

Random sequence genera- Unclear risk Stated to be randomised; randomisation method not specified tion (selection bias)

\begin{tabular}{|c|c|c|}
\hline $\begin{array}{l}\text { Allocation concealment } \\
\text { (selection bias) }\end{array}$ & Unclear risk & Allocation concealment method not specified \\
\hline $\begin{array}{l}\text { Blinding of participants } \\
\text { and personnel (perfor- } \\
\text { mance bias) } \\
\text { All outcomes }\end{array}$ & Low risk & $\begin{array}{l}\text { Participants were blinded as were personnel involved in administering the } \\
\text { study drug and control. Furthermore, the injection technique was specified to } \\
\text { decrease the risk of performance bias due to the risk of unbinding due to dif- } \\
\text { ferences in appearance and viscosity of the trial drug with the control. }\end{array}$ \\
\hline
\end{tabular}

\begin{tabular}{lll}
\hline Blinding of outcome as- & Low risk & $\begin{array}{l}\text { Participants and the study team performing post-operative assessments were } \\
\text { sessment (detection bias) }\end{array}$ \\
All outcomes & blinded.
\end{tabular}

All outcomes

Incomplete outcome data Low risk Low dropout rate, 3 of 189 participants did not complete the study
(attrition bias)

(attritic

All outcomes

\begin{tabular}{lll}
\hline $\begin{array}{l}\text { Selective reporting (re- } \\
\text { porting bias) }\end{array}$ & Low risk & All stated outcomes of interest reported \\
\hline Other bias & Unclear risk & Unclear risk of bias - sample size 50-199 participants/arm \\
& Funded by Pacira Pharmaceuticals \\
\hline
\end{tabular}

\section{Haas 2012}

Phase Il dose-ranging RCT, participant and assessor blinded. 4 parallel groups
Participants enrolled into 2 consecutive cohorts based on efficacy and safety results of previous cohort:
- Cohort 1: randomised 1:1:1 to control (Arm 1) or liposomal bupivacaine $66 \mathrm{mg}$ (Arm 2) or liposomal
bupivacaine $199 \mathrm{mg}$ (Arm 3)
- Cohort 2: randomised 1:1:1:2.5 to control (Arm 1) or liposomal bupivacaine $66 \mathrm{mg}$ (Arm 2) or liposomal
bupivacaine $199 \mathrm{mg}$ (Arm 3) or liposomal bupivacaine $266 \mathrm{mg}$ (Arm 4)
Liposomal bupivacaine or control administered at the end of surgery

$\begin{array}{ll}\text { Participants } & \begin{array}{l}\text { People undergoing } 2 \text { or } 3 \text { column excisional haemorrhoidectomy (incision length }>3 \mathrm{~cm} \text { ) under general } \\ \text { anaesthesia }(n=100)\end{array}\end{array}$

Age 18 years and older

\section{ASA 1-3}

Location: 9 centres (USA and Republic of Georgia)

Dates: July 2007-January 2008

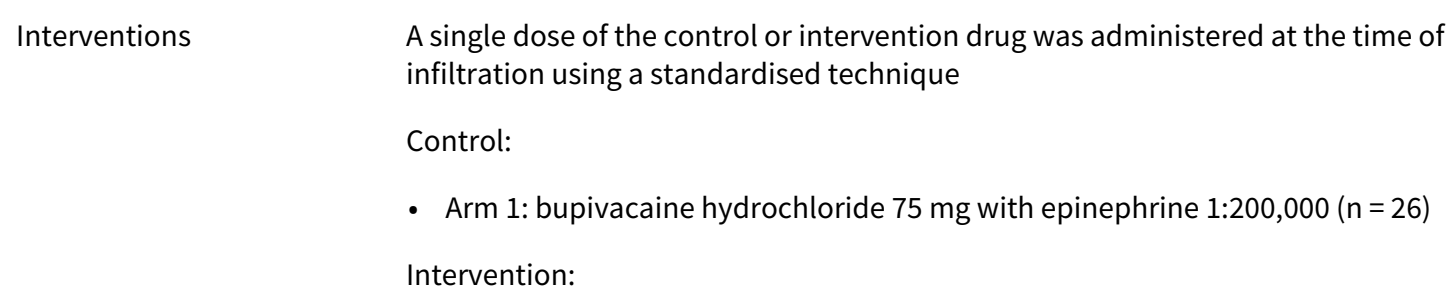


Haas 2012 (Continued)

- Arm 2: liposomal bupivacaine $66 \mathrm{mg}(\mathrm{n}=24)$

- Arm 3: liposomal bupivacaine $199 \mathrm{mg}(\mathrm{n}=25)$

- Arm 4: liposomal bupivacaine $266 \mathrm{mg}(\mathrm{n}=25)$

Outcomes
- Cumulative pain score (AUC) 0 to: $12,24,36,48,60,72,84$ and $96 \mathrm{~h}$
- Pain score (NRS) with bowel movement $0-96 \mathrm{~h}$
- Time to first bowel movement
- Cumulative opioid consumption $(\mathrm{mg}) 0$ to: 72 and $96 \mathrm{~h}$
- Time to first rescue opioid through $96 \mathrm{~h}$
- Proportion of participants not requiring rescue opioids
- Blinded care providers' satisfaction with analgesia through $96 \mathrm{~h}$
- Quality of Life (EuroQol, EQ-5D)
- Time to resumption of work or daily activities through day 30
- Readiness for discharge using the modified Postanesthesia Discharge Scoring System
- Adverse events day 0-day 30

Notes Clinical Trials reference: NCT 00529126

\section{Risk of bias}

\begin{tabular}{|c|c|c|}
\hline Bias & Authors' judgement & Support for judgement \\
\hline $\begin{array}{l}\text { Random sequence genera- } \\
\text { tion (selection bias) }\end{array}$ & Unclear risk & Stated to be randomised; randomisation method not specified \\
\hline $\begin{array}{l}\text { Allocation concealment } \\
\text { (selection bias) }\end{array}$ & Unclear risk & Allocation concealment method not specified \\
\hline $\begin{array}{l}\text { Blinding of participants } \\
\text { and personnel (perfor- } \\
\text { mance bias) } \\
\text { All outcomes }\end{array}$ & Low risk & $\begin{array}{l}\text { To reduce the risk of performance bias, drugs were dispensed by sheathed } \\
\text { syringe by study members not involved with postoperative assessment. Fur- } \\
\text { thermore the injection technique specified to further reduce the risk of perfor- } \\
\text { mance bias. }\end{array}$ \\
\hline $\begin{array}{l}\text { Blinding of outcome as- } \\
\text { sessment (detection bias) } \\
\text { All outcomes }\end{array}$ & Low risk & $\begin{array}{l}\text { All staff members involved in study related evaluation remained blinded } \\
\text { throughout the study }\end{array}$ \\
\hline $\begin{array}{l}\text { Incomplete outcome data } \\
\text { (attrition bias) } \\
\text { All outcomes }\end{array}$ & Low risk & Low dropout rate, 97 of 100 of participants completed the study \\
\hline $\begin{array}{l}\text { Selective reporting (re- } \\
\text { porting bias) }\end{array}$ & High risk & Incomplete reporting of: all time point NRS, discharge readiness and EQ5D \\
\hline Other bias & High risk & $\begin{array}{l}\text { High risk of bias - sample size }<50 \text { participants/arm } \\
\text { Unclear risk of bias - support in preparation of the manuscript was provided by } \\
\text { Peloton Advantage, supported by Pacira Pharmaceuticals }\end{array}$ \\
\hline
\end{tabular}

Langford 2008

Methods Phase II dose-ranging parallel group RCT, participant and assessor blinded 
- Cohort 1: randomised 1:1 to control (Arm 1) or liposomal bupivacaine 155 mg (Arm 2)

- Cohort 2: randomised 1:3 to control (Arm 1) or liposomal bupivacaine 199 mg (Arm 3)

- Cohort 3: randomised 1:3 to control (Arm 1) or liposomal bupivacaine $266 \mathrm{mg}$ (Arm 4)

- Cohort 4: randomised 1:3 to control (Arm 1) or liposomal bupivacaine $310 \mathrm{mg}$ (Arm 5)

Liposomal bupivacaine or control administered at the end of surgery before wound closure

\begin{tabular}{|c|c|}
\hline \multirow[t]{5}{*}{ Participants } & $\begin{array}{l}\text { People undergoing unilateral inguinal hernia repair (tension-free technique) under general anaesthesia } \\
(\mathrm{n}=76)\end{array}$ \\
\hline & Age 18 years and older \\
\hline & ASA $1-2$ \\
\hline & Location: not specified \\
\hline & Dates: December 2004-December 2006 \\
\hline \multirow[t]{8}{*}{ Interventions } & $\begin{array}{l}\text { A single dose of the control or intervention drug was administered at the time of operation via wound } \\
\text { infiltration. The infiltration technique was not specified }\end{array}$ \\
\hline & Control: \\
\hline & - Arm 1: bupivacaine hydrochloride $100 \mathrm{mg}$ with epinephrine $1: 200,000(n=26)$ \\
\hline & Intervention: \\
\hline & - Arm 2: liposomal bupivacaine $155 \mathrm{mg}(\mathrm{n}=12)$ \\
\hline & - Arm 3: liposomal bupivacaine $199 \mathrm{mg}(\mathrm{n}=12)$ \\
\hline & - Arm 4: liposomal bupivacaine 266 mg $(n=12)$ \\
\hline & - Arm 5: liposomal bupivacaine $310 \mathrm{mg}(\mathrm{n}=14)$ \\
\hline \multirow[t]{9}{*}{ Outcomes } & Primary outcome \\
\hline & - Time to use of supplemental rescue medication (opioid or non-opioid) through $96 \mathrm{~h}$ \\
\hline & Secondary outcomes \\
\hline & - Mean pain score (NRS 0-10) at rest and with activity (undefined): 4, 8, 12, 24, 48, 72 and $96 \mathrm{~h}$ \\
\hline & - Cumulative opioid consumption (mg) through $96 \mathrm{~h}$ \\
\hline & $\begin{array}{l}\text { - Proportion of participants requiring supplemental rescue medication (opioid or non-opioid) through } \\
96 \mathrm{~h}\end{array}$ \\
\hline & - Patient satisfaction with postoperative analgesia through $96 \mathrm{~h}$ \\
\hline & $\begin{array}{l}\text { - Adverse events (serious AEs, wound healing, application site reaction, clinical laboratory values, elec- } \\
\text { trocardiogram results) day 0-day } 36\end{array}$ \\
\hline & - Drug pharmacokinetics \\
\hline
\end{tabular}

\section{Risk of bias}

Bias Authors' judgement Support for judgement

Random sequence genera- Unclear risk Stated to be randomised; randomisation method not specified tion (selection bias)

Allocation concealment Unclear risk Allocation concealment method not specified
(selection bias) 
Langford 2008 (Continued)

Blinding of participants and personnel (performance bias)

All outcomes
Unclear risk It is stated that the participant was blinded to treatment, however it is not specified whether the surgeon administering the treatment was blinded presenting an unclear risk of performance bias.

\section{Blinding of outcome as- Unclear risk sessment (detection bias) \\ All outcomes \\ It is stated that the participant and the outcome assessor were blinded to treatment, however it is not clear whether other staff involved in the partici- pants care were blinded presenting an unclear risk of detection bias.}

Incomplete outcome data Low risk No loss to follow up
(attrition bias)

Alloutcomes

Selective reporting (re- Low risk $\quad$ All outcomes specified reported
porting bias)

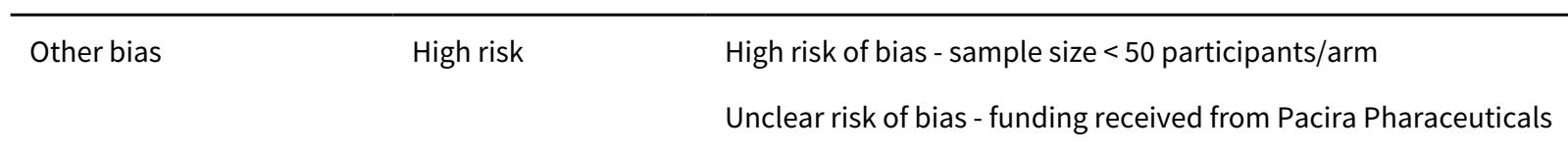

\section{NCT 00744848}

Methods $\quad$ Phase III RCT, participant and assessor blinded. 2 parallel groups.

Liposomal bupivacaine or control administered at the end of surgery

\begin{tabular}{|c|c|}
\hline \multirow[t]{5}{*}{ Participants } & People undergoing 2 or 3 column excisional haemorrhoidectomy under general anaesthesia $(n=204)$ \\
\hline & Age 18 years and older \\
\hline & ASA 1-4 \\
\hline & Location: 20 centres (SA) \\
\hline & Dates: August 2008-February 2009 \\
\hline \multirow[t]{5}{*}{ Interventions } & $\begin{array}{l}\text { A single dose of the control or intervention drug was administered at the time of operation via wound } \\
\text { infiltration using a standardised technique }\end{array}$ \\
\hline & Control: \\
\hline & - Arm 1: bupivacaine hydrochloride $100 \mathrm{mg}$ with epinephrine $1: 200,000(n=103)$ \\
\hline & Intervention: \\
\hline & - Arm 2: liposomal bupivacaine $266 \mathrm{mg}(\mathrm{n}=101)$ \\
\hline \multirow[t]{5}{*}{ Outcomes } & Primary outcome \\
\hline & - Cumulative pain score (AUC) at rest 0-96 h \\
\hline & Secondary outcomes \\
\hline & - Adverse events through $96 \mathrm{~h}$ \\
\hline & - Serious adverse events through $30 \mathrm{~d}$ \\
\hline Notes & Clinical Trials reference: NCT 00744848 \\
\hline
\end{tabular}


NCT 00744848 (Continued)

Risk of bias

\begin{tabular}{|c|c|c|}
\hline Bias & Authors' judgement & Support for judgement \\
\hline $\begin{array}{l}\text { Random sequence genera- } \\
\text { tion (selection bias) }\end{array}$ & Unclear risk & Stated to be randomised; randomisation method not specified \\
\hline $\begin{array}{l}\text { Allocation concealment } \\
\text { (selection bias) }\end{array}$ & Unclear risk & Allocation concealment method not specified \\
\hline $\begin{array}{l}\text { Blinding of participants } \\
\text { and personnel (perfor- } \\
\text { mance bias) } \\
\text { All outcomes }\end{array}$ & Unclear risk & $\begin{array}{l}\text { It was not stated whether the surgeon was blinded or whether a standard in- } \\
\text { jection technique was specified. As such we considered this study to have an } \\
\text { unclear risk of performance bias. }\end{array}$ \\
\hline $\begin{array}{l}\text { Blinding of outcome as- } \\
\text { sessment (detection bias) } \\
\text { All outcomes }\end{array}$ & Unclear risk & $\begin{array}{l}\text { It is stated that the participant and the outcome assessor were blinded to } \\
\text { treatment, however it is not clear whether other staff involved in the partici- } \\
\text { pants care were blinded presenting an unclear risk of detection bias. }\end{array}$ \\
\hline $\begin{array}{l}\text { Incomplete outcome data } \\
\text { (attrition bias) } \\
\text { All outcomes }\end{array}$ & Low risk & No loss to follow up \\
\hline $\begin{array}{l}\text { Selective reporting (re- } \\
\text { porting bias) }\end{array}$ & Low risk & All outcomes specified on clinical trials registry reported \\
\hline Other bias & Unclear risk & $\begin{array}{l}\text { Unclear risk of bias - sample size 50-199 participants/arm } \\
\text { Funded by Pacira Pharmaceuticals }\end{array}$ \\
\hline
\end{tabular}

\section{NCT 00745290}

Methods Phase III RCT, participant and assessor blinded. 2 parallel groups.

Liposomal bupivacaine or control administered intra-operatively (timing not specified)

Participants People undergoing primary unilateral total knee replacement under general anaesthesia $(n=245)$

Age 18 years and older

ASA 1-4

Location: 19 centres (USA)

Dates: August 2008-January 2009

Interventions A single dose of the control or intervention drug was administered at the time of operation via wound infiltration. The infiltration technique was not specified

Control

- Arm 1: bupivacaine hydrochloride $200 \mathrm{mg}$ with $(n=123)$

Intervention

- Arm 2: liposomal bupivacaine $532 \mathrm{mg}(\mathrm{n}=122)$

Outcomes Primary outcome


NCT 00745290 (Continued)

- Cumulative pain score (AUC) with activity (maximum active knee flexion) 0-72 h

Secondary outcomes

- Adverse events through $96 \mathrm{~h}$

- Serious adverse events through $30 \mathrm{~d}$

Notes Clinical Trials reference: NCT 00745290

\section{Risk of bias}

\begin{tabular}{|c|c|c|}
\hline Bias & Authors' judgement & Support for judgement \\
\hline $\begin{array}{l}\text { Random sequence genera- } \\
\text { tion (selection bias) }\end{array}$ & Unclear risk & Stated to be randomised; randomisation method not specified \\
\hline $\begin{array}{l}\text { Allocation concealment } \\
\text { (selection bias) }\end{array}$ & Unclear risk & Allocation concealment method not specified \\
\hline $\begin{array}{l}\text { Blinding of participants } \\
\text { and personnel (perfor- } \\
\text { mance bias) } \\
\text { All outcomes }\end{array}$ & Unclear risk & $\begin{array}{l}\text { It is stated that the participant was blinded to treatment, however it is not } \\
\text { specified whether the surgeon administering the treatment was blinded pre- } \\
\text { senting an unclear risk of performance bias. }\end{array}$ \\
\hline $\begin{array}{l}\text { Blinding of outcome as- } \\
\text { sessment (detection bias) } \\
\text { All outcomes }\end{array}$ & Unclear risk & $\begin{array}{l}\text { It is stated that the participant and the outcome assessor were blinded to } \\
\text { treatment, however it is not clear whether other staff involved in the partici- } \\
\text { pants' care were blinded presenting an unclear risk of detection bias. }\end{array}$ \\
\hline $\begin{array}{l}\text { Incomplete outcome data } \\
\text { (attrition bias) } \\
\text { All outcomes }\end{array}$ & Low risk & No loss to follow up \\
\hline $\begin{array}{l}\text { Selective reporting (re- } \\
\text { porting bias) }\end{array}$ & Low risk & All outcomes specified on clinical trials registry reported \\
\hline Other bias & Unclear risk & $\begin{array}{l}\text { Unclear risk of bias - sample size 50-199 participants/arm } \\
\text { Funded by Pacira Pharmaceuticals }\end{array}$ \\
\hline
\end{tabular}

Smoot 2012

\begin{tabular}{ll}
\hline Methods & Phase III RCT, participant and assessor blinded. 2 parallel groups. \\
& Liposomal bupivacaine or control administered at the end of surgery \\
\hline
\end{tabular}

\begin{tabular}{ll}
\hline Participants & $\begin{array}{l}\text { Women undergoing primary bilateral cosmetic submuscular breast augmentation under general } \\
\text { anaesthesia }(\mathrm{n}=134)\end{array}$ \\
Age 18 years and older \\
ASA 1-4 \\
Location: 11 centres (USA) \\
Dates: November 2008-February 2009 \\
\hline Interventions & $\begin{array}{l}\text { A single dose of the control or intervention drug was administered at the time of operation via wound } \\
\text { infiltration. The infiltration technique was not specified }\end{array}$
\end{tabular}


Smoot 2012 (Continued)

\section{Control}

- Arm 1: bupivacaine hydrochloride $200 \mathrm{mg}$ (100 mg per breast pocket) with epinephrine 1:200,000 ( $\mathrm{n}$ $=70$ )

Intervention

- Arm 2: liposomal bupivacaine $532 \mathrm{mg}$ (266 mg per breast pocket) $(n=64)$

\begin{tabular}{|c|c|}
\hline Outcomes & $\begin{array}{l}\text { Primary outcome } \\
\text { - Cumulative pain score (AUC) with activity (raising both hands above the head and holding for } 5 \mathrm{~s} \text { ) 0-72 } \\
\text { Secondary outcomes } \\
\text { - Cumulative pain score (AUC) with rest and activity } 0 \text { to: } 24,48,72 \text { and } 96 \mathrm{~h} \\
\text { - Pain score (NRS 0-10) at: } 4,8,12,24,36,48,72 \text { and } 96 \mathrm{~h} \\
\text { - Cumulative opioid consumption (mg) through } 96 \mathrm{~h} \\
\text { - Proportion of participants receiving no rescue opioid medication } \\
\text { - Patient satisfaction with postoperative analgesia through } 72 \mathrm{~h} \\
\text { - Time to first bowel movement } \\
\text { - Brief Pain Inventory (BPI) Assessment } 24,48,72 \text { and } 96 \mathrm{~h} \\
\text { - Integrated Rank Assessment (incorporating pain score and concurrent opioid use) } \\
\text { - Blinded care providers' satisfaction with postoperative analgesia (day } 8 \text { ) } \\
\text { - Time to resumption of work or daily activities } \\
\text { - Adverse events (nausea and vomiting, vital signs, wound healing, wound scarring) day } 8 \text { and day } 30\end{array}$ \\
\hline Notes & $\begin{array}{l}\text { Clinical Trials reference: NCT } 00813111 \\
\text { Long-term follow-up reported by Minkowitz } 2012 \text { (Secondary reference of Smoot 2012) }\end{array}$ \\
\hline
\end{tabular}

\section{Risk of bias}

\begin{tabular}{|c|c|c|}
\hline Bias & Authors' judgement & Support for judgement \\
\hline $\begin{array}{l}\text { Random sequence genera- } \\
\text { tion (selection bias) }\end{array}$ & Low risk & Randomisation codes were generated via computer randomisation \\
\hline $\begin{array}{l}\text { Allocation concealment } \\
\text { (selection bias) }\end{array}$ & Low risk & Central randomisation separate to trial sites \\
\hline $\begin{array}{l}\text { Blinding of participants } \\
\text { and personnel (perfor- } \\
\text { mance bias) } \\
\text { All outcomes }\end{array}$ & High risk & $\begin{array}{l}\text { Staff and participants were blinded to treatment. However there was a high } \\
\text { risk of performance bias with respect to the injection technique as no standard } \\
\text { injection technique was specified with injections administered "by the sur- } \\
\text { geon's preferred technique" presenting a high risk of performance bias }\end{array}$ \\
\hline $\begin{array}{l}\text { Blinding of outcome as- } \\
\text { sessment (detection bias) } \\
\text { All outcomes }\end{array}$ & Low risk & Staff performing outcome assessments blinded to treatment allocation \\
\hline $\begin{array}{l}\text { Incomplete outcome data } \\
\text { (attrition bias) } \\
\text { All outcomes }\end{array}$ & High risk & Trial terminated by study sponsor due to "administrative reasons" \\
\hline $\begin{array}{l}\text { Selective reporting (re- } \\
\text { porting bias) }\end{array}$ & Low risk & All outcomes specified reported \\
\hline Other bias & Unclear risk & Unclear risk of bias - sample size 50-199 participants/arm \\
\hline
\end{tabular}


White 2009

\begin{tabular}{ll}
\hline Methods & Phase II dose-ranging RCT, participant and assessor blinded. 4 parallel groups \\
& Timing of liposomal bupivacaine or control administration not specified \\
\hline Participants & People undergoing primary open inguinal hernia repair under general anaesthesia ( $\mathrm{n}=98)$ \\
& Age 18 years and over \\
& ASA 1-3 \\
Location: 7 centres (USA) & Dates: June 2007-August 2008 \\
A single dose of the control or intervention drug was administered at the time of operation via wound \\
infiltration. The infiltration technique was not specified. \\
Control \\
- Arm 1: bupivacaine hydrochloride $105 \mathrm{mg}(\mathrm{n}=24)$ \\
Intervention
\end{tabular}

\begin{tabular}{ll}
\hline Outcomes & Primary outcome \\
- Cumulative pain score (AUC) with activity (sitting from supine) $0-72 \mathrm{~h}$ \\
Secondary outcomes \\
- Adverse events through $96 \mathrm{~h}$ \\
- Serious adverse events through $30 \mathrm{~d}$ \\
\hline Notes & Clinical Trials reference: NCT 00485433 \\
& This conference abstract also reported the outcomes of the study reported by Langford 2008 \\
\hline
\end{tabular}

\section{Risk of bias}

\begin{tabular}{|c|c|c|}
\hline Bias & Authors' judgement & Support for judgement \\
\hline $\begin{array}{l}\text { Random sequence genera- } \\
\text { tion (selection bias) }\end{array}$ & Unclear risk & Stated to be randomised; randomisation method not specified \\
\hline $\begin{array}{l}\text { Allocation concealment } \\
\text { (selection bias) }\end{array}$ & Unclear risk & Allocation concealment method not specified \\
\hline $\begin{array}{l}\text { Blinding of participants } \\
\text { and personnel (perfor- } \\
\text { mance bias) } \\
\text { All outcomes }\end{array}$ & Unclear risk & $\begin{array}{l}\text { It is stated that the participant was blinded to treatment, however it is not } \\
\text { specified whether the surgeon administering the treatment was blinded pre- } \\
\text { senting an unclear risk of performance bias. }\end{array}$ \\
\hline
\end{tabular}


White 2009 (Continued)

\begin{tabular}{|c|c|c|}
\hline $\begin{array}{l}\text { Blinding of outcome as- } \\
\text { sessment (detection bias) } \\
\text { All outcomes }\end{array}$ & Unclear risk & $\begin{array}{l}\text { It is stated that the participant and the outcome assessor were blinded to } \\
\text { treatment, however it is not clear whether other staff involved in the partici- } \\
\text { pants' care were blinded presenting an unclear risk of detection bias. }\end{array}$ \\
\hline
\end{tabular}

\begin{tabular}{lll}
\hline $\begin{array}{l}\text { Incomplete outcome data } \\
\text { (attrition bias) } \\
\text { All outcomes }\end{array}$ & Low risk & No loss to follow up \\
\hline $\begin{array}{l}\text { Selective reporting (re- } \\
\text { porting bias) }\end{array}$ & Low risk & All outcomes specified on clinical trials registry reported \\
\hline Other bias & High risk & High risk of bias - sample size < 50 participants/arm \\
& Unclear risk of bias - 2 authors were linked to Pacira Pharmaceutical \\
\hline
\end{tabular}

AE - Adverse Events

ASA - American Society of Anaesthesiologists Score

AUC - Area Under Curve

BPI - Brief Pain Inventory

NRS - Numeric Rating Scale

$\mathrm{RCT}$ - randomised controlled trial

Characteristics of excluded studies [ordered by study ID]

\begin{tabular}{|c|c|}
\hline Study & Reason for exclusion \\
\hline Bagsby 2014 & Open label sequential cohort study \\
\hline Barrington 2015 & Open label sequential cohort study \\
\hline Baxter 2013 & Review paper evaluating wound healing following liposomal bupivacaine at the surgical site \\
\hline Bergese 2012 & Review paper evaluating the cardiac safety of liposomal bupivacaine after surgical site infiltration \\
\hline Bergese 2012a & Review paper evaluating the efficacy of liposomal bupivacaine when infiltrated at the surgical site \\
\hline Cohen 2012 & Open label sequential cohort study \\
\hline Cohen 2014 & Open label sequential cohort study \\
\hline Collis 2015 & $\begin{array}{l}\text { RCT evaluating the efficacy of liposomal bupivacaine at the surgical site during total knee replace- } \\
\text { ment. Study excluded as not double blind with the outcome assessors not blinded to randomisa- } \\
\text { tion }\end{array}$ \\
\hline Dasta 2012 & Review paper evaluating the efficacy of liposomal bupivacaine when infiltrated at the surgical site \\
\hline Edwards 2015 & Open label sequential cohort study \\
\hline Hu 2013 & Review paper evaluating the pharmacokinetics of liposomal bupivacaine at the surgical site \\
\hline Knight 2015 & $\begin{array}{l}\text { RCT evaluating the efficacy of liposomal bupivacaine at the laparoscopic port site during laparo- } \\
\text { scopic urologic surgery. Study excluded as liposomal bupivacaine assessed was not administered } \\
\text { at the surgical site (kidney/renal tract/prostate) }\end{array}$ \\
\hline Marcet 2013 & Open label sequential cohort study \\
\hline
\end{tabular}




Study Reason for exclusion

Mckeown $2014 \quad$ Open label sequential cohort study

Nadeau 2015

Women undergoing bilateral breast augmentation. Each participant was used as their own control and as such we excluded this study the review

NCT 01206608

Women undergoing bilateral breast augmentation. Each participant was used as their own control and as such we excluded this study from the review

Schroer 2015

RCT evaluating the efficacy of liposomal bupivacaine at the surgical site for the management of pain following total knee arthroplasty. This trial compared $266 \mathrm{mg}$ liposomal bupivacaine mixed with $75 \mathrm{mg}$ bupivacaine hydrochloride against an active control arm of $150 \mathrm{mg}$ bupivacaine hydrochloride. At the time of writing the trial protocol it was not advised to mix liposomal bupivacaine with other drugs, in particular bupivacaine, due to the risk of premature de-encapsulation of liposomal bupivacaine. As such studies evaluating liposomal bupivacaine with another drug were excluded from this review.

In December 2015 an amendment to the FDA-licensed indication was made which approved admixing liposomal bupivacaine with bupivacaine, including co-administration in the same syringe. This amendment was made as it has been proposed that admixing with bupivacaine hydrochloride enhances early postoperative analgesia. As such in future updates of this review trials evaluating liposomal bupivacaine with bupivacaine hydrochloride will be included

Surdam 2015 RCT evaluating the efficacy of liposomal bupivacaine at the surgical site compared with femoral nerve block for total knee replacement. Study excluded as participants in the femoral nerve block group who had persistent quadriceps inhibition after day 0 were also treated with a knee immobiliser which would be expected to impact on outcomes recorded (pain scores, opioid usage, range of movement). Additionally the trial was not double blind with the participants not blinded to randomisation.

\begin{tabular}{ll}
\hline Viscusi 2014 & Review paper evaluating the safety of liposomal bupivacaine at the surgical site \\
\hline Vogel 2013 & Open label sequential cohort study \\
\hline White 2015 & Open label sequential cohort study \\
\hline
\end{tabular}

Characteristics of ongoing studies [ordered by study ID]

NCT01907191

\begin{tabular}{ll}
\hline Trial name or title & Ultrasound guided local infiltration analgesia for hip arthroscopy \\
\hline Methods & Parallel-arm RCT \\
\hline Participants & Participants undergoing hip arthroscopy \\
\hline Interventions & Liposomal bupivacaine vs bupivacaine hydrochloride \\
\hline Outcomes & Opioid consumption \\
\hline Starting date & Pain scores \\
\hline Contact information & July 2013 \\
\hline
\end{tabular}


NCT01907191 (Continued)

Notes Currently recruiting

\section{NCT02011464}

\begin{tabular}{ll}
\hline Trial name or title & Evaluation Exparel delivered in knee replacement \\
\hline Methods & Parallel-arm RCT \\
\hline Participants & Participants undergoing knee replacement \\
\hline Interventions & Liposomal bupivacaine vs placebo (NaCl 0.9\%) \\
\hline Outcomes & Subjective pain \\
& Analgesic use \\
\hline Starting date & Subject satisfaction \\
\hline Contact information & Dec-13 \\
\hline Notes & ClinicalTrials.gov/show/NCT02011464 \\
\hline
\end{tabular}

\section{NCT02044302}

\begin{tabular}{ll}
\hline Trial name or title & A prospective trial to reduce postoperative pain in implant based breast reconstruction \\
\hline Methods & Parallel-arm RCT \\
\hline Participants & Participants undergoing breast reconstruction \\
\hline Interventions & $\begin{array}{l}\text { Liposomal bupivacaine vs placebo vs bupivacaine hydrochloride vs botulinum toxin vs bupivacaine } \\
\text { hydrochloride plus botulinum toxin }\end{array}$ \\
\hline Outcomes & Pain score questionnaire \\
\hline Starting date & April 2014 \\
\hline Contact information & ClinicalTrials.gov/show/NCT02044302 \\
\hline Notes & Currently recruiting \\
\hline
\end{tabular}

\section{NCT02052180}

\begin{tabular}{ll}
\hline Trial name or title & Early postoperative pain control following wrist operations \\
\hline Methods & Parallel-arm RCT \\
\hline Participants & Participants undergoing carpometacarpal arthroplasty or proximal row carpectomy operation \\
\hline & \\
\hline $\begin{array}{l}\text { Liposomal bupivacaine infiltration at the surgical site for the management of postoperative pain (Review) } \\
\text { Copyright @ } 2020 \text { The Cochrane Collaboration. Published by John Wiley \& Sons, Ltd. }\end{array}$
\end{tabular}


NCT02052180 (Continued)

Interventions Liposomal bupivacaine vs bupivacaine hydrochloride

\begin{tabular}{ll}
\hline Outcomes & Changes in pain \\
\hline Starting date & May 2013 \\
\hline Contact information & ClinicalTrials.gov/show/NCT02052180 \\
\hline Notes & Currently recruiting \\
\hline
\end{tabular}

NCT02052557

\begin{tabular}{|c|c|}
\hline Trial name or title & The effect of Exparel on post operative pain and narcotic use after colon surgery \\
\hline Methods & Parallel-arm RCT \\
\hline Participants & Participants undergoing elective colon resection (laparoscopic, robotic or open) \\
\hline Interventions & Liposomal bupivacaine vs bupivacaine hydrochloride \\
\hline \multirow[t]{13}{*}{ Outcomes } & PCA (patient controlled analgesia) usage \\
\hline & Oral pain medications \\
\hline & Total IV (intravenous) narcotic used \\
\hline & Total oral narcotic used \\
\hline & Length of stay \\
\hline & Return of bowel function \\
\hline & Readmission \\
\hline & Toradol Use \\
\hline & Nausea medication \\
\hline & Foley catheter removal \\
\hline & Postoperative pain \\
\hline & Postoperative satisfaction \\
\hline & Home oral narcotic use \\
\hline Starting date & February 2013 \\
\hline Contact information & ClinicalTrials.gov/show/NCT02052557 \\
\hline Notes & Trial completed. Results not yet available - contacted 29 January 2016 \\
\hline
\end{tabular}

\section{NCT02060591}

Trial name or title

Comparison of two periarticular injection medications for adjunctive pain management following total knee arthroplasty (TKA) 
NCT02060591 (Continued)

\begin{tabular}{ll} 
Methods & Parallel-arm RCT \\
\hline Participants & Participants undergoing total knee arthroplasty \\
\hline Interventions & Liposomal bupivacaine vs bupivacaine hydrochloride \\
\hline Outcomes & Measure pain intensity score (pre and postoperatively) by visual analogue scale (VAS) \\
\hline Starting date & January 2014 \\
\hline Contact information & ClinicalTrials.gov/show/NCT02060591 \\
\hline Notes & Currently recruiting \\
\hline
\end{tabular}

NCT02104414

\begin{tabular}{ll}
\hline Trial name or title & Efficacy of rectal infiltration of Exparel for analgesic benefit following hemorrhoidectomy \\
\hline Methods & Parallel-arm RCT \\
\hline Participants & Participants undergoing haemorrhoidectomy \\
\hline Interventions & Liposomal bupivacaine vs placebo (NaCl 0.9\%) \\
\hline Outcomes & Postoperative pain control \\
& Postoperative opioid consumption \\
& Postoperative nausea and vomiting \\
& Frequency of and pain during postoperative bowel movements \\
\hline Starting date & Incidence of urinary retention \\
\hline Contact information & April 2014 \\
\hline Notes & ClinicalTrials.gov/show/NCT02104414 \\
\hline
\end{tabular}

\begin{tabular}{ll}
\hline NCT02111746 & \\
\hline Trial name or title & PAIN - Postoperative Analgesia INvestigation \\
\hline Methods & Parallel-arm RCT \\
\hline Participants & Participants undergoing sternotomy, thoracotomy, laparotomy or mini-thoracotomy \\
\hline Interventions & Liposomal bupivacaine vs bupivacine hydrochloride \\
\hline Outcomes & Change in postoperative pain \\
& Overall opioid use
\end{tabular}


NCT02111746 (Continued)

Mean length of hospital stay

Change from baseline in quality of life

\begin{tabular}{ll}
\hline Starting date & November 2014 \\
\hline Contact information & ClinicalTrials.gov/show/NCT02111746 \\
\hline Notes & Currently recruiting \\
\hline
\end{tabular}

\section{NCT02128646}

Trial name or title

Liposomal bupivacaine (Exparel) for postoperative pain control for open and laparoscopic abdominal hernia repair

\begin{tabular}{ll}
\hline Methods & Parallel-arm RCT \\
\hline Participants & Participants undergoing open or laparoscopic abdominal hernia repair \\
\hline Interventions & Liposomal bupivacaine vs standard care \\
\hline Outcomes & Patient satisfaction with pain management after surgery \\
& Total length of time in post-anaesthesia care unit (PACU) \\
& Change in postsurgical opioid consumption \\
\hline Starting date & April 2014 \\
\hline Contact information & ClinicalTrials.gov/show/NCT02128646 \\
\hline Notes & Currently recruiting \\
\hline
\end{tabular}

\section{NCT02189317}

\begin{tabular}{ll}
\hline Trial name or title & Liposomal bupivacaine for pain control following anterior cruciate ligament reconstruction \\
\hline Methods & Parallel-arm RCT \\
\hline Participants & Participants undergoing anterior cruciate ligament reconstruction \\
\hline Interventions & Liposomal bupivacaine vs no treatment \\
\hline Outcomes & Postoperative pain \\
& Pain medication use \\
\hline Starting date & Patient satisfaction with analgesia \\
\hline Contact information & August 2014 \\
\hline Notes & clinicaltrials.gov/ct2/show/NCT02189317 \\
\hline L & Trial completed. Results not yet available - contacted 29 January 2016 \\
\hline
\end{tabular}

Liposomal bupivacaine infiltration at the surgical site for the management of postoperative pain (Review) 
NCT02197273

\begin{tabular}{ll}
\hline Trial name or title & Liposomal bupivacaine versus standard analgesia in TJA \\
\hline Methods & Parallel-arm RCT \\
\hline Participants & Participants undergoing total joint arthroplasty (shoulder, hip, knee) \\
\hline Interventions & Liposomal bupivacaine vs standard care \\
\hline Outcomes & Length of stay in hospital (days) \\
& Time to postoperative rescue opioids (minutes) \\
& Readmission or ED visit due to pain control within 30 days \\
\hline Starting date & July 2014 \\
\hline Contact information & ClinicalTrials.gov/show/NCT02197273 \\
\hline Notes & Currently recruiting
\end{tabular}

\section{NCT02214810}

\begin{tabular}{ll}
\hline Trial name or title & A study of postsurgical pain control for lower extremity fractures \\
\hline Methods & Parallel-arm RCT \\
\hline Participants & Participants undergoing surgical fixation of a lower extremity fracture \\
\hline Interventions & Liposomal bupivacaine vs bupivacaine hydrochloride \\
\hline Outcomes & Change in pain visual analogue scale (VAS) \\
\hline Starting date & Pain management satisfaction \\
\hline Contact information & January 2015 \\
\hline Notes & ClinicalTrials.gov/show/NCT02214810 \\
\hline
\end{tabular}

\begin{tabular}{ll} 
NCT02219087 & \\
\hline Trial name or title & Liposomal bupivacaine versus standard of care in total knee surgery \\
\hline Methods & Parallel-arm RCT \\
\hline Participants & Participants undergoing total knee replacement \\
\hline Interventions & Liposomal bupivacaine vs standard of care \\
\hline Outcomes & Number physical therapy sessions required
\end{tabular}


NCT02219087 (Continued)

Visual analog scale (VAS) pain scores during admission (0-10 scale)

Length of stay

Opioid consumption

Incidence of opioid-related adverse events

\begin{tabular}{ll}
\hline Starting date & August 2014 \\
\hline Contact information & ClinicalTrials.gov/show/NCT02219087 \\
\hline Notes & Currently recruiting \\
\hline
\end{tabular}

\section{NCT02242201}

\begin{tabular}{ll}
\hline Trial name or title & THA lumbar plexus versus periarticular \\
\hline Methods & Parallel-arm RCT \\
\hline Participants & Participants undergoing total hip arthroplasty \\
\hline Interventions & Liposomal bupivacaine vs ropivacaine hydrochloride vs lumbar plexus block \\
\hline Outcomes & Pain control comparison \\
\hline Starting date & Pain management assessment 0-3 months \\
\hline Contact information & September 2014 \\
\hline Notes & ClinicalTrials.gov/show/NCT02242201 \\
\hline
\end{tabular}

\section{NCT02274870}

Trial name or title

Liposomal bupivacaine for post operative pain after knee replacement surgery

\begin{tabular}{ll}
\hline Methods & Parallel-arm RCT \\
\hline Participants & Participants undergoing knee replacement \\
\hline Interventions & Liposomal bupivacaine vs bupivacaine hydrochloride \\
\hline Outcomes & Number physical therapy sessions required \\
& Visual analog scale (VAS) pain scores during admission (0-10 scale) \\
& Length of stay (LOS, in days) \\
& Opioid consumption in oral morphine equivalents (OMEs, in milligrams) \\
Incidence of opioid-related adverse events (ORAES) during admission \\
Total cost of care (dollars)
\end{tabular}


NCT02274870 (Continued)

$$
\text { Hospital readmission }
$$

\begin{tabular}{ll}
\hline Starting date & August 2014 \\
\hline Contact information & ClinicalTrials.gov/show/NCT02274870 \\
\hline Notes & Currently recruiting
\end{tabular}

\section{NCT02287246}

\begin{tabular}{ll}
\hline Trial name or title & Efficacy of extended-release liposomal bupivacaine for postoperative urogynecologic surgery \\
\hline Methods & Parallel-arm RCT \\
\hline Participants & Participants undergoing urogynecologic surgery \\
\hline Interventions & Liposomal bupivacaine vs placebo $(\mathrm{NaCl} 0.9 \%)$ \\
\hline Outcomes & Cumulative postoperative pain control \\
\hline Starting date & Evaluate vaginal pain on postoperative day 7 \\
\hline Contact information & October 2014 \\
\hline Notes & ClinicalTrials.gov/show/NCT02287246 \\
\hline
\end{tabular}

\section{NCT02296099}

\begin{tabular}{ll}
\hline Trial name or title & Trial liposomal bupivacaine following retropubic suburethral sling for stress urinary incontinence \\
\hline Methods & Parallel-arm RCT \\
\hline Participants & Participants undergoing retropubic suburethral sling for stress urinary incontinence \\
\hline Interventions & Liposomal bupivacaine vs placebo (NaCl 0.9\%) \\
\hline Outcomes & Pain on postoperative day 1 \\
& Pain upon discharge from post-anaesthesia care unit (PACU) \\
& Pain upon discharge from same day surgery \\
& Pain at 4 h after discharge home \\
& Total narcotic consumption \\
& Satisfaction with pain control at 1 week postoperative visit \\
\hline Starting date & November 2014 \\
\hline Contact information & ClinicalTrials.gov/show/NCT02296099 \\
\hline
\end{tabular}


NCT02296099 (Continued)
Notes
Currently recruiting

NCT02299349

\begin{tabular}{ll}
\hline Trial name or title & Bupivacaine liposome suspension versus a concentrated multi drug periarticular injection \\
\hline Methods & Parallel-arm RCT \\
\hline Participants & Participants undergoing total knee arthroplasty \\
\hline Interventions & Liposomal bupivacaine vs ropivacaine hydrochloride \\
\hline Outcomes & Pain scores \\
\hline Starting date & Morphine sulphate equivalent dose \\
\hline Contact information & August 2013 \\
\hline Notes & clinicaltrials.gov/show/NCT02299349 \\
\hline
\end{tabular}

NCT02352922

\begin{tabular}{|c|c|}
\hline Trial name or title & $\begin{array}{l}\text { Randomized trial of wound infiltration with extended-release bupivacaine before laparoscopic or } \\
\text { robotic hysterectomy }\end{array}$ \\
\hline Methods & Parallel-arm RCT \\
\hline Participants & Participants undergoing laparoscopic or robotic hysterectomy \\
\hline Interventions & Liposomal bupivacaine vs bupivacaine hydrochloride \\
\hline \multirow[t]{12}{*}{ Outcomes } & Numerical Rating Scale (NRS) postoperative pain score on postoperative day 1 (POD1) \\
\hline & NRS Pain score at $2 \mathrm{~h}$ \\
\hline & NRS Pain score at $4 \mathrm{~h}$ \\
\hline & NRS Pain score at $8 \mathrm{~h}$ \\
\hline & NRS Pain score at $16 \mathrm{~h}$ \\
\hline & NRS Pain score post-op day 2 \\
\hline & NRS Pain score post-op day 3 \\
\hline & NRS Pain score post-op day 14 \\
\hline & Quality of life as measured by the Brief Pain Inventory (BPI) \\
\hline & Total opioid use prior to hospital discharge \\
\hline & Total opioid use end of post-op day 3 \\
\hline & Total NSAID use end of post-op day 3 \\
\hline
\end{tabular}


NCT02352922 (Continued)

Total opioid use at post-op day 14

Total NSAID use at post-op day 14

Adverse events

\begin{tabular}{ll}
\hline Starting date & July 2015 \\
\hline Contact information & ClinicalTrials.gov/show/NCT02352922 \\
\hline Notes & Currently recruiting \\
\hline
\end{tabular}

\section{NCT02369523}

\begin{tabular}{ll}
\hline Trial name or title & Multimodal pain management following primary TKA \\
\hline Methods & Parallel-arm RCT \\
\hline Participants & Participants undergoing total knee arthroplasty \\
\hline Interventions & Liposomal bupivacaine vs ropivacaine hydrochloride vs continuous femoral nerve block \\
\hline Outcomes & Time to discharge readiness \\
\hline Starting date & September 2014 \\
\hline Contact information & ClinicalTrials.gov/show/NCT02369523 \\
\hline Notes & Currently recruiting \\
\hline
\end{tabular}

\section{NCT02381353}

\begin{tabular}{ll}
\hline Trial name or title & Exparel injection for postoperative orbital pain \\
\hline Methods & Parallel-arm RCT \\
\hline Participants & Participants undergoing enucleation or evisceration of the eye \\
\hline Interventions & Liposomal bupivacaine vs bupivacine hydrochloride \\
\hline Outcomes & Postoperative orbital pain \\
& Postoperative nausea and vomiting \\
& Quantity of oral narcotics used for postoperative pain control \\
& Patient satisfaction \\
\hline Starting date & Postoperative complications \\
\hline Contact information & February 2015 \\
\hline
\end{tabular}


NCT02381353 (Continued)
Notes
Currently recruiting

NCT02426164

\begin{tabular}{ll}
\hline Trial name or title & Liposomal bupivacaine in total knee arthroplasty \\
\hline Methods & Parallel-arm RCT \\
\hline Participants & Participants undergoing total knee arthroplasty \\
\hline Interventions & Liposomal bupivacaine vs bupivacine hydrochloride \\
\hline Outcomes & Mean visual analogue scale (VAS) pain scores Day 0, 1, 2 and 3 \\
\hline Starting date & Complications \\
\hline Contact information & June 2015 \\
\hline Notes & ClinicalTrials.gov/show/NCT02426164 \\
\hline
\end{tabular}

NCT02444533

\begin{tabular}{ll}
\hline Trial name or title & EXPAREL ${ }^{\circledR}$ for pain after tonsillectomy \\
\hline Methods & Parallel-arm RCT \\
\hline Participants & Participants undergoing tonsillectomy \\
\hline Interventions & Liposomal bupivacaine vs no intervention \\
\hline Outcomes & Pain score (pain scores on a 0/10 scale) \\
& Pain medication usage (milligrams used) \\
& Oral intake (patient-recorded oral intake) \\
& $\begin{array}{l}\text { Patient complication (allergic reaction, swallowing dysfunction, hospital admission related to the } \\
\text { study drug) }\end{array}$ \\
\hline Starting date & Post-tonsillectomy bleeding rate \\
\hline Contact information & May 2015 \\
\hline Notes & ClinicalTrials.gov/show/NCT02444533 \\
\hline
\end{tabular}


NCT02449915

\begin{tabular}{ll}
\hline Trial name or title & $\begin{array}{l}\text { Improvement of pain following robotic sacrocolpopexy and rectocele repair for pelvic organ pro- } \\
\text { lapse }\end{array}$ \\
\hline Methods & Parallel-arm RCT \\
\hline Participants & Participants undergoing robotic sacrocolpopexy and rectocele repair for pelvic organ prolapse \\
\hline Interventions & Liposomal bupivacaine vs placebo (NaCl 0.9\%) \\
\hline Outcomes & Global visual analogue score (VAS) for pain \\
\hline Starting date & March 2014 \\
\hline Contact information & ClinicalTrials.gov/show/NCT02449915 \\
\hline Notes & Currently recruiting \\
\hline
\end{tabular}

\section{NCT02472314}

\begin{tabular}{|c|c|}
\hline Trial name or title & Exparel for postoperative pain management in shoulder surgery \\
\hline Methods & Parallel-arm RCT \\
\hline Participants & Participants undergoing surgery for fractures of the shoulder and upper arm \\
\hline Interventions & Liposomal bupivacaine vs bupivacaine hydrochloride (peripheral nerve block) \\
\hline \multirow[t]{8}{*}{ Outcomes } & Quality of analgesia \\
\hline & Time to discharge home \\
\hline & Time to return to work \\
\hline & Postoperative American Shoulder and Elbow surgeons (ASES) \\
\hline & Subjective shoulder value (SSV) \\
\hline & Constant score \\
\hline & Incidence of nerve injury \\
\hline & Postoperative opioid consumption \\
\hline Starting date & June 2015 \\
\hline Contact information & ClinicalTrials.gov/show/NCT02472314 \\
\hline Notes & Yet to recruit \\
\hline
\end{tabular}

\section{NCT02473198}

Trial name or title

Femoral Nerve Block Compared to Exparel in Total Knee Replacement

Methods

Parallel-arm RCT

Liposomal bupivacaine infiltration at the surgical site for the management of postoperative pain (Review) 
NCT02473198 (Continued)

\begin{tabular}{ll} 
Participants & Participants undergoing total knee replacement \\
\hline Interventions & Liposomal bupivacaine vs femoral nerve block \\
\hline Outcomes & Pain Score (VAS) \\
& Functional Outcome (Knee Society Score) \\
\hline Starting date & January 2014 \\
\hline Contact information & https://ClinicalTrials.gov/show/NCT02473198 \\
\hline Notes & Recruiting
\end{tabular}

\section{NCT02480621}

\begin{tabular}{ll}
\hline Trial name or title & Liposomal bupivacaine with bupivacaine in ankle fracture ORIF \\
\hline Methods & Parallel-arm RCT \\
\hline Participants & Participants undergoing ankle fracture open reduction internal fixation \\
\hline Interventions & Liposomal bupivacaine plus bupivacaine hydrochloride vs no treatment \\
\hline Outcomes & Pain levels on a visual analog scale (VAS) \\
\hline Starting date & December 2014 \\
\hline Contact information & ClinicalTrials.gov/show/NCT02480621 \\
\hline Notes & Currently recruiting \\
\hline
\end{tabular}

\section{NCT02499575}

\begin{tabular}{ll}
\hline Trial name or title & Pericapsular Exparel for pain relief in bunionectomy and related procedures \\
\hline Methods & Parallel-arm RCT \\
\hline Participants & $\begin{array}{l}\text { Participants undergoing outpatient first metatarsophalangeal (MTP) joint procedure (bunionecto- } \\
\text { my, 1st MTP fusion, or cheilectomy) }\end{array}$ \\
\hline Interventions & Liposomal bupivacaine vs ropivacaine hydrochloride \\
\hline Outcomes & Opioid use as measured by questionnaire \\
\hline Starting date & Pain relief measured by Defense and Veterans Pain Scale \\
\hline Contact information & July 2015 \\
\hline Notes & ClinicalTrials.gov/show/NCT02499575 \\
\hline
\end{tabular}


NCT02515851

\begin{tabular}{ll}
\hline Trial name or title & $\begin{array}{l}\text { A randomized, double-blind controlled trial of bupivacaine extended-release liposome injection for } \\
\text { postsurgical analgesia in patients undergoing open-reduction internal fixation of the distal radius }\end{array}$ \\
\hline Methods & Parallel-arm RCT \\
\hline Participants & Participants undergoing open-reduction internal fixation of the distal radius \\
\hline Interventions & Liposomal bupivacaine vs placebo \\
\hline Outcomes & Pain medication usage \\
\hline Starting date & August 2015 \\
\hline Contact information & ClinicalTrials.gov/show/NCTO2515851 \\
\hline Notes & Currently recruiting \\
\hline
\end{tabular}

\section{NCT02517905}

Trial name or title

Evaluation of EXPAREL for prolonged postsurgical analgesia in subjects undergoing third molar extraction

\begin{tabular}{ll}
\hline Methods & Parallel-arm RCT \\
\hline Participants & Participants undergoing third molar extraction \\
\hline Interventions & Liposomal bupivacaine vs placebo (NaCl 0.9\%) \\
\hline Outcomes & $\begin{array}{l}\text { Area under the curve (AUC) of the numeric rating scale (NRS) at rest (NRS-R) pain intensity scores } \\
\text { through } 48 \mathrm{~h}\end{array}$ \\
& Treatment-emergent adverse events \\
& Maximum plasma concentration \\
& Time to maximum plasma concentration \\
& Area under the plasma concentration-versus-time curve \\
& Apparent terminal elimination half-life \\
\hline Starting date & August 2015 \\
\hline Nontact information & ClinicalTrials.gov/show/NCT02517905 \\
\hline
\end{tabular}

\section{NCT02542956}

Trial name or title

Comparison of local anesthetic infusion pump versus DepoFoam bupivacaine for pain management 


\begin{tabular}{ll}
$\begin{array}{l}\text { NCT02542956 (Continued) } \\
\text { Methods }\end{array}$ & Parallel-arm RCT \\
\hline Participants & Participants undergoing abdominoplasty \\
\hline Interventions & Liposomal bupivacaine vs bupivacaine hydrochloride (continuous infiltration pump) \\
\hline Outcomes & Recurrence of pain \\
\hline Starting date & October 2014 \\
\hline Contact information & ClinicalTrials.gov/show/NCT02542956 \\
\hline Notes & Currently recruiting \\
\hline
\end{tabular}

NCT02543801

\begin{tabular}{ll}
\hline Trial name or title & A clinical trial of two periarticular multimodal drug injections in total hip arthroplasty \\
\hline Methods & Parallel-arm RCT \\
\hline Participants & Participants undergoing total hip arthroplasty \\
\hline Interventions & Liposomal bupivacaine vs ropivacaine hydrochloride vs bupivacaine hydrochloride \\
\hline Outcomes & Pain score \\
& Narcotic consumption \\
\hline Starting date & Length of stay \\
\hline Contact information & January 2016 \\
\hline Notes & ClinicalTrials.gov/show/NCTO2543801 \\
\hline
\end{tabular}

NCT02571283

\begin{tabular}{ll}
\hline Trial name or title & Peri-articular injection utilizing a pain cocktail with and without Exparel \\
\hline Methods & Parallel-arm RCT \\
\hline Participants & Participants undergoing total knee arthroplasty \\
\hline Interventions & Liposomal bupivacaine vs ropivacaine hydrochloride \\
\hline Outcomes & $\begin{array}{l}\text { The visual pain scale from 1-10 will be used to determine changes in pain control at 3, 12, 24, and } \\
\text { 48 hour time intervals postoperatively }\end{array}$ \\
\hline Starting date & October 2015 \\
\hline Contact information & ClinicalTrials.gov/show/NCT02571283 \\
\hline
\end{tabular}


NCT02571283 (Continued)
Notes
Yet to recruit

NCT02591888

\begin{tabular}{ll}
\hline Trial name or title & $\begin{array}{l}\text { Impact of liposomal bupivacaine administered following placement of a transobturator subu- } \\
\text { rethral sling }\end{array}$ \\
\hline Methods & Parallel-arm RCT \\
\hline Participants & Participants undergoing transobturator suburethral sling \\
\hline Interventions & Liposomal bupivacaine vs placebo (NaCl 0.9\%) \\
\hline Outcomes & Visual analogue scale (VAS) \\
& Numeric rating scale (NRS) \\
& Likert scale to rate their level of satisfaction with their postoperative pain control \\
\hline Starting date & February 2015 \\
\hline Contact information & ClinicalTrials.gov/show/NCT02591888 \\
\hline Notes & Currently recruiting \\
\hline
\end{tabular}

\section{NCT02606448}

\begin{tabular}{ll}
\hline Trial name or title & Exparel infiltration in anterior cruciate ligament reconstruction \\
\hline Methods & Parallel-arm RCT \\
\hline Participants & Participants undergoing anterior cruciate ligament reconstruction \\
\hline Interventions & Liposomal bupivacaine vs ropivacaine hydrochloride (femoral nerve block) \\
\hline Outcomes & Pain levels \\
\hline Starting date & Morphine equivalents \\
\hline Contact information & May 2014 \\
\hline Notes & ClinicalTrials.gov/show/NCT02606448 \\
\hline
\end{tabular}

\section{NCT02616367}

Trial name or title
Comparison of ropivacaine and liposomal bupivacaine for total knee arthroplasty

Parallel-arm RCT 
NCT02616367 (Continued)

\begin{tabular}{ll} 
Participants & Participants undergoing total knee arthroplasty \\
\hline Interventions & Liposomal bupivacaine vs ropivacaine hydrochloride \\
\hline Outcomes & Pain control measure on pain scale of 1-10 \\
& Decreased maximal pain on pain scale of 1-10 \\
\hline Starting date & December 2015 \\
\hline Contact information & ClinicalTrials.gov/show/NCT02616367 \\
\hline Notes & Yet to recruit \\
\hline
\end{tabular}

\section{NCT02659501}

\begin{tabular}{|c|c|}
\hline Trial name or title & Liposomal bupivacaine in implant based breast reconstruction \\
\hline Methods & Parallel-arm RCT \\
\hline Participants & Participants undergoing breast reconstruction \\
\hline Interventions & Liposomal bupivacaine vs bupivacaine hydrochloride \\
\hline \multirow[t]{6}{*}{ Outcomes } & $\begin{array}{l}\text { The effect of liposomal bupivacaine on average postoperative pain levels on postoperative day } 1 \text {, } \\
2,3,4,5,6 \text { and } 7\end{array}$ \\
\hline & The effect of liposomal bupivacaine on postoperative opioid consumption \\
\hline & The effect of liposomal bupivacaine on length of hospital stay \\
\hline & The effect of liposomal bupivacaine on patient satisfaction with postoperative pain control \\
\hline & The effect of liposomal bupivacaine on overall patient satisfaction \\
\hline & The effect of liposomal bupivacaine on opioid-related adverse events \\
\hline Starting date & July 2015 \\
\hline Contact information & clinicaltrials.gov/ct2/show/NCT02659501 \\
\hline Notes & Currently recruiting \\
\hline
\end{tabular}

ASA - American Society of Anaesthesiologists Score

ASES - American Shoulder and Elbow surgeons

AUC - Area Under Curve

BPI - Brief Pain Inventory

BPI - Brief Pain Inventory

ED - Emergency Department

IV - Intravenous

LOS - Length of Stay

MTP - Metatarsophalangeal

NRS - Numeric Rating Scale

NSAID - Non Steroidal Anti Inflammatory Drug

OME - Oral Morphine Equivalents

ORAE - Opioid Related Adverse Event 
ORIF - Open Reduction Internal Fixation

PACU - Post Anaesthesia Care Unit

PCA - Patient Controlled Analgesia

POD1 - Post Operative Day 1

$\mathrm{RCT}$ - randomised controlled trial

SSV - Subjective Shoulder Value

THA - Total Hip Arthroplasty

TJA - Total Joint Arthroplast

TKA - Total Knee Arthroplasty

TSA - Total Shoulder Arthroplasty

VAS - Visual Analogue Scale

\section{DATA AND ANALYSES}

Comparison 1. Liposomal bupivacaine vs control

\begin{tabular}{|c|c|c|c|c|}
\hline Outcome or subgroup title & No. of studies & $\begin{array}{l}\text { No. of partici- } \\
\text { pants }\end{array}$ & Statistical method & Effect size \\
\hline $\begin{array}{l}1 \text { Cumulative pain score } 0 \text { to } \\
72 \text { hours }\end{array}$ & 3 & & $\begin{array}{l}\text { Mean Difference (IV, Random, 95\% } \\
\mathrm{CI})\end{array}$ & $\begin{array}{l}\text { Totals not select- } \\
\text { ed }\end{array}$ \\
\hline 1.1 vs placebo & 1 & & $\begin{array}{l}\text { Mean Difference (IV, Random, 95\% } \\
\mathrm{CI})\end{array}$ & $0.0[0.0,0.0]$ \\
\hline $\begin{array}{l}1.2 \text { vs bupivacaine hydro- } \\
\text { choloride }\end{array}$ & 2 & & $\begin{array}{l}\text { Mean Difference (IV, Random, 95\% } \\
\mathrm{CI})\end{array}$ & $0.0[0.0,0.0]$ \\
\hline $\begin{array}{l}2 \text { Participants not requiring } \\
\text { postoperative opioids }\end{array}$ & 3 & & Risk Ratio (M-H, Random, 95\% Cl) & $\begin{array}{l}\text { Totals not select- } \\
\text { ed }\end{array}$ \\
\hline 2.1 vs placebo & 2 & & Risk Ratio (M-H, Random, 95\% Cl) & $0.0[0.0,0.0]$ \\
\hline $\begin{array}{l}2.2 \text { vs bupivacaine hydrochlo- } \\
\text { ride }\end{array}$ & 1 & & Risk Ratio (M-H, Random, 95\% Cl) & $0.0[0.0,0.0]$ \\
\hline
\end{tabular}

Analysis 1.1. Comparison 1 Liposomal bupivacaine vs control, Outcome 1 Cumulative pain score 0 to 72 hours.

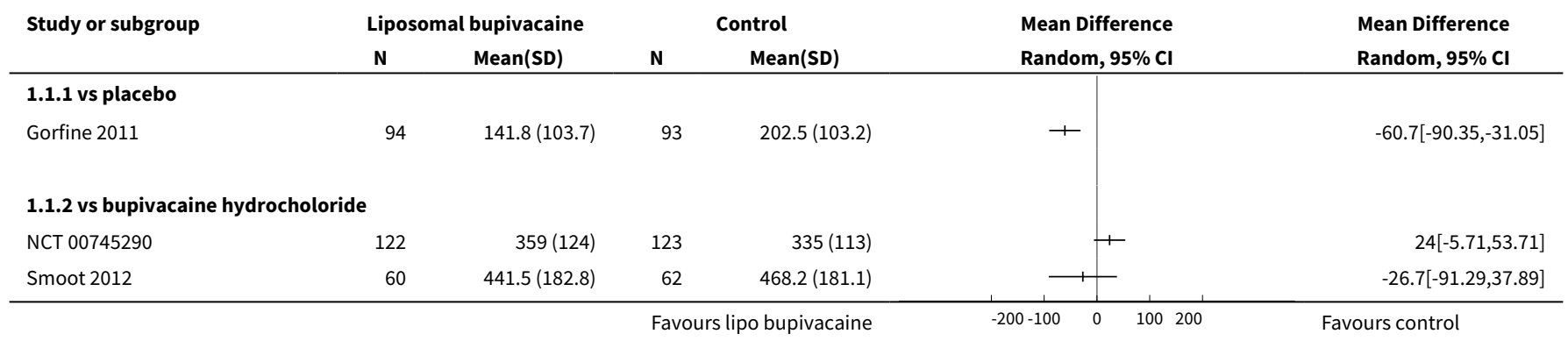




\section{Analysis 1.2. Comparison 1 Liposomal bupivacaine vs control,} Outcome 2 Participants not requiring postoperative opioids.

\begin{tabular}{|c|c|c|c|c|}
\hline Study or subgroup & $\begin{array}{c}\text { Experimental } \\
n / N\end{array}$ & $\begin{array}{c}\text { Control } \\
n / N\end{array}$ & $\begin{array}{c}\text { Risk Ratio } \\
\text { M-H, Random, 95\% Cl }\end{array}$ & $\begin{array}{c}\text { Risk Ratio } \\
\text { M-H, Random, } 95 \% \mathrm{CI}\end{array}$ \\
\hline \multicolumn{5}{|l|}{ 1.2.1 vs placebo } \\
\hline Golf 2011 & $2 / 93$ & $1 / 92$ & + & $0.99[0.95,1.03]$ \\
\hline Gorfine 2011 & $24 / 94$ & 9/93 & + & $0.82[0.72,0.94]$ \\
\hline \multicolumn{5}{|c|}{ 1.2.2 vs bupivacaine hydrochloride } \\
\hline Smoot 2012 & $6 / 60$ & $3 / 60$ & \begin{tabular}{l|l}
1 & - \\
\end{tabular} & $0.95[0.86,1.05]$ \\
\hline
\end{tabular}

\section{APPENDICES}

\section{Appendix 1. Search strategies CENTRAL}

\#1(Liposom* near/5 bupivacaine) or (depo* near/5 bupivacaine):ti,ab,kw (Word variations have been searched) \#2exparel or SKY0402:ti,ab,kw (Word variations have been searched) $\# 3 \# 1$ or \#2 \#4MeSH descriptor: [Pain, Postoperative] this term only \#5((postoperative near/4 pain*) or (post-operative near/4 pain $\left.{ }^{\star}\right)$ or post-operative-pain* or (post* near/4 pain*) or (postoperative near/4 analgesi ${ }^{\star}$ ) or (post-operative near/4 analgesi ${ }^{\star}$ ) or ("post-operative analgesi*")):ti,ab,kw (Word variations have been searched) \#6((post-surgical near/4 pain*) or ("post surgical" near/4 pain*) or (post-surgery near/4 pain*)):ti,ab,kw (Word variations have been searched)

\#7("pain-relief after surg*" or "pain following surg*" or "pain control after"):ti,ab,kw (Word variations have been searched) \#8(("post surg*" or post-surg*) and (pain* or discomfort)):ti,ab,kw (Word variations have been searched) \#9((pain* near/4 "after surg*") or (pain* near/4 "after operat*") or (pain* near/4 "follow* operat*") or (pain* near/4 "follow* surg*")):ti,ab,kw (Word variations have been searched)

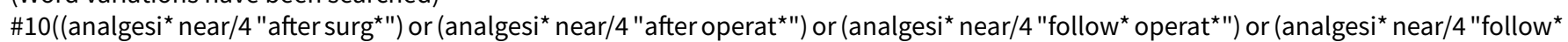
surg*")):ti,ab,kw (Word variations have been searched)

$\# 11 \# 4$ or \#5 or \#6 or \#7 or \#8 or \#9 or \#10

$\# 12 \# 3$ and \#11

\section{MEDLINE}

1. (Liposom adj5 bupivacaine).mp. or (depo* adj5 bupivacaine).mp. [mp=title, abstract, original title, name of substance word, subject heading word, keyword heading word, protocol supplementary concept word, rare disease supplementary concept word, unique identifier]

2. exparel.mp. or SKY0402.mp. [mp=title, abstract, original title, name of substance word, subject heading word, keyword heading word, protocol supplementary concept word, rare disease supplementary concept word, unique identifier]

\section{Pain, Postoperative/}

4. ((postoperative adj4 pain $\left.{ }^{\star}\right)$ or (postoperative adj4 pain ${ }^{\star}$ ) or postoperative-pain ${ }^{\star}$ or (post* adj4 pain ${ }^{\star}$ ) or (postoperative adj4 analgesi ${ }^{\star}$ ) or (postoperative adj4 analgesi $\left.{ }^{\star}\right)$ or "postoperative analgesi*").mp.

5. ((post-surgical adj4 pain*) or ("post surgical" adj4 pain $\left.{ }^{\star}\right)$ or (post-surgery adj4 pain*)).mp.

6. ("pain-relief after surg*" or "pain following surg*" or "pain control after").mp.

7. (("post surg*" or post-surg*) and (pain* or discomfort)).mp.

8. ((pain* adj4 "after surg*") or (pain* adj4 "after operat*") or (pain* adj4 "follow* operat*") or (pain* adj4 "follow* surg*")).mp.

9. ((analgesi ${ }^{\star}$ adj4 "after surg*") or (analgesi* adj4 "after operat*") or (analgesi* adj4 "follow* operat*") or (analgesi" adj4 "follow* surg*")).mp. 
10. or/3-9

11. randomized controlled trial.pt.

12. controlled clinical trial.pt.

13. randomized.ab.

14. placebo.ab.

15. drug therapy.fs.

16. randomly.ab.

17. trial.ab.

18. or/11-17

19. exp animals/ not humans.sh.

20. 18 not 19

21. 1 or 2

22. 10 and 20 and 21

\section{Embase}

1. (Liposom adj5 bupivacaine).mp. or (depo* adj5 bupivacaine).tw. [mp=title, abstract, subject headings, heading word, drug trade name, original title, device manufacturer, drug manufacturer, device trade name, keyword]

2. exparel.mp. or SKY0402.tw. [mp=title, abstract, subject headings, heading word, drug trade name, original title, device manufacturer, drug manufacturer, device trade name, keyword]

3. Pain, Postoperative/

4. ((postoperative adj4 pain $\left.{ }^{\star}\right)$ or (post-operative adj4 pain $\left.{ }^{\star}\right)$ or post-operative-pain ${ }^{\star}$ or $\left(\right.$ post $^{\star}$ adj4 pain ${ }^{\star}$ ) or (postoperative adj4 analgesi $\left.{ }^{\star}\right)$ or (post-operative adj4 analgesi ${ }^{\star}$ ) or "post-operative analgesi*").mp.

5. ((post-surgical adj4 pain*) or ("post surgical" adj4 pain*) or (post-surgery adj4 pain*)).mp.

6. ("pain-relief after surg*" or "pain following surg*" or "pain control after").mp.

7. (("post surg*" or post-surg*) and (pain* or discomfort)).mp.

8. ((pain* adj4 "after surg*") or (pain* adj4 "after operat" ) or (pain* adj4 "follow* operat*") or (pain* adj4 "follow* surg*")).mp.

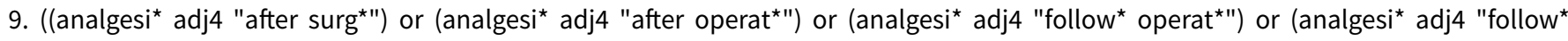
surg*")).mp.

10. or/3-9

11. 1 or 2

12. 10 and 11

13. random\$.tw.

14. factorial\$.tw.

15. crossover\$.tw.

16. cross over\$.tw.

17. cross-over\$.tw.

18. placebo\$.tw.

19. (doubl\$ adj blind\$).tw.

Liposomal bupivacaine infiltration at the surgical site for the management of postoperative pain (Review) 
20. (singl\$ adj blind\$).tw.

21. assign\$.tw.

22. allocat\$.tw.

23. volunteer\$.tw.

24. Crossover Procedure/

25. double-blind procedure.tw.

26. Randomized Controlled Trial/

27. Single Blind Procedure/

28. or/13-27

29. (animal/ or nonhuman/) not human/

30. 28 not 29

31. 12 and 30

\section{ISI Web of Science}

\#16 \#15 AND \#11

\#15 \#14 OR \#13 OR \#12

\#14 TOPIC: ((((singl ${ }^{\star}$ OR doubl* OR trebl* OR tripl $\left.{ }^{\star}\right)$ SAME $\left(\right.$ blind $^{\star}$ OR mask $\left.\left.\left.\left.{ }^{\star}\right)\right)\right)\right)$

\#13 TOPIC: (((controlled clinical trial OR controlled trial OR clinical trial OR placebo)))

\#12 TOPIC: (( (randomised OR randomized OR randomly OR random order OR random sequence OR random allocation OR randomly allocated $\mathrm{OR}$ at random $\mathrm{OR}$ randomized controlled trial)))

\#11 \#10 AND \#3

\#10 \#9 OR \#8 OR \#7 OR \#6 OR \#5 OR \#4

\#9 TOPIC: (((analgesi* near/4 "after surg*") or (analgesi* near/4 "after operat*") or (analgesi* near/4 "follow* operat*") or (analgesi* near/4 "follow* surg*")))

\#8 TOPIC: (((pain* near/4 "after surg*") or (pain* near/4 "after operat $\left.{ }^{\star} "\right)$ or (pain* near/4 "follow* operat ") or (pain* near/4 "follow surg*")))

\#7 TOPIC: ((("post surg*" or post-surg*) and (pain* or discomfort)))

\#6 TOPIC: (("pain-relief after surg*" or "pain following surg*" or "pain control after"))

\#5 TOPIC: (((post-surgical near/4 pain*) or ("post surgical" near/4 pain*) or (post-surgery near/4 pain*)))

\#4 TOPIC: (((postoperative near/4 pain*) or (post-operative near/4 pain $\left.{ }^{\star}\right)$ or post-operative-pain* or (post* near/4 pain $\left.{ }^{\star}\right)$ or (postoperative near/4 analgesi $\left.{ }^{\star}\right)$ or (post-operative near/4 analgesi ${ }^{\star}$ ) or ("post-operative analgesi`")))

\#3 \#2 OR \#1

\#2 TOPIC: (exparel or SKY0402)

\#1 TOPIC: ((Liposom near/5 bupivacaine) or (depo* near/5 bupivacaine))

\section{Appendix 2. Cumulative pain intensity calculation}

We calculated cumulative pain over 72 hours using the trapezoidal method to measure the mean area under the curve (AUC). To account for the use of rescue analgesia the windowed worst-observation-carried-forward + last-observation-carried-forward (wWOCF+LOCF) imputation method was used. The wWOCF+LOCF accounts for the effect of a rescue analgesia by replacing pain scores recorded within one half life of rescue medication administration ( 6 hours for oxycodone/acetaminophen or ketorolac) with the pain score recorded prior to rescue medication administration.) 
Where pain scores were missing we replaced them in one of three ways.

- Where the missing score occurred before any pain scores were recorded we used the median score from other participants at the same time point in the same treatment group

- Where the missing score occurred between two non-missing scores linear interpolation was performed.

- Where the missing score occurred after the last non-missing score the last observation was carried forward.

WHAT'S NEW

\begin{tabular}{lll}
\hline Date & Event & Description \\
\hline 18 February 2020 & Review declared as stable & See Published notes. \\
\hline
\end{tabular}

\section{CONTRIBUTIONS OF AUTHORS}

Thomas Hamilton wrote the protocol with input from Vassilis Athanassoglou. Statistical and methodological advice were provided by Marialena Trivella. The search strategy was designed by Joanne Abbott with input from Thomas Hamilton. Other authors provided general advice on the protocol. Future updates of this review will be performed by Thomas Hamilton.

\section{DECLARATIONS OF INTEREST}

- TWH is an orthopaedic registrar and manages patients with peri-operative and postoperative pain. TWH receives funding from the National Institute for Health Research (NIHR).

- VA: none known; VA is a consultant anaesthetist and manages patients with peri-operative and postoperative pain.

- SM none known.

- LHS: none known; LHS is a nurse and surgical assistant and manages patients with perioperative and post-operative pain.

- MT: none known.

- DM is a consultant orthopaedic surgeon and manages patients with perioperative and postoperative pain. DM receives funding from Zimmer Biomet (1998 to present) who manufacture orthopaedic implants, including knee replacements.

- HGP is a consultant orthopaedic surgeon and manages patients with peri-operative and postoperative pain. HGP receives funding from Zimmer Biomet (2015 to present) who manufacture orthopaedic implants, including knee replacements.

\section{SOURCES OF SUPPORT}

\section{Internal sources}

- No sources of support supplied

\section{External sources}

- National Institute for Health Research, UK, Other.

TWH is supported by the NIHR Biomedical Research Centre, based at Oxford University Hospitals Foundation Trust, Oxford

\section{DIFFERENCES BETWEEN PROTOCOLANDREVIEW}

In line with current Cochrane guidance, we have added selective outcome reporting and blinding of participants and personnel (performance bias) to the 'Risk of bias' assessment and also completed a GRADE assessment for all included studies. These were not included in the protocol but have been included in this review and will be included in subsequent updates. In our protocol we stated we would assess for adverse events as both a primary and secondary outcome. To avoid duplication we have assessed the incidence of serious adverse events including the incidence of cardiac events and incidence of wound complications as a primary outcome, and incidence of adverse events as a secondary outcome.

\section{NOTES}

We updated the searches in full in October 2019, and while we did identify some potentially relevant studies, none were likely to change the conclusions. Therefore, this review has now been stabilised following discussion with the authors and editors. The review will be reassessed for updating in 2022. If appropriate, we will update the review before this date if new evidence likely to change the conclusions is published, or if standards change substantially which necessitate major revisions. 


\section{N D EX TERMS}

\section{Medical Subject Headings (MeSH)}

Anesthetics, Local [ ${ }^{*}$ administration \& dosage] [adverse effects]; Arthroplasty, Replacement, Knee; Bupivacaine [ ${ }^{\star}$ administration \& dosage] [adverse effects]; Liposomes; Mammaplasty; Pain Measurement; Pain, Postoperative [*drug therapy]; Randomized Controlled Trials as Topic

\section{MeSH check words}

Humans 